A Summary Report on Feed Preparation Offgas and Glass Redox Data for Hanford Waste Vitrification Plant: Letter Report

M. D. Merz

March 1996

Prepared for the U.S. Department of Energy under Contract DE-AC06-76RLO 1830

Pacific Northwest National Laboratory Operated for the U.S. Department of Energy by Battelle Memorial Institute

\title{
Baltelle
}

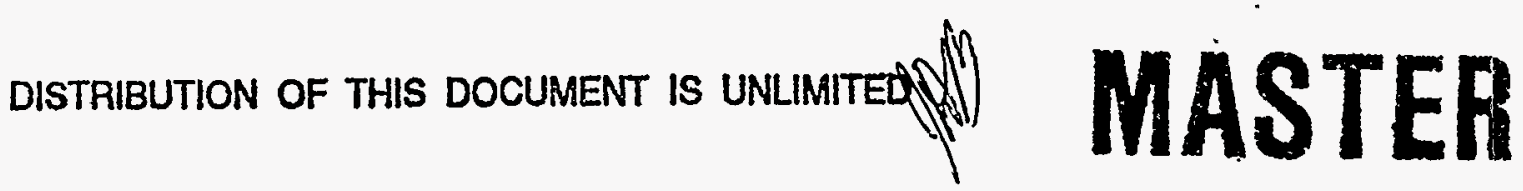




\section{A Summary Report on Feed Preparation Offgas and Glass Redox Data for Hanford Waste Vitrification Plant: Letter Report}

M. D. Merz

March 1996

Prepared for the U.S. Department of Energy under Contract DE-AC06-76RLO 1830

Pacific Northwest National Laboratory

Richland, Washington 99352

Reprint of historical document PHTD-C93-03.02L, dated May 1994. Data, formatting, and other conventions reflect standards at the original date of printing. Technical peer reviews and editorial reviews may not have been performed. 


\title{
DISCLAISMER
}

This report wass prepared as an account of work sponscred by en agency of the United States Covernment. Neither the United Staies Covernment nor any agency thereof, nor Eatielle Mermorial Instituie, nor any of their employees, makes any Harranty, express or implied, or assumes any legal liability or responsibility for the accuracy, completeness, or.usefulness of any information, apparafus, product, or process disclosed, or represents that its use would not infringe privately ow'ned rights. Reference herein io any speciñc commercial product, process, or senice by irade name, irácemark, manuíactuier, or othenwise c'ües not necessarily constitu!e or imply its enoorsement, recommendation, or favoring by the United States Government or any agency thereof, or Banelle Memorial Instiute. The views and opinions of authors expressed herein do not necessarily state or reflect those of the United States Covernment or any agency thersof.

\author{
PACIFIC NORTHWEST NATIONAL LABORATORY \\ operäied by \\ BATTELLE \\ for the \\ UNITED STATES DEPARTMENT OF ENERGY \\ under Contract DE-ACO6-76RLO 1830
}

Printed in the Uniled States of America

Available to DOE and DOE coniractors from the

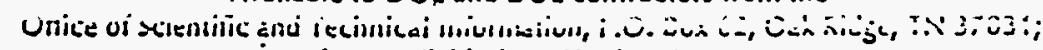
prices available from (615) $576-8401$.

Available to the public from the National Technical information Senice, U.S. Depariment of Commerce, 5285 Port Royal Rd., Springfield, VA 22167 


\section{ACKNOWLEDGMENTS.}

The author appreciated the guidance of Karyn Wiemers in providing background information useful in defining the scope of this report and in facilitating the inclusion of considerable information prior to availability in other reports. The author also appreciated the help of Mike Elliott in obtaining original offgas plots for analysis of the Kernforschungs. zentrums Karlsruhe (KfK) tests, Mike Powell, R. Gaskill, and Mari Langowski for providing preliminary data on the Slurry Integrated Performance Testing (SIPT)2 test, John Morrey for providing additional details on the radioactive core tests, Matt Cooper for further details on the Research Scale Melter (RSM) feed preparation container and stirring, and Nick Hutson for additional information on the Integrated DWPF Melter System-High Level Waste Vitrification Plant (IDMS-HWVP) tests. Both Harry Smith and Mari Langowski were very helpful in providing details of specific tests and techniques, which were essential to making comparisons of the various tests and interpreting the laboratory scale tests. 


\section{SUMMARY}

Offgas data, slurry chemistry data and test system characteristics were tabulated and analyzed for tests conducted to date on Neutralized Current Acid Waste (NCAW) feed preparation. The test data from 18 separate tests on various process scales were reduced to a normalized basis, moles/initial slurry volume, for comparison of results from small-scale tests through full-scale tests.

Peak total offgas generation rate correlated reasonably well with formic acid addition rate with an upper bound on generation rate of approximately $0.4(\mathrm{moles} / \mathrm{min}) /($ liter added acid/h). Small-scale tests tended to fall 30 to $60 \%$ below this bound, except at the highest acid addition rates, where the rates were close to this bound. The large-scale tests tended to be close to this bound.

Total offgas generation increased in proportion to amount of formic acid added, initial carbonate concentration, and initial nitrite concentration, but with considerable scatter. An upper bound of approximately 0.4 moles total offgas/(moles acid + moles carbonate + moles nitrite) was observed, though many of the tests produced significantly lower amounts of gas.

Correlations of data from the various tests can be used to predict peak offgas generation rates for $\mathrm{CO}_{2}, \mathrm{NO}_{x}$, and $\mathrm{H}_{2}$ based on initial chemistry and formic acid addition rate. Peak $\mathrm{CO}_{2}$ generation rate was largely dependent on formic acid addition rate for all 18 tests. Peak $\mathrm{NO}_{\mathbf{x}}$ generation rate correlated well with initial nitrite, carbonate, and nitrate concentrations, and acid addition rate except for 2 of the 18 tests.

Total $\mathrm{CO}_{2}$ generated could not be correlated very well for all tests with test conditions such as total acid added, initial carbonate and added base with available data. This was largely a shortcoming of a limited number of tests relative to the number of variables that affect $\mathrm{CO}_{2}$ generation. An overall plot of the amount of $\mathrm{CO}_{2}$ relative to $\mathrm{NO}_{x}$ and $\mathrm{N}_{2} \mathrm{O}$ indicated that the extent of various reactions for nitrite destruction differed significantly for the various tests. Trends were noted such as increases of total $\mathrm{CO}_{2}$ with amount of formic acid added and amount of noble metals 
in the slurry. Further analysis and data are required to separate the various effects of chemistry and test conditions on total $\mathrm{CO}_{2}$ production. A correlation with considerable scatter was found for total $\mathrm{NO}_{\mathrm{x}}$ with. amount of formic acid added, initial carbonate and nitrite concentrations, and added base. However, excellent agreement was found between total $\mathrm{NO}_{x}$ for the engineering-scale KfK and laboratory-scale Lab KfK tests run under similar conditions.

Peak $\mathrm{N}_{2} \mathrm{O}$ generation rate increased with acid addition rate, initial nitrite, carbonate and hydroxide concentrations and with the amount of noble metals. A reasonable graphical correlation was shown, with an upper bound indicated.

Total $\mathrm{N}_{2} \mathrm{O}$ was not successfully correlated with test conditions, and additional analysis and data are required to understand the factors determining this quantity. The observed maximum was about 0.1 moles $\mathrm{N}_{2} \mathrm{O}$ /liter of slurry for most tests with the highest observed being 0.16 moles/liter. The ratio of $\mathrm{N}_{2} \mathrm{O}$ to $\mathrm{NO}_{x}$ was less than 0.5 for most tests except for those with high carbonate and excess base (added $\mathrm{NaOH}$ ), where the ratio was as high as 6 .

Total $\mathrm{H}_{2}$ offgas generation increased above a threshold point with amount of formic acid available toward the end of nitrite destruction, i.e. formic acid - $2 \times$ carbonate - nitrite - hydroxide. Hydrogen production appeared to be bimodal with a transition to higher amounts above a critical amount of available formic acid. The effect of noble metals was considered and improved the correlation somewhat. The effect of added base was taken into account by using a term to correct for the amount of acid consumed in reaching the appropriate $\mathrm{pH}$ range. Because the overall analysis of $\mathrm{CO}_{2}$ production indicated that different proportions of various reactions occurred in the tests, a simple effect of initial nitrite level would not be expected to be applicable over all tests. Peak $\mathrm{H}_{2}$ generation rate was consistently proportional to the total $\mathrm{H}_{2}$ observed.

Total $\mathrm{NH}_{3}$ generated, as measured by slurry and condensate analyses, correlated somewhat with total $\mathrm{H}_{2}$ and increased in proportion with $\mathrm{H}_{2}$. However, there was considerable scatter in this correlation, which indicated that factors that apparently did not affect $\mathrm{H}_{2}$ generation caused 
significant differences in the amount of $\mathrm{NH}_{3}$ measured. Total $\mathrm{NH}_{3}$ correlated well with total formic acid added. Ammonia data were missing for three of the large-scale tests and one lab test.

The data on initial $\mathrm{pH}$ and initial chemistry (nitrate, nitrite, and carbonate concentrations) were tabulated and were generally complete for the various tests, though $\mathrm{pH}$ data were not uniformly reported and available. The $\mathrm{pH}$ data at test temperatures does not appear to be sufficiently accurate to reliably predict the effect of initial $[\mathrm{OH}]$. Post-digestion chemistry (nitrate, nitrite, and formate) and $\mathrm{pH}$ were similarly tabulated, and data for 5 of the 18 tests were either not reported or were not available. Chemistry and $\mathrm{pH}$ data were reported for 5 of the 8 tests that included frit addition. After frit addition, the nitrate ranged from 0.24 to 0.54 molar, the nitrite from 0.00 to 0.21 molar, and the formate from 0.36 to 1.42 molar for these 5 tests with frit addition. Ambient $\mathrm{pH}$ after frit addition ranged from 6.69 to 10.03 for the melter feed.

Small-scale tests can be reliably used to predict peak offgas generation rates and total offgas for $\mathrm{CO}_{2}, \mathrm{NO}_{4}, \mathrm{~N}_{2} \mathrm{O}$ and $\mathrm{H}_{2}$, particularly when test conditions are similar. Differences in total offgas quantities normalized per liter of slurry were small for different scale of test. Differences in peak generation rates were in the range of 22 to $44 \%$ and were not consistently higher or lower with scale of test.

Data on glass redox, $\mathrm{Fe}^{2+} / \mathrm{Fe}^{3+}$, were correlated with the molar ratio $\left([\mathrm{HCOOH}]+\left[\mathrm{NO}_{2}\right]\right) /\left(\left[\mathrm{NO}_{3}\right]\right)$, which was consistent with an earlier correlation for slurries that did not contain nitrite. Thus, initial nitrite diminished the effect of formic acid on redox of glasses made from NCAW slurries, and the redox correlated with the ratio (added formic acid initial nitrite)/(initial nitrate) for feed preparation. 
4.0 RESULTS AND DISCUSSION $\ldots \ldots \ldots \ldots \ldots \ldots \ldots \ldots \ldots \ldots \ldots$

4.1 Scaling Parameters for Various Tests . . . . . . . . . . . 6

4.2 Test Operating Conditions and Slurry Chemistry Data ..... 9

4.3 Offgas Data for Feed Preparation Tests ............. 9

4.4 Analysis of Peak Total Offgas Rate and Total Offgas ...... 11

4.5 Correlation of Peak $\mathrm{CO}_{2}$ with Formic Acid Addition Rate . . . 11

4.6 Analysis of Total $\mathrm{CO}_{2}$ Produced during Feed Preparation .... 13

4.7 Correlation of Peak $\mathrm{NO}_{x}$ Offgas Rates with Waste Feed

Chemistry and Acid Feed Rate. ................ 14

4.8 Analysis of Total $\mathrm{NO}_{x}$ Produced during Feed Preparation .... 15

4.9 Correlation of Peak $\mathrm{N}_{2} \mathrm{O}$ Rate with Waste Feed Chemistry and Acid Feed Rate ....................... 17

4.10 Comparison of Total $\mathrm{N}_{2} \mathrm{O}$ with Total $\mathrm{NO}_{x}$ and Correlation with Formic Acid Addition and Waste Feed Chemistry .... 17

4.11 Correlation of Peak and Total $\mathrm{H}_{2}$ with Formic Acid and Waste Feed Chemistry ..................... 18

4.12 Correlation of $\mathrm{NH}_{3}$ with $\mathrm{H}_{2}$ Offgas and Formic Acid

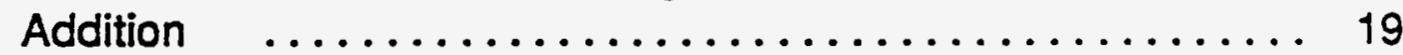

4.13 Observations on Other Gases ................. 20

4.14 Scaling Relations and Prediction of Peak and Total Offgas for Full-Scale Processing from Small-Scale Tests . . . . . . 20

4.15 Variations in Feed Chemistry and pH after Frit Addition . . . 23

4.16 Glass Redox Dependence on Formic Acid Addition and Initial Slurry Nitrate and Nitrite Concentrations ...... 23 
5.1 Sources and Methods for Tabulation of Data .......... 25

5.2 Documents (publicly available) $\ldots \ldots \ldots \ldots \ldots \ldots \ldots \ldots, 26$

5.3 Documents (not publicly available) $\ldots \ldots \ldots \ldots \ldots \ldots \ldots 27$.

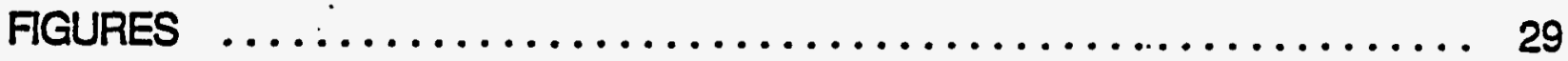

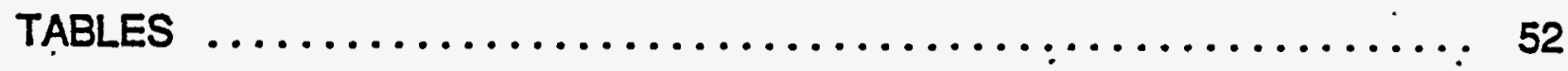

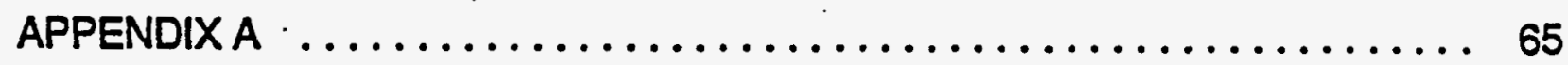

A1.1 Rate of Conversion of $\mathrm{NO}$ to $\mathrm{NO}_{2} \ldots \ldots \ldots \ldots \ldots \ldots \ldots$

APPENDIXB $\ldots \ldots \ldots \ldots \ldots \ldots \ldots \ldots \ldots \ldots \ldots \ldots \ldots \ldots \ldots \ldots \ldots \ldots \ldots$

B1.1 Hanford Waste Vitrification Plant Neutralized Current

Acid Waste Target Compositions ............. 67 


\section{FIGURES}

Figure 1. Average Purge Gas Flow per Unit Volume of Slurry for Feed Preparation Tests.

Figure 2. Peak Total Offgas Rate versus Formic Acid Addition Rate. . . 31

Figure 3. Total Offgas versus (Formic Acid Addition + Initial

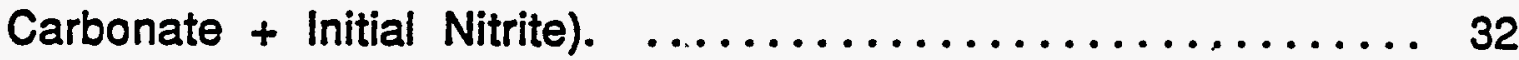

Figure 4. Peak $\mathrm{CO}_{2}$ Offgas Rate for Feed Preparation Tests. $\ldots \ldots \ldots 33$

Figure 5. Peak $\mathrm{CO}_{2}$ Offgas Rate versus Formic Acid Addition Rate. ... 34

Figure 6. Total $\mathrm{CO}_{2}$ Offgas for Feed Preparation Tests. $\ldots \ldots \ldots \ldots, 35$

Figure 7. Total $\mathrm{CO}_{2}$ Offgas minus Initial Carbonate versus $2 \times \mathrm{N}_{2} \mathrm{O}$ Offgas $+1 / 2 \times \mathrm{NO}_{x}$ Offgas. $\ldots \ldots \ldots \ldots \ldots \ldots \ldots \ldots \ldots \ldots \ldots$

Figure 8. Total $\mathrm{CO}_{2}$ Offgas minus Initial Carbonate versus Acid Addition minus $2 \times$ Initial Carbonate minus Added Base.

Figure 9. Peak $\mathrm{NO}_{x}$ Offgas Rate versus Formic Acid Addition Rate $\mathrm{x}$ Initial Nitrite / Initial Nitrate. .................... 38

Figure 10. Total $\mathrm{NO}_{x}$ Offgas versus Formic Acid Addition $\mathrm{x}$ Initial Nitrite

Figure 11. Peak $\mathrm{N}_{2} \mathrm{O}$ Offgas Rate versus Formic Acid Addition Rate $\mathrm{x}$ Initial Nitrite $\times(2 \times$ Carbonate + Added Base $) . \ldots \ldots \ldots \ldots \ldots 40$

Figure 12. $\mathrm{N}_{2} \mathrm{O} / \mathrm{NO}_{x}$ Offgas Ratio versus Formic Acid Addition Rate $\mathrm{x}$ Initial Nitrite $\times(2 \times$ Initial Carbonate + Added Base $) . \ldots \ldots 41$

Figure 13. Total $\mathrm{H}_{2}$ and $\mathrm{NH}_{3}$ Produced During Acid Addition and Digestion for Each Test.

Figure 14. Total $\mathrm{H}_{2}$ Offgas versus Formic Acid Addition. 
Figure 15. Total $\mathrm{H}_{2}$ Offgas versus Available Formic Acid . ....... 44

Figure 16. Total $\mathrm{H}_{2}$ Offgas versus Available Formic Acid with Correction for Added Base.

Figure 17. Total $\mathrm{H}_{2}$ Offgas versus Available Formic Acid with Added Base and Noble Metal Corrections. . . . . . . . . . . . . 46

Figure 18. Peak $\mathrm{H}_{2}$ Offgas Rate versus Total $\mathrm{H}_{2}$ Offgas. $\ldots \ldots \ldots \ldots 47$

Figure 19. Total $\mathrm{NH}_{3}$ Produced During Feed Preparation versus Total $\mathrm{H}_{2}$ Offgas.

Figure 20. Total $\mathrm{NH}_{3}$ Measured versus Total Formic Acid Addition During Feed Preparation. ...................... 49

Figure 21. Offgas Profiles Showing Offgas Rate versus Time for Laboratory-Scale KfK and Engineering-Scale KfK Tests. . . . . . . 50

Figure 22. $\mathrm{Fe}^{2+} / \mathrm{Fe}^{3+}$ Ratio of Glasses versus (Formic Acid Addition Initial Nitrite)/(Initial Nitrate).

Figure A.1 Conversion of $\mathrm{NO}$ to $\mathrm{NO}_{2}$ at $95^{\circ} \mathrm{C}$ in Air for Various Starting Concentrations. 


\section{TABLES}

Table 1. System Characteristics for Various Feed Preparation Tests. . 53

Table 2. Summary of Acid Addition/Digest/Recycle and Frit Addition Conditions for Feed Preparation Tests. ................ 55

Table 3. Operating Conditions and Slurry Chemistry For Feed

Preparation Tests. ........................... 56

Table 4. Offgas Data for Feed Preparation Tests. $\ldots \ldots \ldots \ldots \ldots \ldots .60$

Table 5. Total Offgas Data for All Tests Showing Comparison of

Laboratory-Scale KfK and Engineering-Scale Kfk Tests. . . . . . . 63

Table 6. Redox $\mathrm{Fe}^{2+} / \mathrm{Fe}^{3+}$ of Glasses and Related Slurry Feed Preparation Chemistry Data. ...................... 64 


\subsection{INTRODUCTION}

Tests to evaluate feed processing options for the Hanford Waste Vitrification Plant (HWVP) were conducted by a number of investigators, and considerable data were acquired for tests of different scale, including recent full-scale tests. In this report, a comparison was made of the characteristics of feed preparation observed in tests of scale ranging from $57 \mathrm{ml}$ to full-scale of 28,000 liters. These tests included Pacific Northwest Laboratory (PNL) laboratory-scale tests, Kernforschungszentrums Karlsruhe (KfK) melter feed preparation, Research Scale Melter (RSM) feed preparation, Integrated DWPF Melter System (IDMS) feed preparation, Slurry Integrated Performance Testing (SIPT) feed preparation, and formic acid addition to Hanford Neutralized Current Acid Waste (NCAW) core samples. The data presented herein were drawn mainly from draft reports and include system characteristics such as slurry volume and depth, sweep gas flow rate, headspace, and heating and stirring characteristics. Operating conditions such as acid feed rate, temperature, starting $\mathrm{pH}$, final $\mathrm{pH}$, quantities and type of frit, nitrite, nitrate, and carbonate concentrations, noble metal content, and waste oxide loading were tabulated. Offgas data for $\mathrm{CO}_{2}, \mathrm{NO}_{x}, \mathrm{~N}_{2} \mathrm{O}, \mathrm{NO}_{2}, \mathrm{H}_{2}$ and $\mathrm{NH}_{3}$ were tabulated on a common basis. Observation and non-observation of other species were also noted.

One objective of this report was to present data from the above tests on a common basis for comparison purposes. Another objective was to determine upper bounds and trends for peak offgas generation rates and total amounts of gas generated as functions of test conditions. These trends and upper bounds will be useful in the interpretation of data for the support of HWVP design. Data on feed chemistry will be useful for interpreting and controlling feed material behavior in a continuous glass. melter. The offgas data were analyzed for correlations with operating conditions and selected feed components. Several plots are presented showing correlation over a range of conditions and over tests of different scale. This analysis of data will be useful for predicting offgas peak rates and volumes of specific gases. Data on final feed material, specifically nitrate, nitrite, formate concentrations, slurry waste oxide loading and $\mathrm{pH}$ after frit addition were also tabulated where available. These data are relevant to understanding melter feed rheology and cold cap chemistry during melting. The redox state of glasses made from some of the slurries were tabulated and correlated with initial slurry chemistry and feed preparation. 


\section{- 2.0 CONCLUSIONS AND RECOMMENDATIONS}

A number of observations were made during the analyses of peak offgas rates and total offgas amounts. The conclusions were based on attempts to correlate tabulated data over tests of different scale and to relate trends to the chemistry data and test conditions. The limited chemical data, particularly initial $\mathrm{pH}$ and carbonate concentration, contributed to uncertainty and prevented conclusive correlations in some cases. These shortcomings were noted appropriately. Where possible, previously reported correlations were used to show consistency with tests of different scale. Recommendations were made regarding additional testing and inclusion of other data to improve understanding of key effects.

- Peak offgas generation rates for $\mathrm{CO}_{2}, \mathrm{NO}_{x}$, and $\mathrm{H}_{2}$ can be predicted based on initial chemistry and formic acid addition rate.

Peak $\mathrm{CO}_{2}$ generation rate was largely dependent on formic acid addition rate for all 18 tests.

- Peak $\mathrm{NO}_{x}$ generation rate correlated well with initial nitrite, carbonate, and nitrate, and acid addition rate except for 2 of the 18 tests analyzed.

- Total offgas and total $\mathrm{CO}_{2}$ generation were not predictable over a range of conditions based on available data, and further analysis and tests are required to separate the various effects of chemistry and test type on both of these quantities.

- The overall analysis of $\mathrm{CO}_{2}$ production indicated that different proportions of various reactions occurred in the various tests, which indicated that a simple correlation of total $\mathrm{NO}_{x}, \mathrm{~N}_{2} \mathrm{O}$, and $\mathrm{H}_{2}$ with initial nitrite, nitrate, carbonate concentrations and formic acid addition would not be expected to be applicable over all tests. Further tests are needed to understand initial conditions affecting the balance of these reactions and differences between laboratoryscale and large-scale tests. Possible differences due to slurry preparation techniques were not examined. 
- Total $\mathrm{NO}_{x}$ generation generally increased with formic acid addition and initial nitrite concentration for most of the tests. Exceptions to the correlation were attributed to the effect of added base, which. appeared to suppress $\mathrm{NO}_{x}$ formation and promote $\mathrm{N}_{2} \mathrm{O}$ formation. The effects of noble metal content could not be determined with the limited data.

- Total $\mathrm{H}_{2}$ generation increased above a threshold point with amount of formic acid available (i.e. formic acid-2 $\times$ carbonate-nitritehydroxide). Hydrogen production appeared to be bimodal with a transition to higher amounts above a threshold amount of available formic acid: Consideration of noble metal content did not improve the correlation significantly. Initial measured $\mathrm{pH}$ could not reliably be used to correct for the amount of acid consumed in reaching the appropriate $\mathrm{pH}$ range. The reproducibility of $\mathrm{pH}$ measurements at elevated temperatures should be examined to determine whether procedures can be developed for improving reliability of measurements. In addition, the buffering capacity of the various slurries should be measured by titration to provide reference data on the amount of acid required to reach 2 or 3 reference $\mathrm{pH}$ levels. Improvements of $\mathrm{pH}$ measurement and titration data could make $\mathrm{pH}$ measurements more useful for interpreting offgas data, comparing slurries, and controlling feed preparation.

- Peak $\mathrm{H}_{2}$ generation rate was consistently proportional to the total $\mathrm{H}_{2}$ observed.

- Total $\mathrm{NH}_{3}$ generated, as measured by slurry and condensate analyses, correlated somewhat with total $\mathrm{H}_{2}$ generated and increased in proportion. However, total $\mathrm{NH}_{3}$ varied by about a factor of 5 to 6 at a given level of total $\mathrm{H}_{2}$ generation, which indicated that factors not affecting $\mathrm{H}_{2}$ generation had a significant effect on $\mathrm{NH}_{3}$ generated.

- Gases such as $\mathrm{CO}, \mathrm{N}_{2}$ and $\mathrm{HCN}$ do not appear to be products of feed preparation during formic acid addition and digestion, though identification of $\mathrm{HCN}$ in one test remains an open issue. 
- Small-scale tests can be reliably used to predict peak offgas generation rates and total offgas for $\mathrm{CO}_{2}, \mathrm{NO}_{x}, \mathrm{~N}_{2} \mathrm{O}$ and $\mathrm{H}_{2}$, . particularly when test conditions are similar. One set of tests allowed direct comparison of small-scale and large-scale tests under similar conditions to compare total offgas for these gases and $\mathrm{NH}_{3}$. Differences in total offgas quantities normalized per liter of slurry were small. Differences in peak generation rates were in the range of 22 to $44 \%$ and were not consistently higher or lower depending on scale of test. Direct comparisons of other small-scale and large-scale tests were not considered reliable because of differences in test conditions. Additional laboratory-scale testing is recommended to more closely duplicate the full-scale SIPT2 test conditions.

- Data on glass redox, $\mathrm{Fe}^{2+} / \mathrm{Fe}^{3+}$, were correlated with the molar ratio $\left([\mathrm{HCOOH}]-\left[\mathrm{NO}_{2}\right]\right) /\left(\left[\mathrm{NO}_{3}\right]\right)$, which was consistent with an earlier correlation for slurries that did not contain nitrite. Thus, initial nitrite diminished glass redox for a given amount of formic acid. addition, and glass redox correlated with the ratio (added formic acid - initial nitrite)/(initial nitrate) for feed preparation of NCAW slurries.

- This report or an equivalent document should be routinely updated to provide a single source to be used for integrated test planning and data evaluation and plant design. Additional data analyses are expected to make the upper bounds and trends in peak offgas generation rates and total offgas generation more reliable in terms of the effects of test conditions such as acid addition rate, amount of acid added, initial nitrite, nitrate and carbonate concentrations, and noble metal content. Effects of $\mathrm{pH}$ and temperature should be more comprehensively bounded by inclusion of other test data. 


\subsection{APPROACH}

A summary of a significant portion of offgas generation and redox process testing data obtained for HWVP feed preparation of NCAW slurries was prepared. Chemical data and test system characteristics were also tabulated. The goal was to compile these data in a uniform manner and to examine the data for consistency between small-scale and large-scale tests. Then an analysis of the effects of initial slurry chemistry on offgas/redox behavior was performed. After initial compilation of data was complete, a meeting was held with a number of the investigators familiar with the data to provide a consensus on the approach to compilation. This was done to make the compilation useful to others, to provide an opportunity for an initial review, and to facilitate obtaining data that might be available but not in current reports.

The effects of feed chemistry, including initial nitrate, nitrite, carbonate and noble metal concentrations, and excess added $\mathrm{NaOH}$ were then examined for each of offgas species, and graphical correlations were prepared. Where possible, equations for peak rates and total offgas amounts were developed for graphical correlations, and upper bounds were indicated in some cases. The degree to which correlations were successful was not quantified. It would be premature to quantify the reliability of correlations or any of the data because the reproducibility of tests is not known, and the accuracies of results were not reported for any of the data. Generally, it would be expected that chemical data should not be biased more than $10 \%$, but the uncertainty in other data has not been quantified. No duplicate tests were reported, though a.small-scale test was compared to bench-scale test $(50 \mathrm{ml}$ vs. $1000 \mathrm{ml}$ ) and the results agreed within 10\% (Morrey et al. 1993). Further analysis of other engineering-scale KfK batches not tabulated in this report might provide an indication of the reproducibility of large-scale tests.

Additional review of the data by the original investigators was not performed, which probably would have given additional insights into interpretation of correlations of the offgas data and additional explanations for some of the deviations. More completely integrating this report with data on foaming, melter cold-cap chemistry and melter could provide greater insight into process performance and mechanisms. 


\subsection{RESULTS AND DISCUSSION}

A number of test operating conditions and slurry chemistry conditions can affect offgas generation during HWVP feed preparation. In comparing process tests of different scale, the general expectation is that the chemistry of reactions will not be affected by volume of slurry. However, it cannot be assumed that mixing and transport processes will necessarily be equivalent for small-scale and full-scale tests. In addition, the recycle of condensate during boiling may affect slurry chemistry, promote specific reactions and thereby affect offgas. Thus, there is potential for the extent of reactions producing $\mathrm{CO}_{2}, \mathrm{NO}, \mathrm{NO}_{2}, \mathrm{~N}_{2} \mathrm{O}, \mathrm{H}_{2}$ and $\mathrm{NH}_{3}$ to be affected by scale and system operating conditions. In order to discern possible effects, basic system characteristics such as slurry volume, slurry depth, power of mixing, gas flow rate, and gas turnover rates were tabulated along with slurry chemistries and acid feed rate. Offgas data were tabulated for $\mathrm{CO}_{2}, \mathrm{NO}_{x}, \mathrm{NO}, \mathrm{NO}_{2}, \mathrm{~N}_{2} \mathrm{O}, \mathrm{H}_{2}$ and $\mathrm{NH}_{3}$ for acid addition period and digestion period in HWVP feed preparation. Observations on the occurrences of other gases, such as $\mathrm{CO}, \mathrm{HCN}, \mathrm{N} 2$ and $\mathrm{O} 2$, were included in a separate section.

\subsection{Scaling Parameters for Various Tests}

The evolution of gases from heated and stirred slurries during feed preparation could, in principle, depend on various factors such as reaction rate of materials as affected by mixing, temperature and intrinsic chemical reaction rates, transport of gas to the surface, and dimensions which were characteristic of the particular system. The rate at which products are removed by sweep gas could also be important in interpreting data. The characteristics of the various test systems used to obtain data are summarized in Table 1. It should be noted that the volume of slurry being treated ranged from 0.057 liters to 28,011 liters (full scale), which corresponded to a scale-up factor of about $500,000: 1$ for the smallest . tests.

Most of the tabulated parameters are straightforward and require no explanation. A typical slurry volume for the test type is given for 1 or 2 test runs in this table. Slurry area is the area exposed to the gas phase, and the slurry area per unit volume, $S / \mathrm{N}$, equivalent to reciprocal of the 
slurry depth was considered a parameter relevant to the release of gas from the slurry. The stirring power, watts/liter, was calculated from voltage and current values, though data were available only for one test type. The turnover rates of the gas phase, expressed as ratio of purge gas flow rate to slurry volume and purge gas flow rate to head space above the slurry, were also tabulated, and these varied by more than an order of magnitude. The ratio of slurry volume/head space volume was included since this quantity is important in calculating the magnitude of pressure surges during peak offgas generation. This parameter also varied by an order of magnitude. Similarly, the quantity, nominal purge gas flow rate/slurry volume, determines the moles of gas per unit slurry volume per unit time that the system can handle without a pressure increase. Acomparison of this parameter, expressed as moles/min/liter slurry is shown in Figure 1, and significant differences were indicated. However, it appears that these factors were not strongly determinant of the types and quantities of gases evolved for the tests conducted to date, though these factors were not examined thoroughly.

In all systems except the laboratory-scale tests and radioactive tests, the pressure during feed preparation was below atmospheric pressure, in the range of 0.95 to 0.99 atm ( -20 to -3 inches water): The laboratoryscale tests and radioactive tests were slightly above atmospheric pressure, near 1.01 to $1.02 \mathrm{~atm}(+5$ to +10 inches water). The sweep gas was air in all tests except the laboratory-scale tests (Ar) and the radioactive core tests (Ar-0.3\% He). In general, these differences did not appear to correlate with the types or volumes of gas released among the tests. It should be noted that air provides the opportunity for NO to be converted to $\mathrm{NO}_{2}$, as discussed in Appendix A. Most investigators reported $\mathrm{NO}_{x}$, which was the sum of $\mathrm{NO}$ and $\mathrm{NO}_{2}$. Primary reactions during feed preparation, i.e. in the slurry, produce NO, but NO can subsequently react with oxygen if present in the sweep gas to produce $\mathrm{NO}_{2}$. Two investigations (Hutson 1992 and Grunewald et al. 1993) reported NO and $\mathrm{NO}_{2}$ separately with $\mathrm{NO}_{2}$ in the range of 25 to $75 \%$ of the total $\mathrm{NO}_{x}$. For purposes of correlating data in this report, amount of $\mathrm{NO}_{x}$ reported was assumed equal to the amount of NO produced in primary reactions with no account for possible diminution by condensation or losses to piping. In all tests, any $\mathrm{NO}_{x}$ captured in the condenser was lost to the gas analyzer. For the IDMS HWVP1 test, recycle of condensate during digestion may have 
returned some of the $\mathrm{NO}_{x}$. offgas to the slurry as nitrate as well. The overall effect could be a systematic negative bias to the reported $\mathrm{NO}_{x}$. No estimates of the magnitude of this bias were reported, and further analysis of condensate chemistry data would be necessary to estimate this quantity.

The particular reactions that occurred may have been affected by differences in heater configuration and rate and degree of mixing, as evidenced by differences in species identified in some cases. Quantitative data pertaining to mixing and heating were not readily available. The geometry of the system, combined with the placement of heating coils and stirring system may be important with regard to the proportions of various gases such as $\mathrm{NO}, \mathrm{NO}_{2}, \mathrm{~N}_{2} \mathrm{O}$ and to some extent $\mathrm{CO}_{2}$ and to the appearance of unusual gas species such as $\mathrm{HCN}$, which may have occurred in the RSM tests. In the RSM tests, the heater coil was not completely immersed because the volume of slurry was small relative to the tank volume, and the possibility of exposure of the slurry to temperatures higher than the nominal temperature existed. Qualitatively, the laboratory-scale tests probably had the most vigorous stirring since the heating source was outside the test vessel for these two types of tests, with a center stirring paddle for the 1.5 liter tests and a magnetically driven stirring bar for the smaller radioactive tests. The larger scale tests used a circular steam coil about half the diameter of the vessel with stirring paddles down the center of the coil. Further details of construction and analysis would be necessary to relate differences in feed preparation to mixing and heating configurations.

When examining the offgas data for correlation of $\mathrm{NO}_{x}$ with initial chemistry of the slurry, it was noted that correlation was improved if only the laboratory-scale tests were considered. In this case the effect of noble metal addition was revealed when the complexity of other scale effects was eliminated. Thus, it appeared that improved correlation resulted when conditions of stirring and heating and geometry were identical. Further analyses of these types of effects are required to draw further conclusions. 


\subsection{Test Operating Conditions and Ślurry Chemistry Data}

An overall summary of the feed preparation steps for the tests compared is given in Table 2. As indicated, the times for acid addition and digestion times and temperatures varied to some extent. For the laboratory-scale tests, only tests Lab1.01 and KfK included recycle and frit addition, see Appendix B for target compositions. For brevity, all the laboratory-scale tests were not shown in the table. Thus only 8 of the 18 tests tabulated included data on frit addition. The operating conditions and slurry chemistry data for the 18 tests analyzed are presented in Table 3. Chemistry data for the radioactive melter feed after acid addition and frit addition were not yet available. The data include initial slurry volume which was used to normalize all of the tabulated offgas and $\mathrm{NH}_{3}$ data on a per liter basis. The tabulated waste oxide loading, $\mathrm{g} / \mathrm{L}$, was the loading that corresponded to the initial volume. Formic acid feed rate was normalized as (volume of added acid) $\times$ (wt\% acid/100) /volume slurry/(duration of addition) to account for differences in strength of acid used for the various tests. All the slurries were targeted at the NCAW composition, but differences in preparation technique existed, as discussed by Smith et al.(1993). The slurry designation followed the identification used in that. report. The details of preparation were not. considered for correlations made in this report. Temperatures of formic acid addition and digestion were given either as a range or a single value, depending on whether the temperature varied significantly during each phase. The process time was given as the duration of the formic acid addition and the total time beyond that (including heat up) for the digestion.

\subsection{Offgas Data for Feed Preparation Tests}

A number of gases are produced during feed preparation and were discussed in detail by Smith et al.(1993). Smith summarized the reactions according to three phases, or stages, where each stage is dominated by particular reactions. The principle reactions producing $\mathrm{CO}_{2}$, $\mathrm{NO}_{x}$. (or equivalently $\mathrm{NO}$ as discussed in 4.1 above), $\mathrm{N}_{2} \mathrm{O}, \mathrm{H}_{2}$ and $\mathrm{NH}_{3}$ were given as: 


\section{Stage 1}

$$
\begin{aligned}
& \mathrm{H}_{2} \mathrm{CO}_{3} \longrightarrow \mathrm{H}_{2} \mathrm{O}+\mathrm{CO}_{2} \uparrow \\
& \log \left\{\left[\mathrm{H}_{2} \mathrm{CO}_{3}\right] /\left[\mathrm{HCO}_{3}\right]\right\}=6.45-\dot{\mathrm{pH}}
\end{aligned}
$$

Stage 11

$$
\begin{aligned}
& 3 \mathrm{HNO}_{2} \longrightarrow \mathrm{H}^{+}+\mathrm{NO}_{3}^{-}+2 \mathrm{NO} \uparrow+\mathrm{H}_{2} \mathrm{O} . \\
& \log \left(\left\{\left[\mathrm{HNO}_{2}\right] /\left[\mathrm{NO}_{2}\right]\right]=3.35-\mathrm{pH}\right. \\
& 2 \mathrm{HNO}_{2}+2 \mathrm{NaCOOH} \longrightarrow \mathrm{N}_{2} \mathrm{O} \uparrow+2 \mathrm{CO}_{2} \uparrow+2 \mathrm{NaOH}+\mathrm{H}_{2} \mathrm{O} \\
& 2 \mathrm{HNO}_{2}+\mathrm{NaCOOH} \longrightarrow 2 \mathrm{NO} \uparrow+\mathrm{CO}_{2} \uparrow+\mathrm{NaOH}+2 \mathrm{H}_{2} \mathrm{O}
\end{aligned}
$$

Stage III

$$
\begin{aligned}
& \mathrm{HCOOH} \rightarrow \mathrm{CO}_{2} \uparrow+\mathrm{H}_{2} \uparrow \quad \text { (catalyzed) } \\
& \mathrm{NO}_{3}^{-}+5 \mathrm{HCOOH} \rightarrow \mathrm{NH}_{3}+4 \mathrm{CO}_{2} \uparrow+\mathrm{COOH}^{-}+3 \mathrm{H}_{2} \mathrm{O} \\
& \mathrm{Me}^{3+}+3 e^{-} \rightarrow \mathrm{Me} \text { (black residue) }
\end{aligned}
$$

$$
\text { where } \mathrm{Me}=\mathrm{Pd}, \mathrm{Rh}, \mathrm{Ru}, \mathrm{Cu}, \mathrm{Ag}, \mathrm{Te}, \mathrm{Se} \text { and } \mathrm{Pb} \text {, for example }
$$

The degree to which several of these reactions occur is complex, as discussed by Smith et al.(1993). Five of these reactions can produce $\mathrm{CO}_{2}$, and reaction 1 during Stage I generally produces $\mathrm{CO}_{2}$ equal to carbonate (plus a small amount due to manganese oxide) on a molar basis. The Stage II reactions producing $\mathrm{CO}_{2}$ can occur in varying amounts, depending in a complex way on test conditions. Accordingly, the amounts of $\mathrm{NO}$ and $\mathrm{N}_{2} \mathrm{O}$ produced are also highly dependent on test conditions. The Stage III reactions, which produce $\mathrm{H}_{2}$ and $\mathrm{NH}_{3}$ after the $\mathrm{pH}$ has been lowered and nitrite is depleted, also vary in a manner not completely understood and are thought to occur when noble metals catalyze the direct decomposition of formic acid. Other reactions also exist and are discussed in more detail by Smith et al.(1993). 
The offgas data and $\mathrm{NH}_{3}$ data for the tests are presented in Tables 4 . The - moles generated are normalized by initial slurry volume. Total moles offgas, peak gas generation rate and time of the peak are tabulated for the acid addition period and the digestion period separately. Data for $\mathrm{CO}_{2}$, $\mathrm{NO}_{x}, \mathrm{~N}_{2} \mathrm{O}$, and $\mathrm{H}_{2}$ were reported for almost all tests and $\mathrm{NO}$ and $\mathrm{NO}_{2}$ only for KfK and HWVP tests. Ammonia data were separated into that found in the condensate, expressed per liter of slurry, and the total amount (including condensate and slurry analyses), also expressed as per liter of slurry. Data on $\mathrm{NH}_{3}$ generated during recycle waste stream and frit additions were also available for a limited number of tests.

\subsection{Analysis of Peak Total Offgas Rate and Total Offgas}

The peak total offgas generation rate generally was dominated by the initial $\mathrm{CO}_{2}$ peak offgas but not in all cases. In some cases, i.e. Lab 1.01, Lab 1.02, Lab 1.04b, Lab KfK, and Kfk tests, the peak total offgas occurred toward the end of the formic acid addition, see Table 4. NO $\mathrm{N}_{x}$ offgas contributed significantly to peak total offgas in these tests and was the major constituent for Lab 1.02, Lab 104b, Lab KfK and KfK tests. The peak total offgas rate increased with increase in formic acid addition rate, Figure 2. The upper bound was higher than that for peak $\mathrm{CO}_{2}$ offgas, as indicated by the upper curve and shown below for $\mathrm{CO}_{2}$ in section 4.5. The total for Lab 1.01 was suspect, since difficulty with $\mathrm{NO}_{x}$ measurement was reported, as indicated in Figure 2. The total for this test was likely above $0.010 \mathrm{moles} / \mathrm{liter} / \mathrm{min}$., however.

Total offgas showed an approximate correlation with initial carbonate and nitrite concentrations and the amount of formic acid added, Figure 3. The upper bound ranged from 0.4 moles /liter at 1 molar sum of these quantities to about 0.9 moles/liter for 2.25 molar sum (carbonate + acid + nitrite).

\subsection{Correlation of Peak $\mathrm{CO}_{2}$ with Formic Acid Addition Rate}

Peak $\mathrm{CO}_{2}$ offgas rate generally occurred during the early period of formic acid addition, Table 4. All feed slurries, with the exception of the radioactive core sample and simulant, were. assumed to have the same nominal initial carbonate concentration (in most tests initial carbonate 
was not measured, though presumed near the nominal value of 0.125 molar), and carbonate level was presumed not to be a major difference among the tests. The data for peak $\mathrm{CO}_{2}$ are shown for comparison in Figure 4. The peak $\mathrm{CO}_{2}$ observed during formic acid addition correlated reasonably well with the formic acid addition rate, with the addition rate normalized as $100 \times$ wt\% acid $\times$ liters acid/hour/liter slurry, Figure 5, as suggested by an earlier treatment of other data by Wiemers et al.(1993). Thus, there appeared to be no significant effect of slurry volume, geometry, heating or stirring in this case. The least squares correlation gave a line:

$$
\begin{aligned}
& \text { Peak } \mathrm{CO}_{2}=0.323 \times \mathrm{AR}-0.00122 \text { moles/liter slurry/min } \\
& \text { where } \mathrm{AR}=\begin{array}{l}
\text { acid addition rate in liters of } 100 \% \text { acid/liter } \\
\text { slurry } / \mathrm{h} .
\end{array}
\end{aligned}
$$

A conservative upper bound was estimated by the line:

Peak $\mathrm{CO}_{2}=0.435 \times \mathrm{AR}-0.0015$ moles/liter slurry $/ \mathrm{min}$.

The data for the Lab 1:01 test appeared high compared to the rest of the data and deviated most from the least squares correlation. The overall correlation over all scales of testing does not necessarily mean that the rate of gas release was controlled solely by the rate at which formic acid was available for reaction for the destruction of carbonate. If this were the case, the release would be uniform over time rather than building to a peak. But it does imply that the transport conditions were not significantly different in the various tests and that the reaction and release was largely the same on a normalized volume basis. The intrinsic stirring promoted by gas release may be a determining factor for the case when large volumes of gas are released, such as during the carbonate destruction. The appearance of a peak is characteristic of the rapid evolution of $\mathrm{CO}_{2}$ as the $\mathrm{pH}$ drops to the range where carbonic acid is driven to evolve $\mathrm{CO}_{2}$, as discussed by Smith et al.(1993). The peak values were close to the predicted rate of half the formic acid addition rate, on a molar basis, shown by the dashed line in Figure 5. At the high range of addition rate, above 0.02 liters acid/liter slurry/h, there was a tendency. for the values to be higher than this predicted rate. It is probably 
simplistic to expect the peak value to equal half the addition rate as this would imply that a steady-state condition existed, whereas it was apparent that a considerable fraction of $\mathrm{CO}_{2}$ was released below the observed peak rate.

An analysis of the time of occurrence of the peak $\mathrm{CO}_{2}$ was not performed, though it would be expected to correlate with amounts of formic acid required to bring the $\mathrm{pH}$ to the range of 7.3 to 7.5, as suggested by Smith et al.(1993). The time would be expected to vary in a manner predictable from the acid neutralization capacity of the slurry and formic acid addition rate.

\subsection{Analysis of Total $\mathrm{CO}_{2}$ Produced during Feed Preparation}

The total amounts of $\mathrm{CO}_{2}$ released for the various tests are summarized in Figure 6. The prediction of total $\mathrm{CO}_{2}$ produced involves assumptions about the specific reactions occurring during preparation, as discussed by Smith et al.(1993) and King (1993). Material balance analyses were not performed on the data tabulated here but a preliminary comparison of the data was made on the basis of a parameter discussed by Smith et al.(1993), the amount of $\mathrm{CO}_{2}$ relative to observed amounts of $\mathrm{N}_{2} \mathrm{O}$ and $\mathrm{NO}_{x}$. The excess $\mathrm{CO}_{2}$ produced (defined by subtracting the amount of carbonate from the total) was plotted versus $2 \times$ total $\mathrm{N}_{2} \mathrm{O}+0.5 \times$ total $\mathrm{NO}_{x}$, Figure 7. Generally, data falling near the line of $1: 1$ ratio indicated that nitrite destruction occurred by direct reaction with formic acid whereas a smaller amount indicated reactions involving the disproportionation of nitrous acid. For amounts of $\mathrm{CO}_{2}$ above the line, other reactions involving $\mathrm{H}_{2}$ or $\mathrm{NH}_{3}$ production, reduction of $\mathrm{MnO}_{2}, \mathrm{Fe}_{2} \mathrm{O}_{3}$, or possibly other transition metal oxides probably occurred. Consistent with this hypothesis, the total $\mathrm{H}_{2}$ observed was highest for points above the line, as indicated in parenthesis near each point. It was apparent that deviations from the 1:1 line. were not correlated with the scale of the tests, and probably depended on other differences such as noble metal content, initial nitrite and nitrate concentrations and acid feed rate. As discussed above in 4.3, the deviations depend on the extent of the various Stage II and Stage III reactions, which determine the amounts of $\mathrm{CO}_{2}$ relative to $\mathrm{NO}_{x}$ and $\mathrm{N}_{2} \mathrm{O}$, in contrast to the predictable amount produced in Stage I. 
A graph of total $\mathrm{CO}_{2}$ was prepared to indicate possible correlation with the estimated amount of carbonate, amount of formic acid added, and excess base added, Figure 8. This graph indicated that several other factors probably also affected the amount of $\mathrm{CO}_{2}$ generated. Here the amount of $\mathrm{CO}_{2}$ in excess of the carbonate-produced portion was plotted against the amount of formic acid added in excess of the amount required to destroy the carbonate and neutralize the added base. In general, all the effects causing the scatter of data are not understood, but the excess . amount of $\mathrm{CO}_{2}$ appeared to increase with excess amount of formic acid added. Noble metals tended to increase the amount of $\mathrm{CO}_{2}$, e.g. noble metal content was higher for Lab 1.04, Lab 1.04a, RSM 2 tests than the other tests, and higher for Lab SIPTnm compared to Lab SIPT. The four tests with the KfK slurry, i.e. Lab 1.04b, Lab 1.07, Lab KfK and KfK, generally correlated well and showed increase of $\mathrm{CO}_{2}$ with excess amount of acid added. The HWVP2 test may have had high $\mathrm{CO}_{2}$ due to the effect of the heel left from HWVP1. A better understanding of these effects would probably result if titration data were available to indicate the amount of formic acid required to bring each slurry to a reference neutralization point, or neutralization capacity of the slurry. This would better define the relative amount of formic acid available for nitrite destruction and a could be used as a predictive tool for the extent of reactions producing NO and $\mathrm{N}_{2} \mathrm{O}$ and associated amounts of $\mathrm{CO}_{2}$.

\subsection{Correlation of Peak $\mathrm{NO}_{x}$ Offgas Rates with Waste Feed Chemistry and Acid Feed Rate.}

An analysis of the peak rates of $\mathrm{NO}_{x}$ was performed to correlate the various rates with formic acid addition and initial nitrite, nitrate, and carbonate concentrations of the slurries. Correlation with other chemical variations such as noble metal content and geometrical factors and scale of experiment were also sought, but no relationship was found. The initial nitrite, amount of formic acid added and rate of formic acid addition should have strong effects on peak $\mathrm{NO}_{x}$, as suggested by equations 3 ) and 4). in section 4.3 above. A reasonable correlation was found using parameters derived from the net reaction for formation of nitrous acid followed by the disproportionation of nitrous acid to produce $\mathrm{NO}$ gas, $\mathrm{NO}_{3}{ }^{\circ}$ and $\mathrm{H}_{2} \mathrm{O}$ : 
$3 \mathrm{NO}_{2}^{-}+3 \mathrm{H}^{+} \longrightarrow 2 \mathrm{NO} \uparrow+\mathrm{H}_{2} \mathrm{O}+\mathrm{NO}_{3}{ }^{-}+\mathrm{H}^{+}$

- Even though gas evolution rate is not governed by an equilibrium equation, the propensity to evolve gas should be driven by excesses of reactants producing the gas and reduced by the excesses of the products of reaction. The results of the analysis are summarized in Figure 9 , as calculated from data summarized in Tables 3 and 4. An empirical approach was taken . after identification of potential species affecting the rate. Thus, a reasonable correlation of the data resulted by ignoring the exponents and correlating with $\left[\mathrm{NO}_{2}\right] \times\left[\mathrm{H}^{+}\right] /\left[\mathrm{NO}_{3}{ }^{-}\right]$, achieved by using the formic acid rate of addition for the $\mathrm{H}^{+}$term, initial nitrite concentration and $1 /$ (initial nitrate) concentration as the scaling factors, which gave an upper bound on peak $\mathrm{NO}_{x}$ offgas generation rate:

$$
\begin{aligned}
& \text { Peak } \mathrm{NO}_{x}=0.074 \times\left[\mathrm{NO}_{2}^{-}\right] \times \mathrm{AR} /\left[\mathrm{NO}_{3}\right] \text {, moles/l/min. } \\
& \text { where. }\left[\mathrm{NO}_{2}^{-}\right]=\text {initial nitrite, moles/liter } \\
& \mathrm{AR}^{-}=\text {formic acid addition rate, liters/liter/h } \\
& {\left[\mathrm{NO}_{3}^{-}\right]=\text {initial nitrate, moles/liter }}
\end{aligned}
$$

The two tests Lab 1.04 and Lab 1.04a had 0.33 mole/liter of $\mathrm{NaOH}$ added and also were higher in noble metal content than most of the other tests. The excess base along with normal nitrite probably accounted for the production of greater quantities of $\mathrm{N}_{2} \mathrm{O}$ in preference to $\mathrm{NO}_{x}$. A minor improvement in correlation of the data resulted if an additional factor of $1 /(2 \times$ initial carbonate + added base) was used to represent the formate ion concentration in the above equation. This term could be interpreted as representing the amount of formate ion produced by carbonate-to- $\mathrm{CO}_{2}$ release and neutralization. However, the overall improvement was minor with the available data, and the correlation of the CoreR1.1 test with the rest of the data worsened.

\subsection{Analysis of Total $\mathrm{NO}_{\mathrm{x}}$. Produced during Feed Preparation}

An attempt to correlate total amount of $\mathrm{NO}_{\mathrm{x}}$ with initial nitrite, acid addition and initial nitrate was not successful, and the effects of added base, noble metal content and initial carbonate were not separable with the limited data available. With the exception of three tests, the general 
trend was an increase of $\mathrm{NO}_{x}$ with amount of formic acid and initial nitrite. Thus, a graph of total $\mathrm{NO}_{x}$ versus acid addition $x$ initial nitrite can be used as a platform for discussing the major effects discerned, Figure 10. The most notable exceptions to the general trend were Lab 1.04 and Lab 1.04a tests, which had 0.33 molar $\mathrm{NaOH}$ added and also had the highest noble metal content. Lab 1.01, which also had high noble metal content, also indicated low $\mathrm{NO}_{x}$, but these data were suspect and were not included in the figure. Consideration of the possible effect of initial nitrate did not improve the overall correlation. Smith et al. (1993) observed that the production of $\mathrm{N}_{2} \mathrm{O}$ from nitrite was favored by alkaline conditions. The low amounts of total $\mathrm{NO}_{x}$ for tests. Lab 1.04 and Lab1.04a (and possibly Lab 1.01) could possibly be attributed to the larger amount . of noble metals in these three slurries. However, there is no direct evidence that noble metals promote $\mathrm{N}_{2} \mathrm{O}$ in preference to $\mathrm{NO}$, although King (1993) reported that $\mathrm{Pd}$ promoted the conversion of $\mathrm{NO}$ to $\mathrm{N}_{2} \mathrm{O}$ in a closed system. All the tests considered here are open system tests. Thus the notable exceptions to the overall trend in Figure 10 can be attributed to excess base and promotion of $\mathrm{N}_{2} \mathrm{O}$ in preference to $\mathrm{NO}$ generation. It is possible that the conversion of nitrite to $\mathrm{N}_{2} \mathrm{O}$ was catalyzed by noble metals in the alkaline slurries and that this additionally detracted from $\mathrm{NO}_{x}$ generation. The authors concluded that additional data are required to clarify the effect of noble metals on $\mathrm{NO}_{x}$ generation and other factors that affected total $\mathrm{NO}_{x}$ generation.

The temperature during acid addition had a strong effect on $\mathrm{NO}_{x}$ production, e.g. other tests reported by Smith et al.(1993) not tabulated here indicated that lowering the acid addition temperature to $85^{\circ} \mathrm{C}$ caused an appreciable increase in $\mathrm{NO}_{x}$ relative to $\mathrm{N}_{2} \mathrm{O}$. Thus the effect of increased base (or possibly noble metal content) on $\mathrm{NO}_{x}$ production depended on temperature as well, and the suppression of $\mathrm{NO}_{x}$ seen for tests 1.01, 1.04 and 104a in Figure 10. was more than offset when the temperature during the acid addition was dropped $10 \mathrm{C}$.

It should be noted that there was good agreement between the total $\mathrm{NO}_{\mathrm{x}}$ offgas for the full-scale SIPT2 and laboratory-scale Lab SIPT tests and for the engineering-scale KfK and laboratory-scale Lab KfK tests. Thus even though the correlation attempted over all tests, as shown in Figure 10, was not good for the parameters selected, agreement existed between. 
large-scale and small-scale tests when the parameters were more nearly identical. The differences of total $\mathrm{NO}_{x}$ were in the range of 15 to $20 \%$ for these two comparisons.

\subsection{Correlation of Peak $\mathrm{N}_{2} \mathrm{O}$ Rate with Waste Feed Chemistry and Acid Feed Rate}

The peak $\mathrm{N}_{2} \mathrm{O}$ generation rate generally appeared to increase with acid addition rate, initial nitrite, carbonate, and excess hydroxide. A graphical correlation was attempted, comprised of factors taking each of these into account, Figure 11. Considerable scatter was apparent. Though high $\mathrm{pH}$ is thought to promote $\mathrm{N}_{2} \mathrm{O}$ production (Smith et al.1993), initial pH was not used in this correlation because of the apparent poor accuracy and reproducibility of $\mathrm{pH}$ measurements at temperature, as evidenced by inconsistent values for Lab.1.04, Lab 1.04a and Lab 1.04b, each of which had excess $\mathrm{NaOH}$ added ( 0.33 molar). Instead, the amount of added $\mathrm{NaOH}$ was used for these three tests for the correlation, and no $[\mathrm{OH}]$ correction was made for the other tests. The RSM1 test slurry had a notably high $\mathrm{pH}$, 10.8, which was the same as the highest measured for these three Lab tests. The outlying point for RSM1 might have fit the correlation better if a reliable correction were made for [OH]. An upper bound on peak $\mathrm{N}_{2} \mathrm{O}$ was drawn ignoring the RSM1 point.

\subsection{Comparison of Total $\mathrm{N}_{2} \mathrm{O}$ with Total $\mathrm{NO}_{x}$ and Correlation} with Formic Acid Addition and Waste Feed Chemistry

A simple correlation of the total $\mathrm{N}_{2} \mathrm{O}$ offgas with amount of formic acid, initial carbonate, nitrite and noble metal concentrations was not found. Generally, the amount of $\mathrm{N}_{2} \mathrm{O}$ was smaller than the amount of $\mathrm{NO}_{x}$, with $\mathrm{N}_{2} \mathrm{O} / \mathrm{NO}_{x}$ less than 0.5 for most of the tests, but was in the range of 4 to 6 for tests with high carbonate (SimS2.4) and excess base (Lab1.04 and Lab1.04a), Figure 12. Test RSM1, as discussed above may have had high $[\mathrm{OH}]$ as well, which would make it fit the general trend better if a correction were made. In general, as reported by Smith et al.(1993), the prediction of total amount of $\mathrm{N}_{2} \mathrm{O}$ is complex, and there is limited understanding of the factors affecting production, though increase in base and increased temperature both tended to promote $\mathrm{N}_{2} \mathrm{O}$ over NO. The observed maximum was about 0.1 moles/liter, except for the tests with 
excess base which produced about 0.16 moles/liter.

\subsection{Correlation of Peak and Total $\mathrm{H}_{2}$ with Formic Acid and Waste Feed Chemistry}

The total amounts of $\mathrm{H}_{2}$ for the various tests are shown in Figure 13, and for comparison, the amounts of $\mathrm{NH}_{3}$ are also shown. A simple correlation indicated dependence of total $\mathrm{H}_{2}$ on amount of formic acid added, Figure 14. Formic acid addition in Lab 1.04 a test was deliberately stopped just prior to high $\mathrm{H}_{2}$ evolution so it is on the threshold of producing above 0.01 moles/liter, as occurred in Lab 1.04. The amount of $\mathrm{H}_{2}$ produced in the various tests was further compared with an estimate of the amount of formic acid remaining at the end of nitrite destruction, Figure 15, with an additional term taking into account initial excess $[\mathrm{OH}]$, Figure 16, and with an addition factor for the nominal amount of rhodium in the slurry, Figure 17. The available amount of formic acid was estimated by subtracting $2 \times$ carbonate and the nitrite concentration, on a molar basis, from the total formic acid/liter slurry. Nitrite destruction can consume formic acid in the ratio of 0.5 to 1 moles acid/mole nitrite, depending on the extent of Stage II reactions 2), 3) and 4) given in section 4.3. Thus the correction used corresponded to the maximum amount of acid that could be consumed by nitrite destruction. The $[\mathrm{OH}]$ term was used to adjust Lab 1.04, Lab $1.04 \mathrm{a}$ and Lab $1.04 \mathrm{~b}$ acid by 0.33 molar because each of these tests had excess base added in that amount. The degree of correlation appeared better using ( 0.1 + rhodium concentration) rather than the concentration as a factor, Figure 17. This empirical correlation of the tabulated data would work just as well based on total noble metal content of these slurries, since the amounts of Pd and Ru were generally in proportion to the Rh concentration. However, the results of King(1993) indicated that $\mathrm{Rh}$ was the appropriate noble metal affecting $\mathrm{H}_{2}$ production. The degree of correlation was good for 15 of the 18 tests considered, with HWVP1 and RSM1 exceptional and no analytical data reported on RSM2. The RSM1 test produced much less $\mathrm{H}_{2}$ than any of the other tests and had the smallest amount of formic acid added. These correlations support the earlier finding by Wiemers et al.(1993) that a transition to large amounts of $\mathrm{H}_{2}$ occurred as formic acid/nitrite ratio was increased above a threshold and are consistent with the observation by Smith et al.(1993) that $\mathrm{H}_{2}$ was 
generated in Stage III. Additional tests should be performed to more clearly define the effect of other test conditions, such as noble metal, nitrite, and carbonate concentrations and initial $\mathrm{pH}$, on the transition between high and low $\mathrm{H}_{2}$. The peak $\mathrm{H}_{2}$ offgas rate correlated with total $\mathrm{H}_{2}$, Figure 18. Thus, both peak and total $\mathrm{H}_{2}$ are predictable to the extent shown in the above correlations.

\subsection{Correlation of $\mathrm{NH}_{3}$ with $\mathrm{H}_{2}$ Offgas and Formic Acid Addition}

The total amount of $\mathrm{NH}_{3}$ generated during acid addition and digestion increased with increasing total amount of $\mathrm{H}_{2}$, Figures 13 and 19. There was, however, close to an order of magnitude spread in amount of $\mathrm{NH}_{3}$ for a given observed $\mathrm{H}_{2}$ level, with the total variation of $\mathrm{NH}_{3}$ over the all the tests being about 3 orders of magnitude. Thus, other factors that did not affect $\mathrm{H}_{2}$ production caused significant changes in the amount of $\mathrm{NH}_{3}$ produced. On the basis of initial slurry conditions and operating conditions, the amounts of $\mathrm{NH}_{3}$ measured appeared to best correlate with the amount of formic acid added, Figure 20. Notable exceptions were the HWVP tests, which produced relatively large amounts of $\mathrm{NH}_{3}$ for the amount of formic acid added. The preexistence of residual frit in the tank and the return of condensate during digestion may have contributed to the high $\mathrm{NH}_{3}$ for HWVP1, as discussed by Hutson (1992). A test similar to Lab 1.08, Lab $1.08 \mathrm{~b}$ reported by Smith et al.(1993) (not tabulated in this report), which deliberately had a heel left in the test vessel, also had somewhat higher $\mathrm{NH}_{3}$ produced, $2 \times 10^{-3}$ moles/liter, close to the value for HWVP2. Excluding the HWVP data, the best fit line gave:

$$
\log \left[\mathrm{NH}_{3}\right]=3.26 \times \text { [formic acid] }-6.24 \text { (all quantities moles/l) }
$$

A conservative bound would increase this by about a factor of 3 . In examining the correlation shown in Figure 16, it is apparent that other effects must be taken into account to explain factors of 5 to 6 in the $\mathrm{NH}_{3}$ for a given acid addition. Attempts at reducing the scatter with correlations with noble metal content, initial carbonate, initial $\mathrm{pH}$, nitrite, and nitrate did not convincingly improve on the correlation with acid addition. Replicate runs to estimate experimental error are necessary to further develop correlations with meaningful interpretation of uncertainties. 


\subsection{Observations on Other Gases}

Some isolated observations of other gases were made during the course of testing in some cases. The instances cited are cases where the investigator was attempting to measure the particular gas, and usually observed that the gas did not appear.

For the laboratory-scale tests by Smith et al.(1993), no carbon monoxide, nitrogen or oxygen was noted in lab SIPTnm and no carbon monoxide or generated nitrogen was noted in lab $\mathbf{1 . 0 2}$.

For the research scale melter tests by Cooper et al.(1993), carbon monoxide was noted at a level of 0.5 to $1.2 \%$ in the offgas, but with the reservation that hydrogen cyanide may have caused the apparent. signal in the $\mathrm{CO}$ analyzer, since carbon monoxide was not indicated by the gas chromatograph.

For the IDMS-HWVP tests by Hutson (1992); no carbon monoxide was observed.

Details regarding observations on other gases were not available for the full-scale SIPT tests and laboratory-scale radioactive tests.

\subsection{Scaling Relations and Prediction of Peak and Total Offgas for Full-Scale Processing from Small-Scale Tests}

Prior studies have suggested that total offgas and peak offgas rates for tests of different scale, when normalized on the basis of sludge weight, are the same when acid addition, acid addition rate, initial chemistry and temperature are the same. Two studies ( $\mathrm{Ha}$ et al. 1992, Hau et al. 1993) show similarities in the specific gases evolved, the timing of gas evolution, and increases in peak $\mathrm{H}_{2}$ with increases in formic acid addition rate for both 0.5 liter and 4000 liter tests. No specific guidance was given on scaling the results. Thus, the general assumption was that the scaling relation was not complex. Confirmation of this is not easily. achieved, considering the expense of full-scale testing and the number of variables involved, such as acid addition rate, total acid added, initial 
carbonate level, initial $\mathrm{pH}$, noble metal content, initial nitrite and nitrate concentrations, as well as details of slurry preparation, and stirring conditions.

- The most straightforward confirmation with the data tabulated in this report is by comparison of small-scale and full-scale tests with nearly the same test conditions. Comparisons of two sets of tests were considered in this regard, the full-scale SIPT2 with laboratory-scale Lab SIPT and engineering-scale KfK with laboratory-scale Lab KfK. However, several differences between SIPT2 and Lab SIPT tests made comparison of these two tests unreliable. The normalized acid addition rate for the SIPT2 test was about one half of that for the Lab SIPT, Table 3, which was necessary to avoid overpressurization of the tank. The acid addition rate was deliberately decreased to reduce the peak offgas rates. Also, the nitrate concentration of the SIPT2 test slurry was about $60 \%$ of the Lab SIPT test slurry. It would be advisable to perform a laboratory-scale test with the same nitrate level and acid addition rate as the full-scale SIPT2 test to make a valid comparison of scale effects. Moreover, the acid addition timing was considerably different in the full-scale SIPT2 test compared to the laboratory-scale test, and this condition should be more closely duplicated in the laboratory-scale test to make the comparison more reliable. In contrast, it appeared that a reliable comparison could be made between the KfK test and the Lab KfK test. Even though the KfK test was about $1 / 8$ of full scale (volume basis); a comparison for scale effects between this test and the much smaller Lab KfK test should be valid.

The offgas profiles of the Lab KfK and KfK tests are compared in Figure 21. Several similarities are apparent in the comparison, but differences also stand out. The general sequence of gas evolution was the same, $\mathrm{CO}_{2}$ followed by $\mathrm{NO}_{x}, \mathrm{~N}_{2} \mathrm{O}$ and then $\mathrm{H}_{2}$. The lab-scale test peak heights were about $22 \%$ higher for $\mathrm{CO}_{2}, 44 \%$ lower for $\mathrm{NO}_{x}$, and $25 \%$ lower for $\mathrm{N}_{2} \mathrm{O}$. The $\mathrm{H}_{2}$ peaks were similar in magnitude, but equipment problems during the Lab KfK test may have affected the peak measurement around 3 $h$. The large $\mathrm{H}_{2}$ peak at $6 \mathrm{~h}$ was probably an artifact of an unplanned temperature rise (Smith et al.1993) in the lab-scale test.

The total $\mathrm{NO}_{x}$ was about $20 \%$ lower for the Lab KfK compared to the engineering-scale KfK test, whereas amounts of $\mathrm{N}_{2} \mathrm{O}$ were nearly identical 
for the two tests, and amounts of $\mathrm{H}_{2}$ were nearly identical as well.

Amounts of $\mathrm{NH}_{3}$ were not reported for the Lab KfK and KfK tests.

A comparison of the percent of total gas for $\mathrm{CO}_{2}, \mathrm{NO}_{x}, \mathrm{~N}_{2} \mathrm{O}$ and $\mathrm{H}_{2}$ showed very close agreement for the Lab KfK and KfK tests, shown in bold type in Table 5.

Based on the above comparison of the Lab KfK and KfK tests, excellent agreement was found between laboratory-scale and.large-scale tests, though this agreement has not been confirmed for full-scale tests. In making an assessment of scaling effects on the basis of the data. tabulated here, a more complex evaluation is possible using the figures presented earlier in this report wherein variations in initial nitrite, nitrate, carbonate, and $\mathrm{pH}$ as well as acid feed rate, total acid added and waste oxide loading were used as normalizing parameters to develop master plots for all the data. The degree of agreement varied, but the following conclusions could be inferred until further data are developed:

Total offgas was generally dominated by $\mathrm{CO}_{2}$, and the fraction of $\mathrm{CO}_{2}$ was in the range of $47 \%$ to $87 \%$ for large-scale tests (HWVP, KfK and SIPT2). The trend toward lower fraction of $\mathrm{CO}_{2}$ was found in the corresponding small-scale test, i.e. Lab KfK.

Total $\mathrm{NO}_{x}$ could be reasonably correlated with acid addition and initial nitrite and depended on other differences not clearly defined with available data. The fraction of $\mathrm{NO}_{x}$ varied considerably over all the tests considered, but was generally lower than the fraction of $\mathrm{CO}_{2}$. However, for the Lab KfK and KfK tests, the fraction of $\mathrm{NO}_{x}$ was comparable to the fraction of $\mathrm{CO}_{2}$ Moreover, the total amounts of $\mathrm{NO}_{x}$ and $\mathrm{CO}_{2}$ were in good agreement, which indicated that a smallscale test could be used to predict large-scale behavior for $\mathrm{NO}_{x}$ and $\mathrm{CO}_{2}$ Similarly, $\mathrm{N}_{2} \mathrm{O}$ was only roughly correlated with test conditions over all the tests, yet the production of $\mathrm{N}_{2} \mathrm{O}$ was nearly the same in these two KfK tests.

Total $\mathrm{H}_{2}$ varied by more than 3 orders of magnitude over the various tests, and could be correlated with formic acid addition, initial 
base, initial carbonate and noble metal content to within only about an order of magnitude. This indicated that other factors may have strong effects. For the $\mathrm{KfK}$ and Lab. KfK tests, excellent agreement existed between the amounts of $\mathrm{H}_{2}$ produced, 3.6 to $3.7 \times 10^{-4}$ moles/liter, and the fraction of $\mathrm{H}_{2}$ relative to total gas, 0.06 to $0.07 \%$.

Generally, the sequence of evolution of specific gases was the. same in small-scale and large-scale tests and followed the scheme outlined by Smith et al.(1993) in laboratory-scale tests.

\subsection{Variations in Feed Chemistry and $\mathrm{pH}$ after Frit Addition}

The data on initial $\mathrm{pH}$ and initial chemistry (nitrate, nitrite, and carbonate) were tabulated and were generally complete for the various tests, though $\mathrm{pH}$ data were not uniformly reported and available. Postdigestion chemistry (nitrate, nitrite, and formate) and $\mathrm{pH}$ were similarly tabulated, and data for 5 of the 18 tests were either not reported or were not available. Chemistry and $\mathrm{pH}$ data were reported for 5 of the 8 tests that included frit addition. After frit addition, the nitrate ranged from 0.24 to 0.54 molar, the nitrite from 0.00 to 0.21 molar, and the formate from 0.36 to 1.42 molar for these 5 tests. Ambient $\mathrm{pH}$ for melter feed ranged from 6.69 to 10.03 . Some of these differences are obviously related to amounts of formic acid added and initial chemistry differences. Details of frit additions were not included in this report, and incorporation of this information remains as a task to facilitate analysis of the variations in final feed chemistry.

\subsection{Glass Redox Dependence on Formic Acid Addition and Initial Slurry Nitrate and Nitrite Concentrations}

- A previous report by Wiemers (1990) indicated that the glass redox, as measured by $\mathrm{Fe}^{2+} / \mathrm{Fe}^{3+}$ in the resultant glass, depended on the ratio of added formic acid to initial nitrate concentration and was largely independent of carbonate level. This correlation indicated acceptable redox, i.e. $0.005<\mathrm{Fe}^{2+} / \mathrm{Fe}^{3+}<0.3$, when the $(\mathrm{HCOOH}) /\left(\mathrm{NO}_{3}\right)$ ratio $=3$. At the time of that study, nitrite was not included in the slurry makeup, though it was recognized as a relevant factor. Additional redox data were 
available for some of the tests examined in the present report, and these are shown in Table 6. It might be expected that initial nitrite would consume formic acid and thereby decrease the redox of the glass produced from the slurry. Thus as a first approximation, the initial amount of nitrite. could be subtracted from the formic acid addition, on a molar basis, as a measure of its effect. A plot of the all the data was prepared to take into account initial nitrite, Figure 22, shown with the earlier data reported by Wiemers (1990) and that of Farnsworth(1987) and Elliott et al.(1991). As indicated, some of the simulants of Farnsworth had high total $\mathrm{Fe}$ and required less formic acid for acceptable redox, as discussed by Wiemers (1990). The nitrite-containing slurries produced glasses that were more highly oxidized, as indicated by generally lower values of $\mathrm{Fe}^{2+} / \mathrm{Fe}^{3+}$ for a given $(\mathrm{HCOOH}) /\left(\mathrm{NO}_{3}{ }^{-}\right)$ratio. If the nitrite concentration is subtracted from the formic acid addition (earlier data unchanged since the slurries contained no nitrite), then all the data more or less correlated consistently, as shown in Figure 22. Thus the combined effect of initial nitrite and added formic acid on glass redox appears predictable based on the earlier correlation by simply. subtracting the nitrite from the acid addition on a molar basis. The normalizing parameter for this correlation was $\left(\mathrm{HCOOH}-\mathrm{NO}_{2}\right] /\left(\mathrm{NO}_{3}\right)$. 


\subsection{REFERENCES}

\subsection{Sources and Methods for Tabulation of Data}

The data that formed the basis of this report were taken from best sources available, in most cases draft reports, as follows:

PNL laboratory-scale test results were drawn from a draft report ( Smith et al.1993). Results from tests 1.01, 1.02, 1.04, 1.04a, 1.04b, KfK, 1.07, $1.08,1.16$ (SIPT) and 1.16(SIPT $w$ noble metals) were tabulated.

The research scale melter test results were taken from a draft report (Cooper et al. 1993). Results from both RSM 1 and RSM 2 were analyzed.

The IDMS results for HWVP1 and HWVP2 were taken from a draft report (Hutson 1992). In addition, updated plots of some data and information on flow rates were obtained by telecon and fax ${ }^{1}$.

The KfK Batch 5 data were taken from a draft report (Grunewald et al. 1993). Integration of plotted offgas data was done to arrive at total gas evolved for these tests, and only the Batch 5 results were analyzed and tabulated. This batch was selected as typical, was conducted toward the end of the campaign, and the gas analysis results appeared representative and complete. Data were also available on glass redox for this batch ${ }^{2}$.

Radioactive core and simulant data were provided in a manuscript from a presentation (Morrey 1992), as well as updated information on further details of the tests ${ }^{3}$. Only the in-cell test results were tabulated and analyzed, namely test $S 2.4$ (simulant) and test $R 1.1$ ( radioactive core sample). Offgas values included offgas during recycle waste stream simulant addition. 1993.

1 Hutson, N., private communication, Westinghouse Savannah River Company, July

2 Elliott, M.L., private communication, Pacific Northwest Laboratory, Richland, Washington, September 1993.

3 Morrey, E.V., private communication regarding recent determinations of noble metal content and carbonate of simulants and core sample and details of experimental geometry and volumes, June 1993. 
The results from the SIPT-2 test were -provided in conversations with PNL staff analyzing test results ${ }^{4}$. These results are preliminary and were not available in written reports.

The dimensions of feed preparation tanks were taken directly from reports where possible or from drawings provided by the investigators. In all cases the data on nominal sweep gas flow were available from reports, except for the SIPT tests. The slurry volumes were reported in all cases for each test and were not identical for each run. All offgas data were normalized on the basis of initial slurry volume, taken where possible as the volume at the initiation of formic acid addition. The gram waste oxide loadings per liter ( $g$ WO/L) tabulated were the initial values before formic acid addition and final values after recycle waste stream and frit additions. The available radioactive test data and available SIPT data did not include information on recycle waste stream and frit additions.

\subsection{Documents (publicly available)}

Ha, B.C., D.M. Ferrara, and N.E. Bibler, 1992, Hydrogen Production During Processing of Radioactive Sludge Containing Noble Metals in Proceedings - of The International Topical Meetings on Nuclear and Hazardous Waste Management Spectrum '92, ANS, US DOE and AES Japan, Boise, ID, Vol2, p 961.

Hau, C.W., D.M. Ferrara, N.E. Bibler, B.C. Ha and J.A. Ritter, 1993, . Development of a Nitric/Formic Acid Process to Reduce Hydrogen Emissions During Sludge Treatment in the DWPF, in Proceeding of Waste Management '93, Tucson, AZ, Vol.2 p 963.

Morrey, E.V., M.L. Elliott, and J.M. Tingey, 1993, Laboratory-Scale Vitrification and Leaching of Hanford High-Level Waste for Validating Simulant and Glass Properties. (Offaas Analysis during Formating of the Third NCAW Core Sample (102-AZ-C1)), PNL-SA-21885, presented at Waste Management, March 4, 1993, Tucson, AZ.

4 Powell, M.R., J.R. Gaskill and M.H. Langowski, June, 1993, private communication regarding preliminary data from SIPT-2 test, formating and digestion conducted March 10-11, 1993, Pacific Northwest Laboratory, Richland, Washington. 
Yost, D.M., H.R. Russell, Jr., 1944, Systematic Chemistry of the 5th and 6th Group Nonmetallic Elements, Prentice Hall, N.Y.

\subsection{Documents (not publicly available)}

Cooper, M.F., M.L. Elliott, L.L. Eyler, C.J. Freeman and J.J. Higginson, March 1993, Research-Scale Melter Test Report, PHTD-C93-04.01B Draft, Pacific Northwest Laboratory, Richland, Washington.

Elliot, M.L., E.V. Morrey and J.M. Tingey, September 1991, Radioactive Formating. Vitrification and Product Testing. Status Letter Report to Westinghouse Hanford Company, Doc. PHTD-C91-05.05F, Pacific Northwest Laboratory, Richland, Washington.

Farnsworth, R.K. 1987. The Effect of Feed Composition and Formic Acid Addition on Glass Redox State, Letter Report to Westinghouse Hanford Company, No. HWVP-87-V110203A, Prepared by Pacific Northwest Laboratory, Richland, Washington.

Grunewald, W., G. Roth, W. Tobie, S. Weisenburger, and K. Weiss, 1993. Vitrification of Noble Metals Containing NCAW-Simulaint with an. Engineering Scale Melter , Feb. 15 draft report prepared for Pacific Northwest Laboratory, Richland, Washington, (ESM)Kerforschuunszentrum Karlsruhe (KfK) Institut fur Nucleare Entsorgungstechnik (INE).

Hutson, N., 1992. Integrated DWPF Melter System (IDMS) Campaign Report: Hanford Waste Vitrification Plant (HWVP) Process Demonstration, August 24 draft report to Westinghouse Hanford Company, Revision O WSRC-TR92-403, Westinghouse Savannah River Company, Aiken, South Carolina.

King, R.B., 1993. Recent Studies on the Treatment of Alkaline Nuclear Wastes with Formic Acid for Vitrification Plants; interim report for Contract 125770-A-A2 between University of Georgia and Pacific Northwest Laboratories, presented June 8 at Pacific Northwest Laboratory, Richland, Washington. 
Smith, H.D., K.D. Wiemers, M.H. Langowski, M.R. Powell and D.E. Larson, September, 1993. Evaluation of HWVP Feed Preparation Chemistry for An NCAW Simulant - Fiscal Year 1992: Evaluation of Offoas Generation and Ammonia Formation. Technical Report to Westinghouse Hanford Company, Milestone PHTD-C93-03.02b, Pacific Northwest Laboratory, Richland, Washington.

Wiemers, K.D.,1990. The Effect of HWVP Feed Nitrate and Carbonate content on Glass Redox Adjustment, Technical Report to Westinghouse Hanford Company, HWVP-90-1.2.2.03.03A, Pacific Northwest Laboratory, Richland, Washington.

Wiemers, K.D.; M.H. Langowski, M.R. Powell and D.E. Larson, 1993. Evaluation of HWVP Feed Preparation Chemistry for an NCAW Feed Simulant-Fiscal Year 1991: Evaluation of Offgas Generation. Reductant Requirements, and Thermal Stability of an HWVP NCAW Feed Simulant. Technical Report to Westinghouse Hanford Company, PHTD-C91.03.02C, Pacific Northwest Laboratory, Richland, Washington. 
FIGURES

$$
\therefore
$$

29 


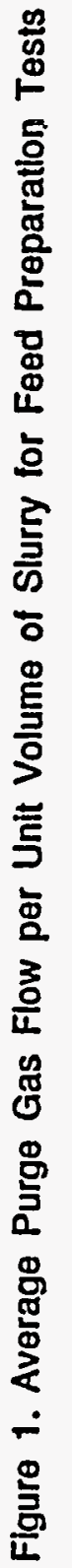

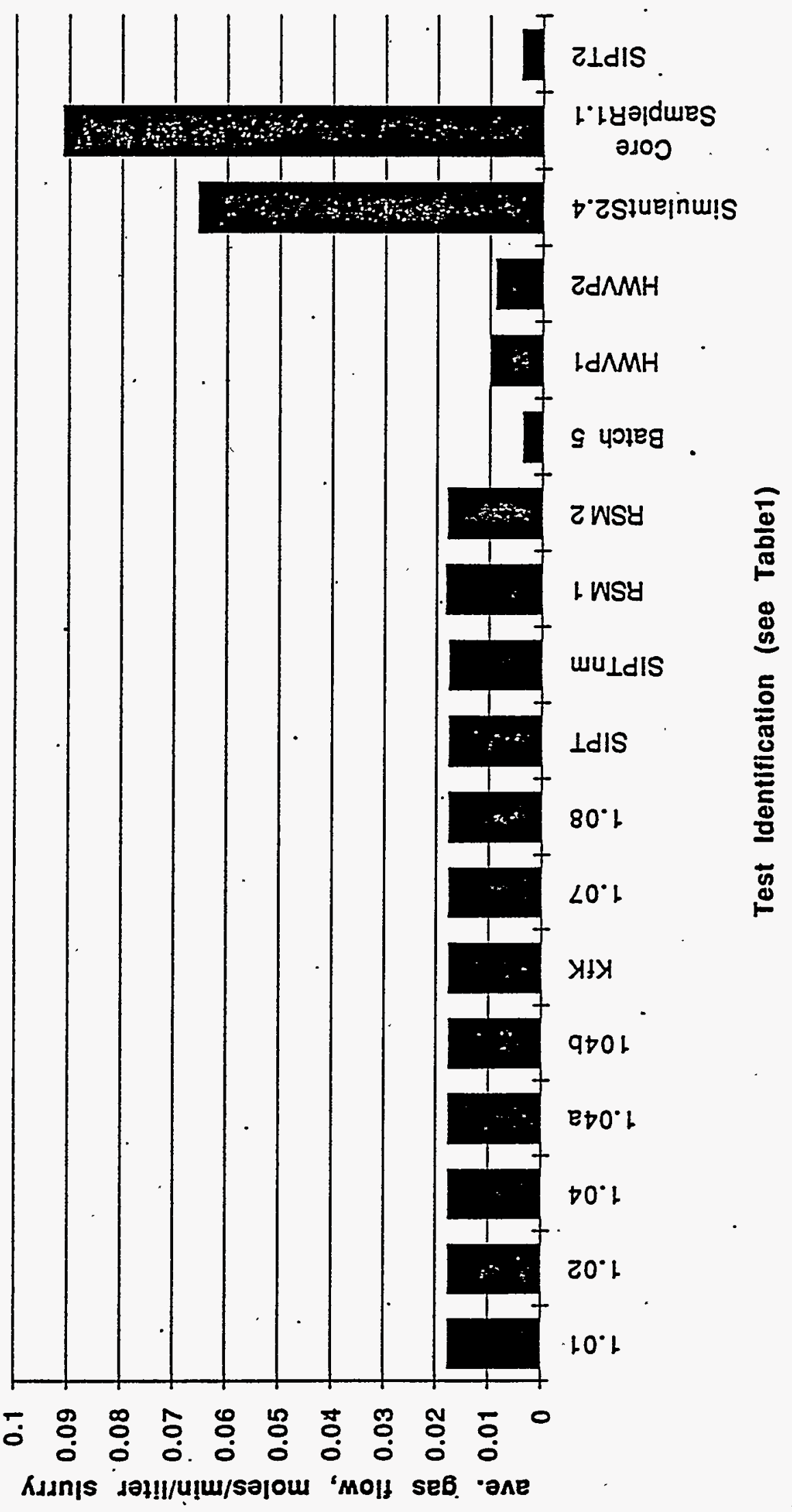


Figure 2. Peak Total Offgas Rate vs. Formic Acid Addition Rate.

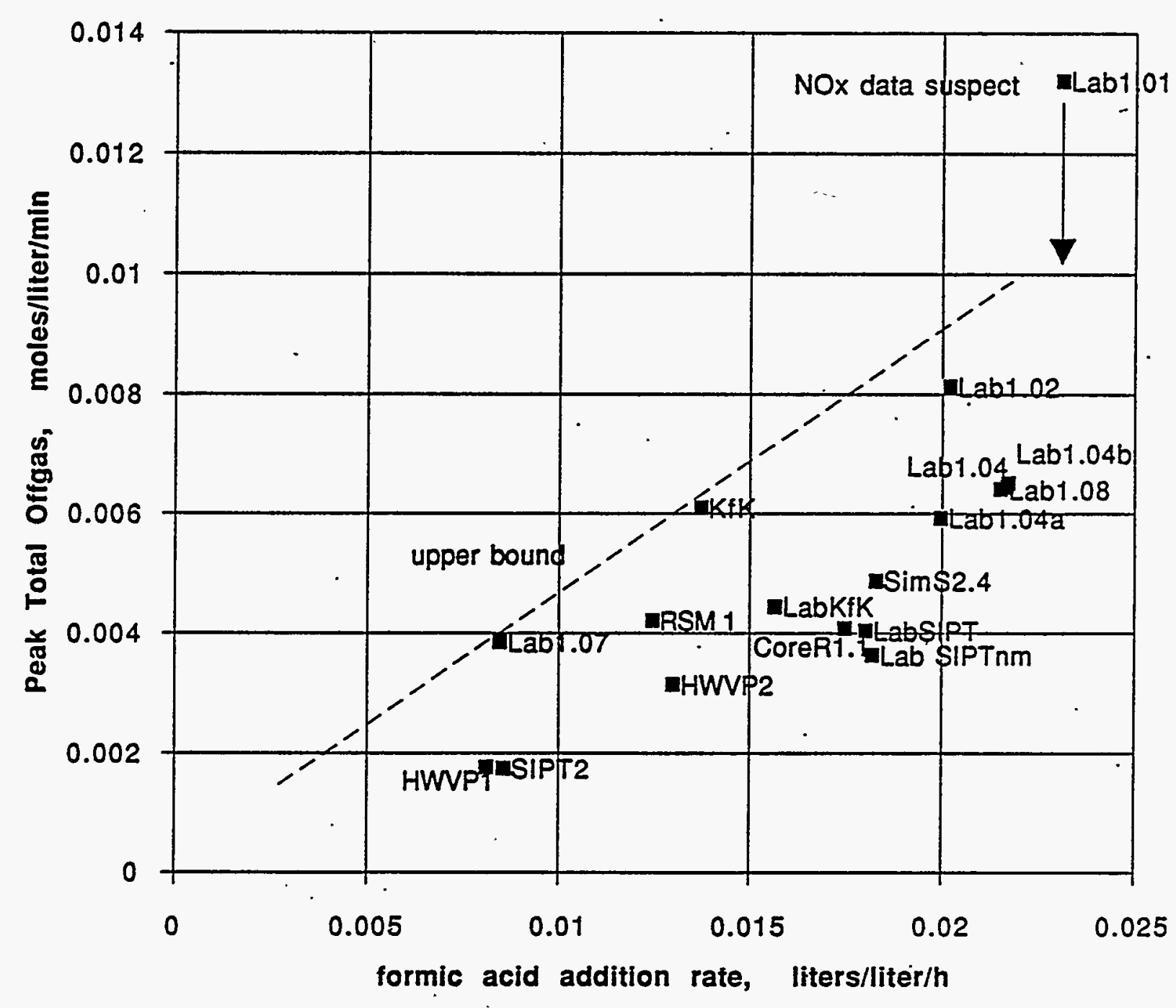


Figure 3. Total Offgas vs. Formic Acid Addition + Initial Carbonate + Initial Nitrite

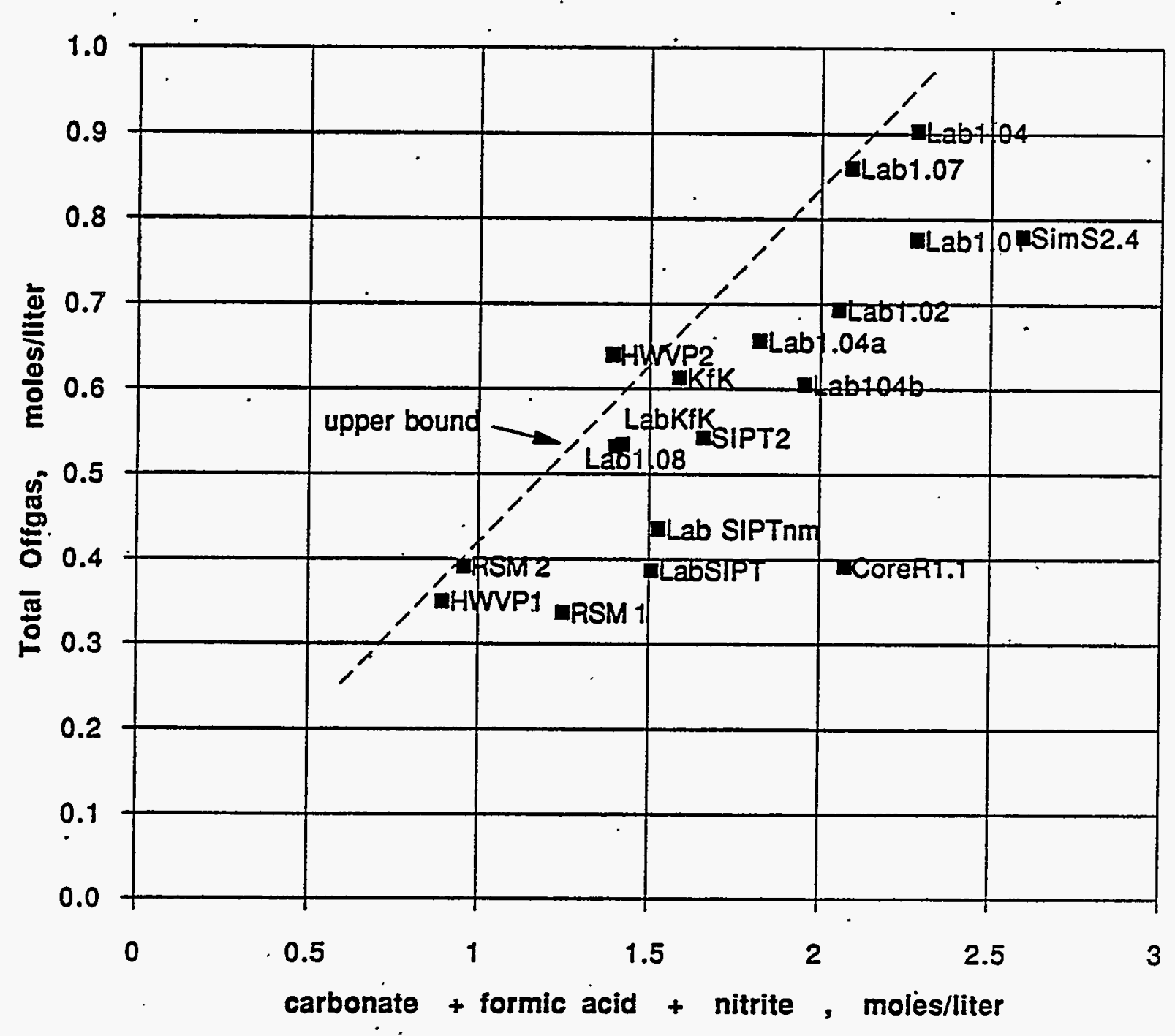




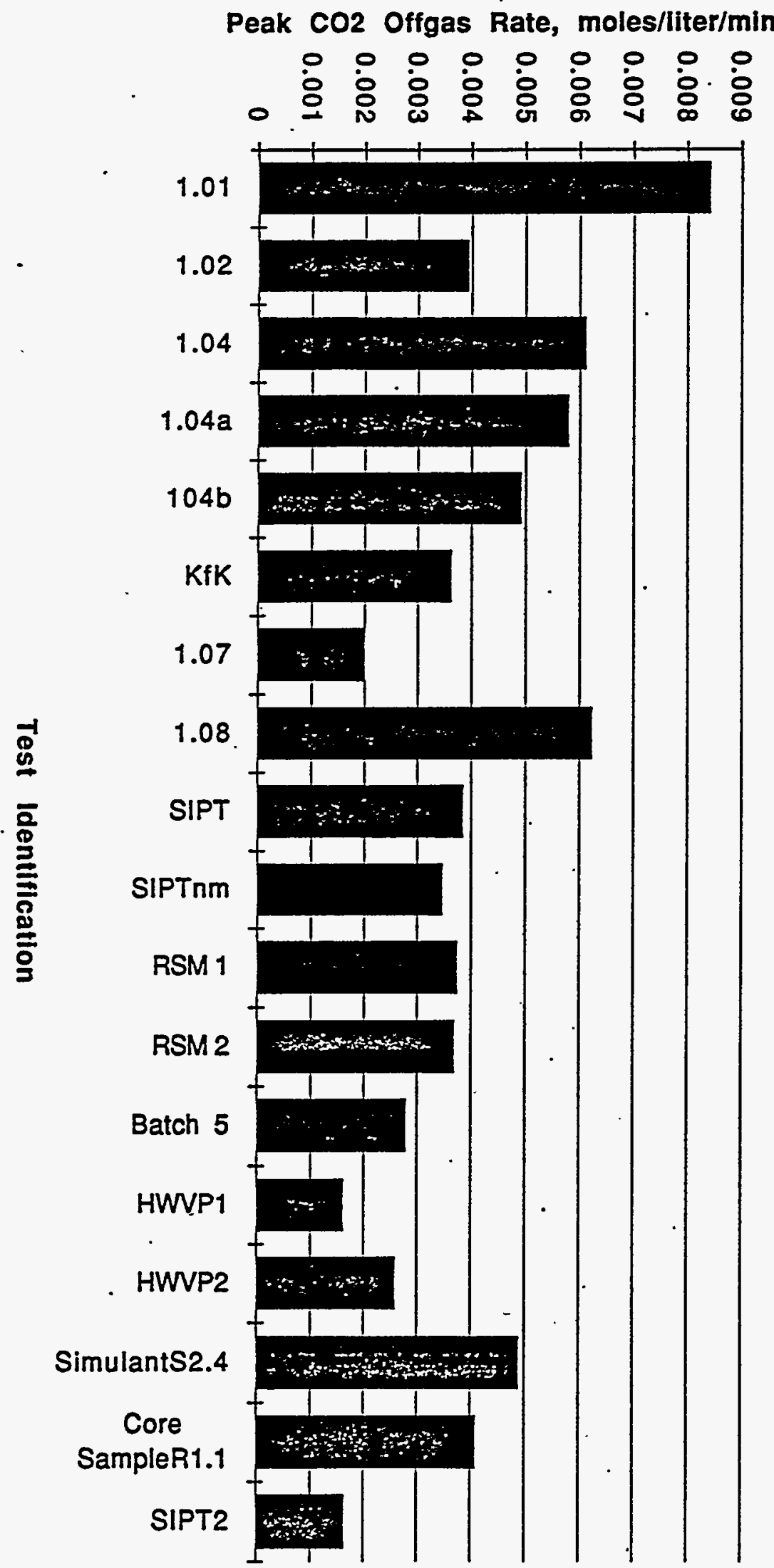

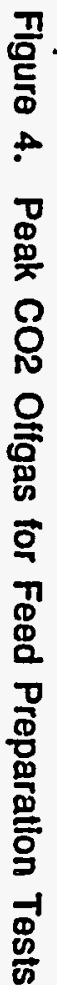


Figure 5. Peak CO2 Olfgas Rate versus Formic Acid Addition Rate

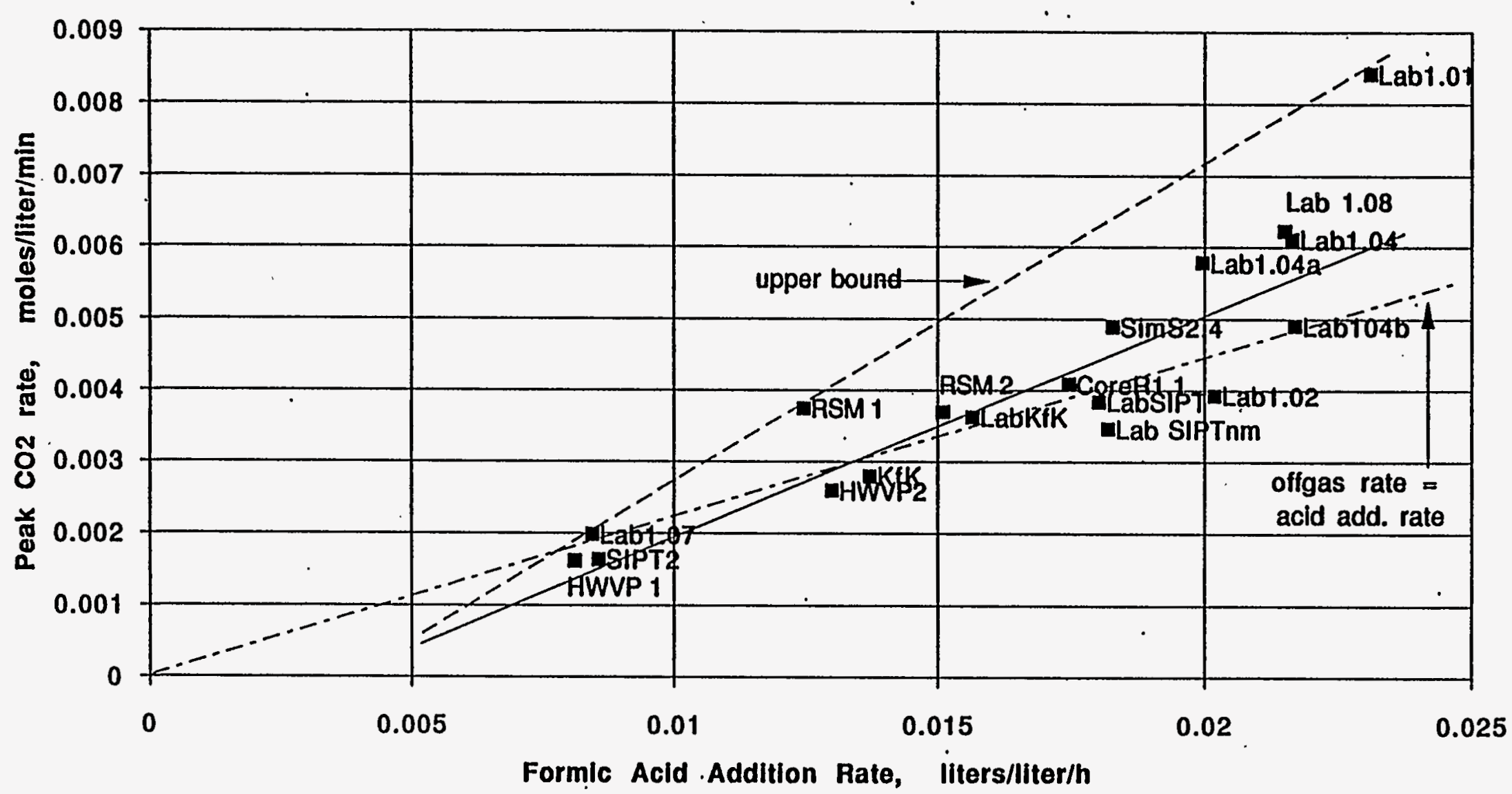




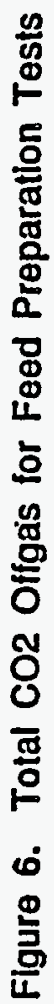

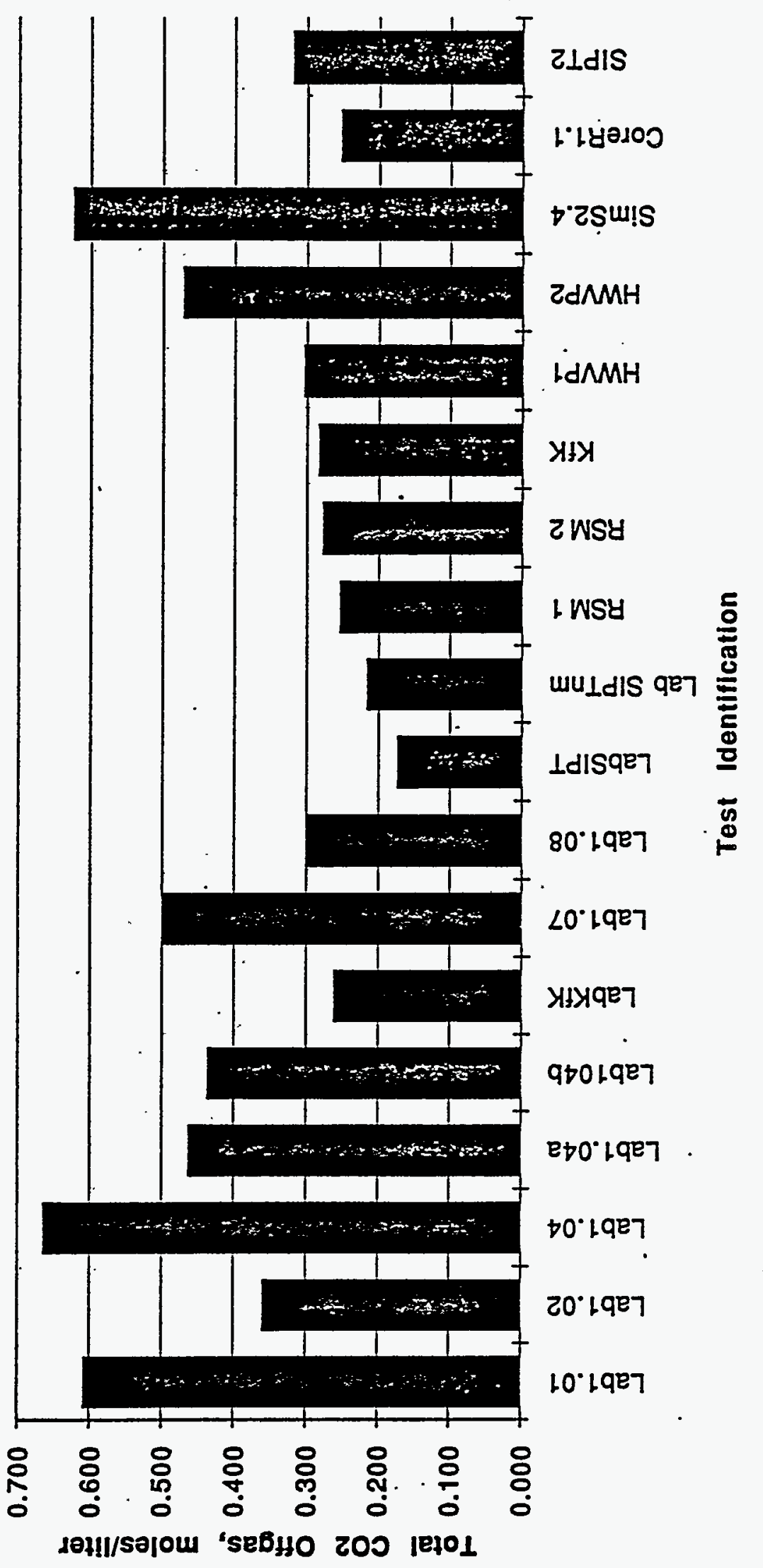


Flgure 7. Total CO2 Offgas minus Initial Carbonate versus $2 \times[\mathrm{N2O}]+0.5 \times[\mathrm{NO}]$.

Number in bracket = total $\mathrm{H} 2$ offgas, moles/iter slurry.

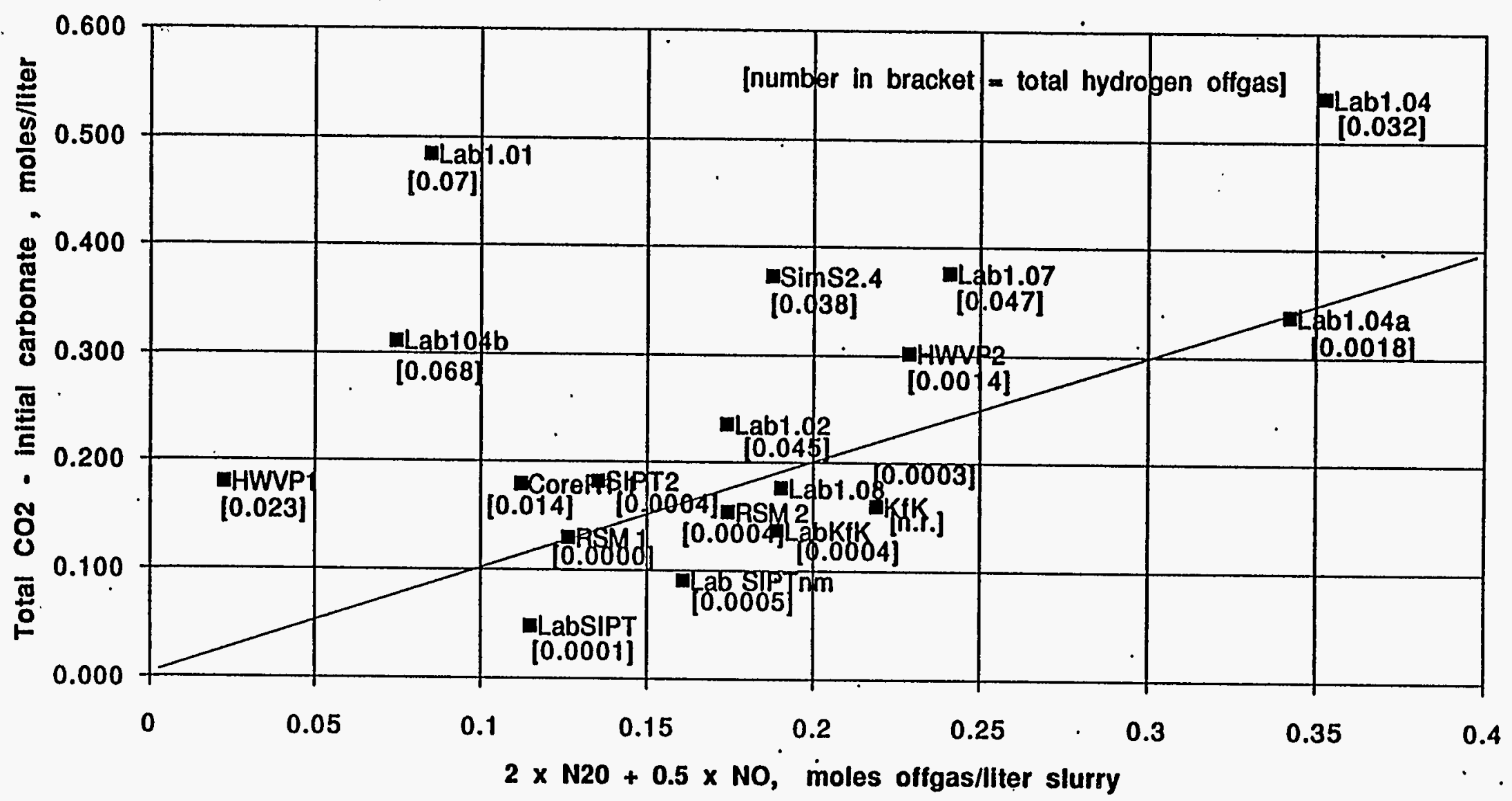




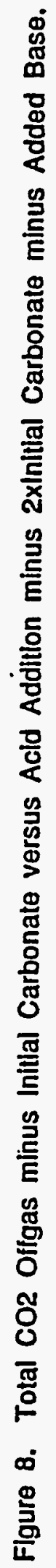

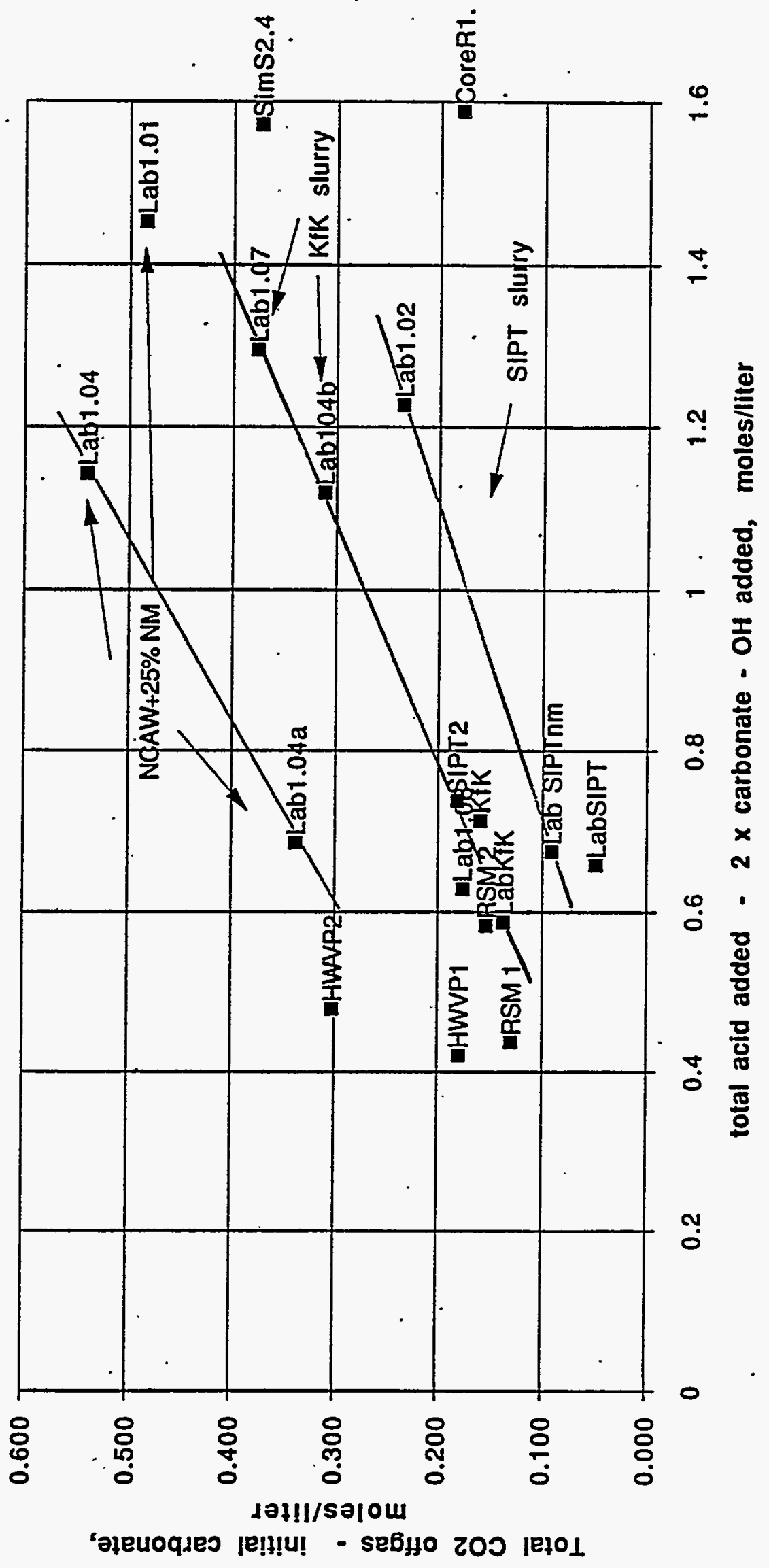



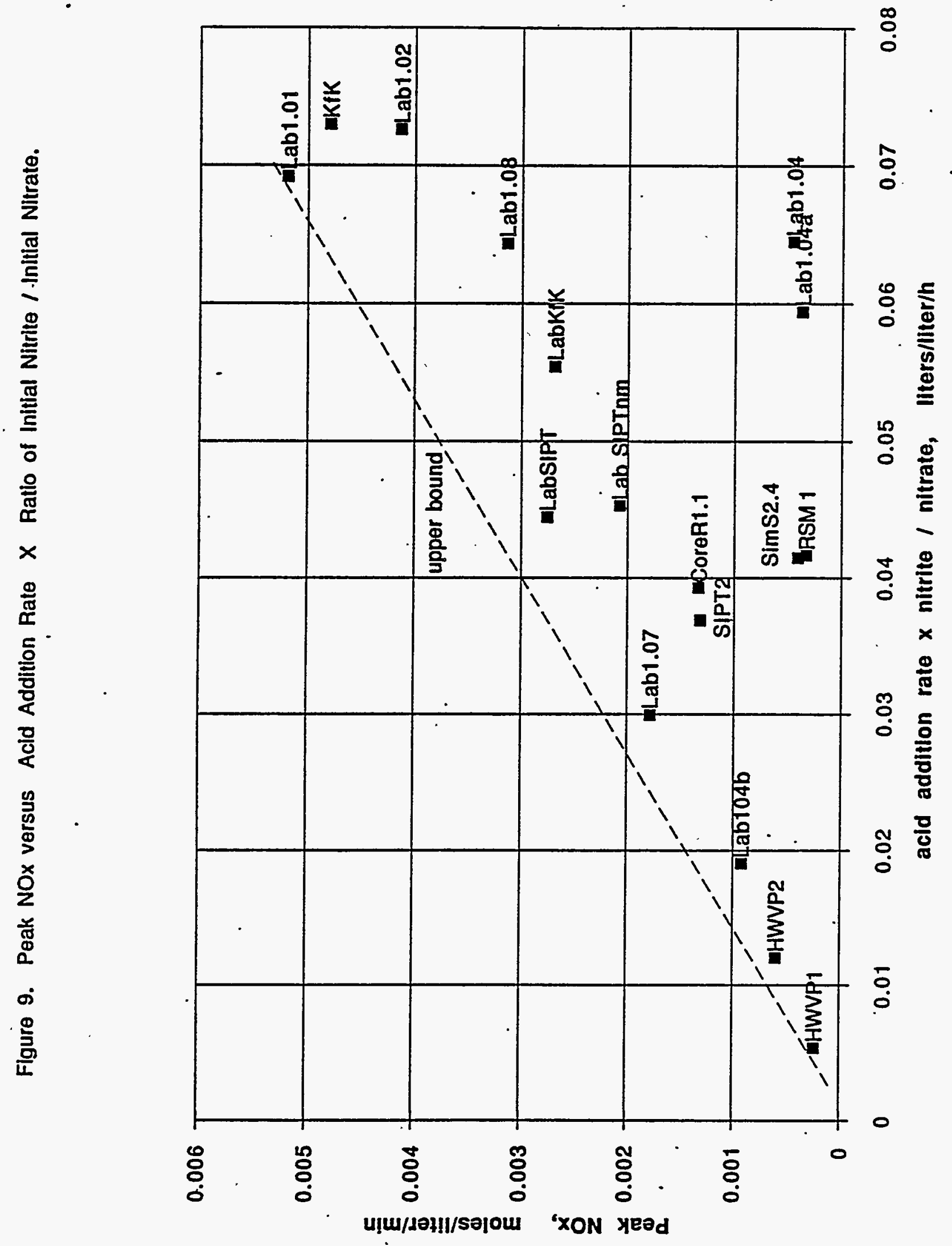


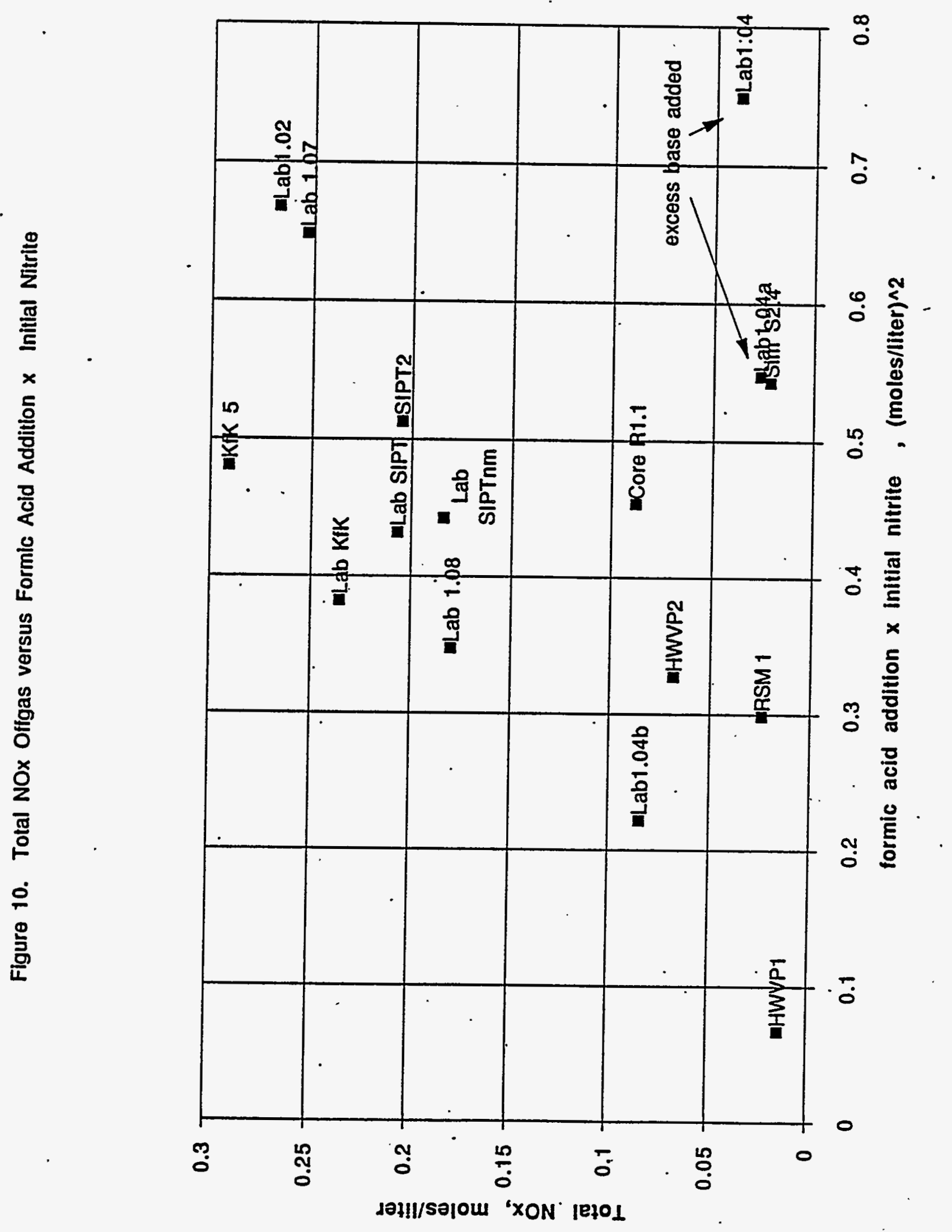


Figure 11. Peak N20 Olfgas Rate versus Formic Acid Addition Rate $\times$ Initlal Nitrite $\times(2 \times$ Initial Carbonate + Added Hydroxide $)$

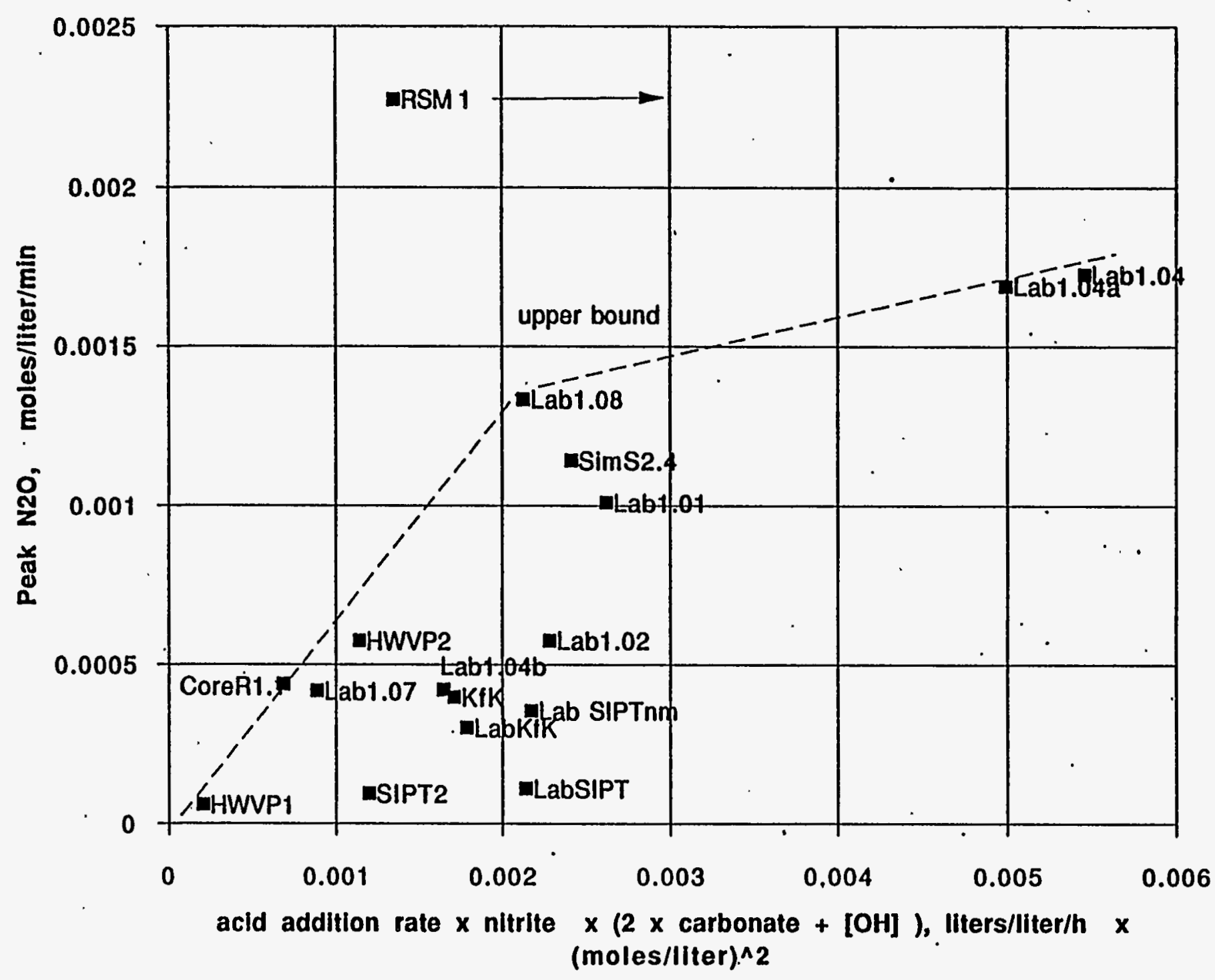


Figure 12. Ratlo of N2O/NOx Correlated with Formic Acid Addition and Initial Carbonate, Added OH, and Initial Nitrite Concentrations

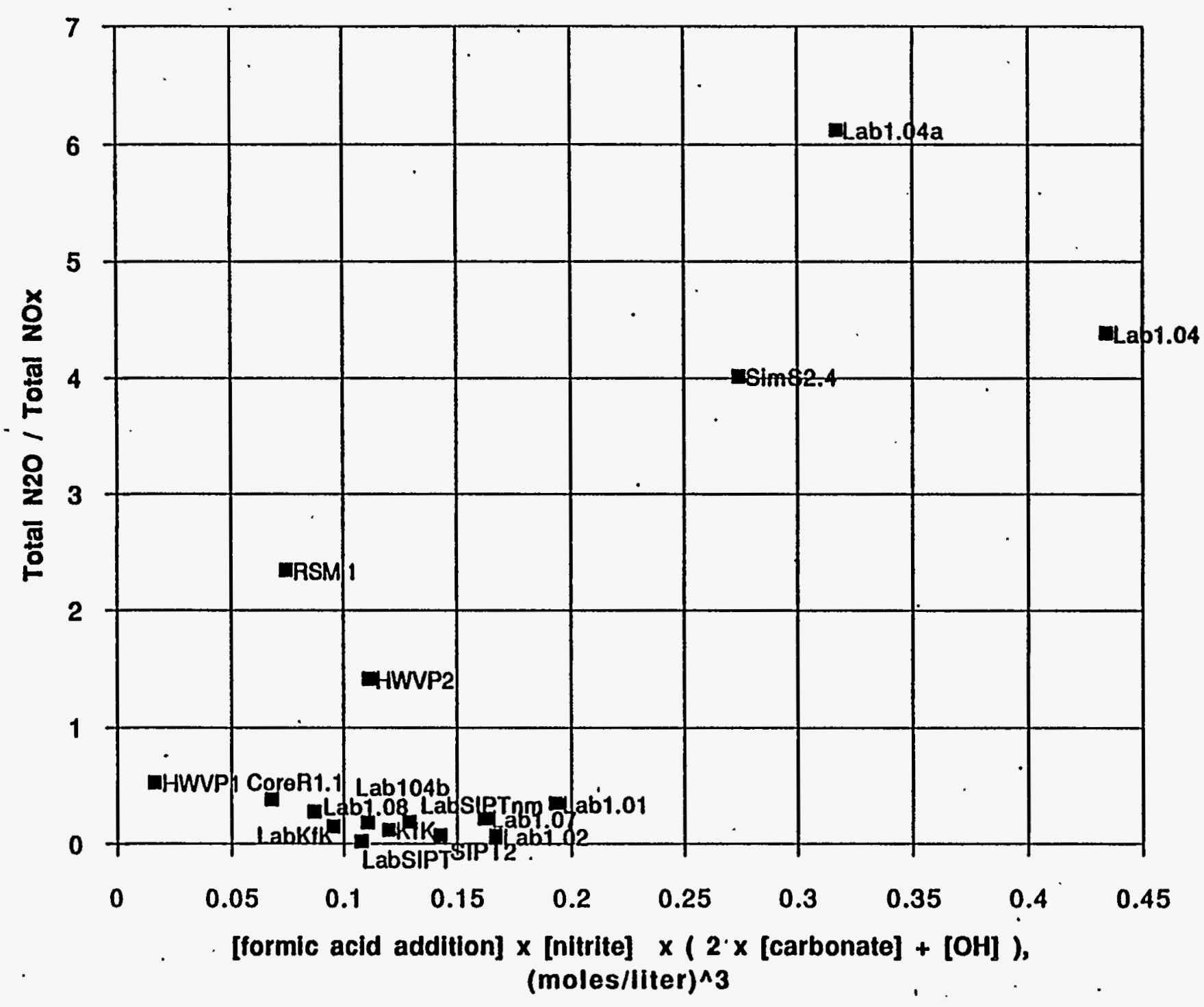


Flgure 13. Total Hydrogen and Ammonia Produced during Acld Addition and Digestion

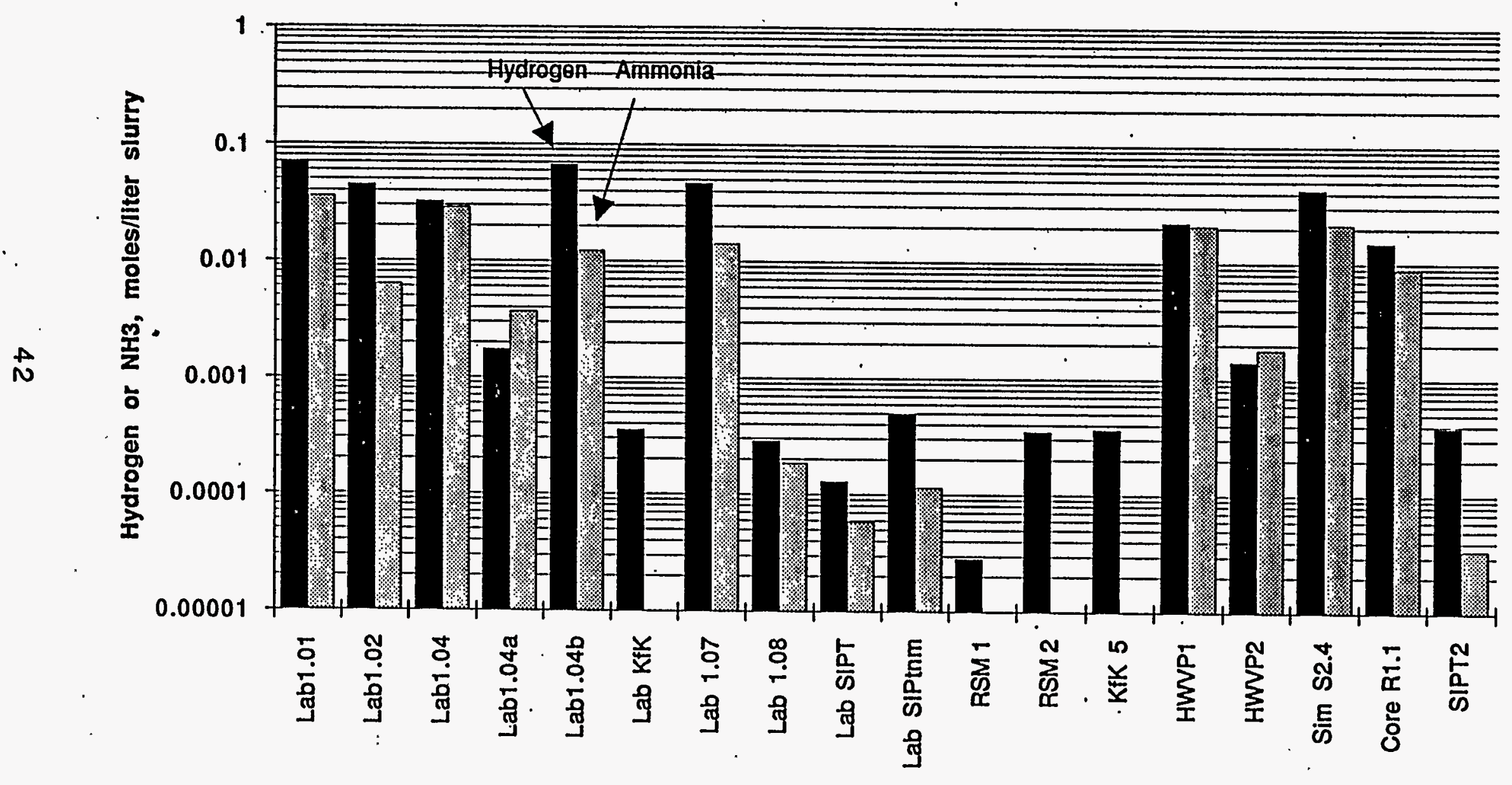




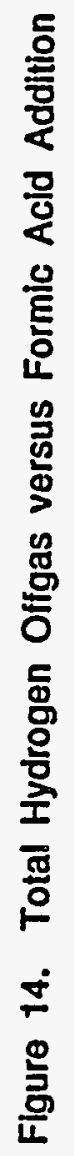

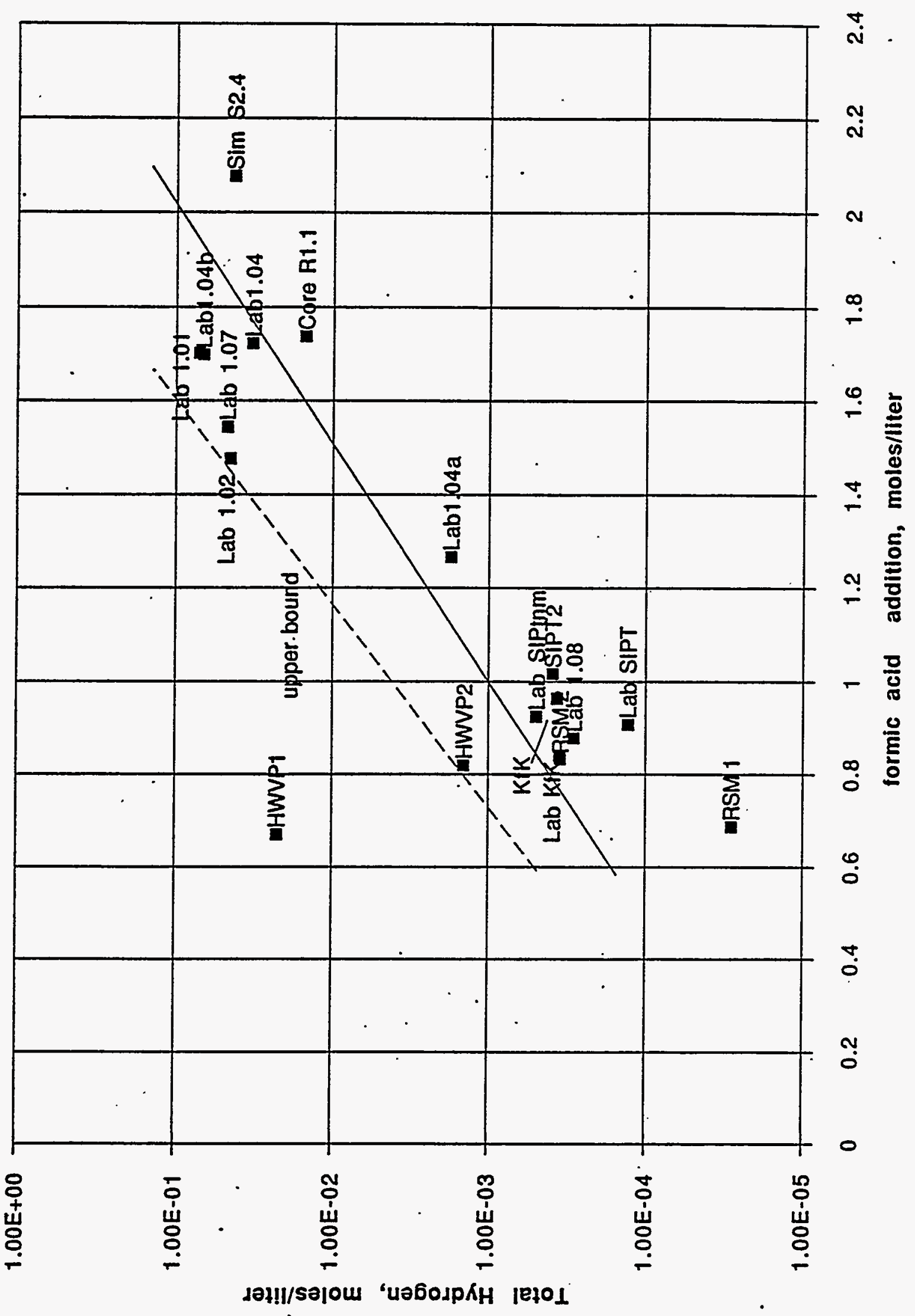


Figure 15. Total Hydrogen Offgas versus Avallable Acid (no added base correction)

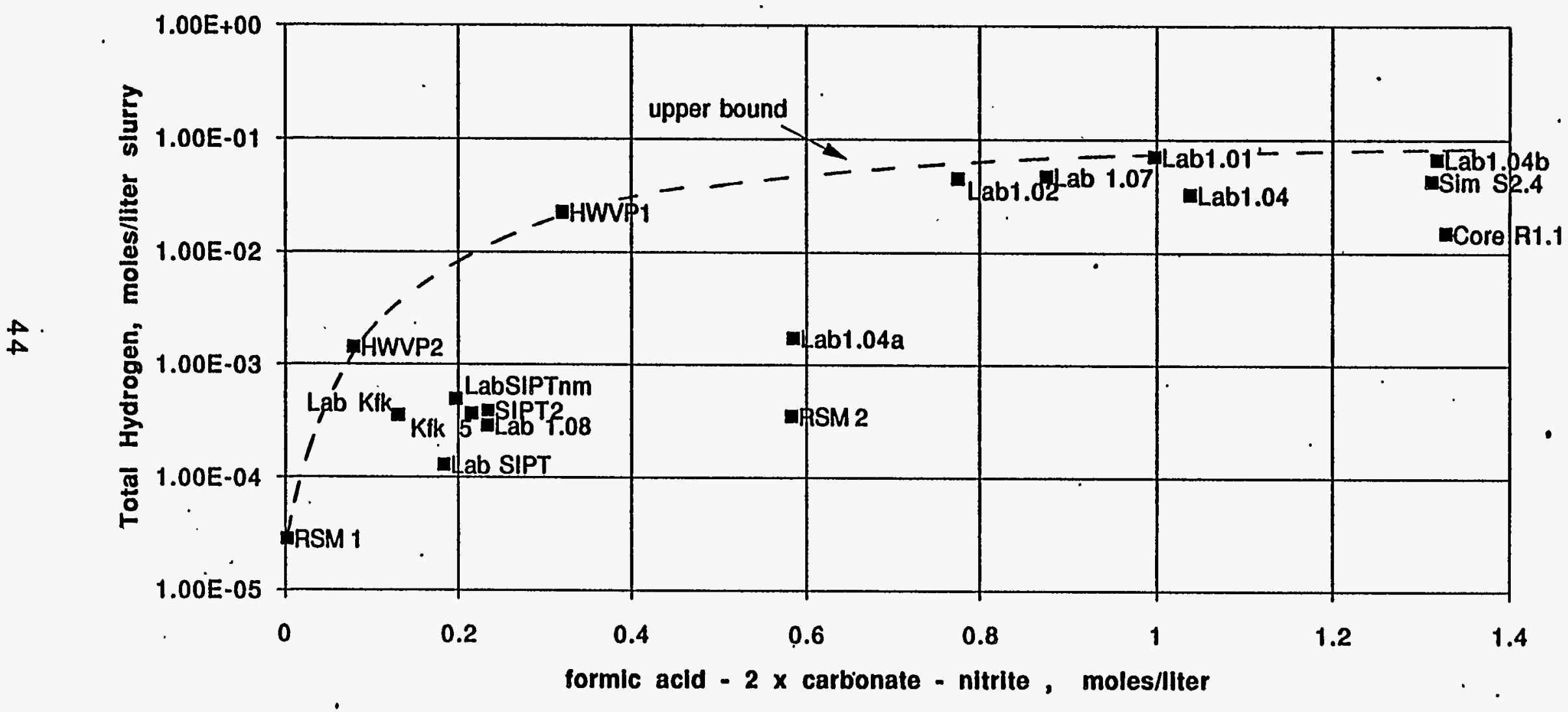


Figure 16. Total Hydrogen Offgas Correlated with Available Formic Acld with Correction for Added Base.

o

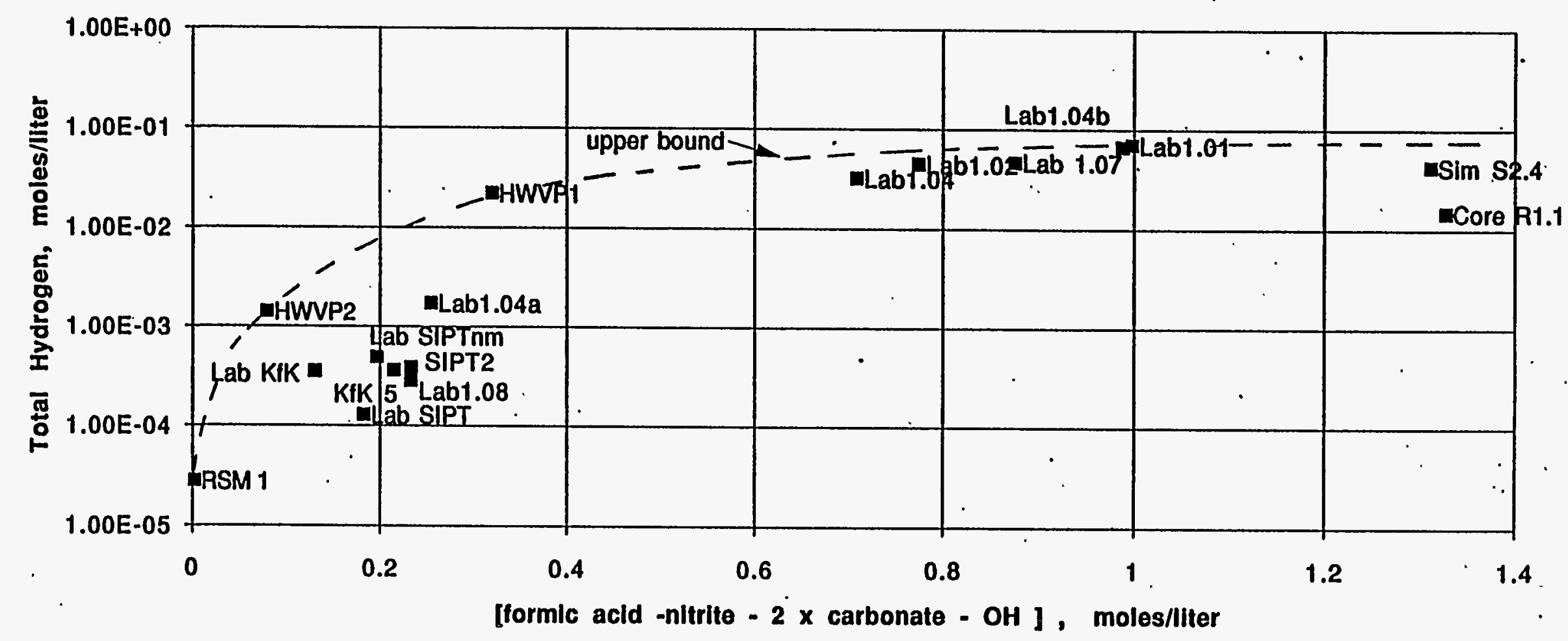


Flgure 17. Total Hydrogen Offgas Correlated with Avallable Formic Acld with Added Base and Noble Metal Correctlons

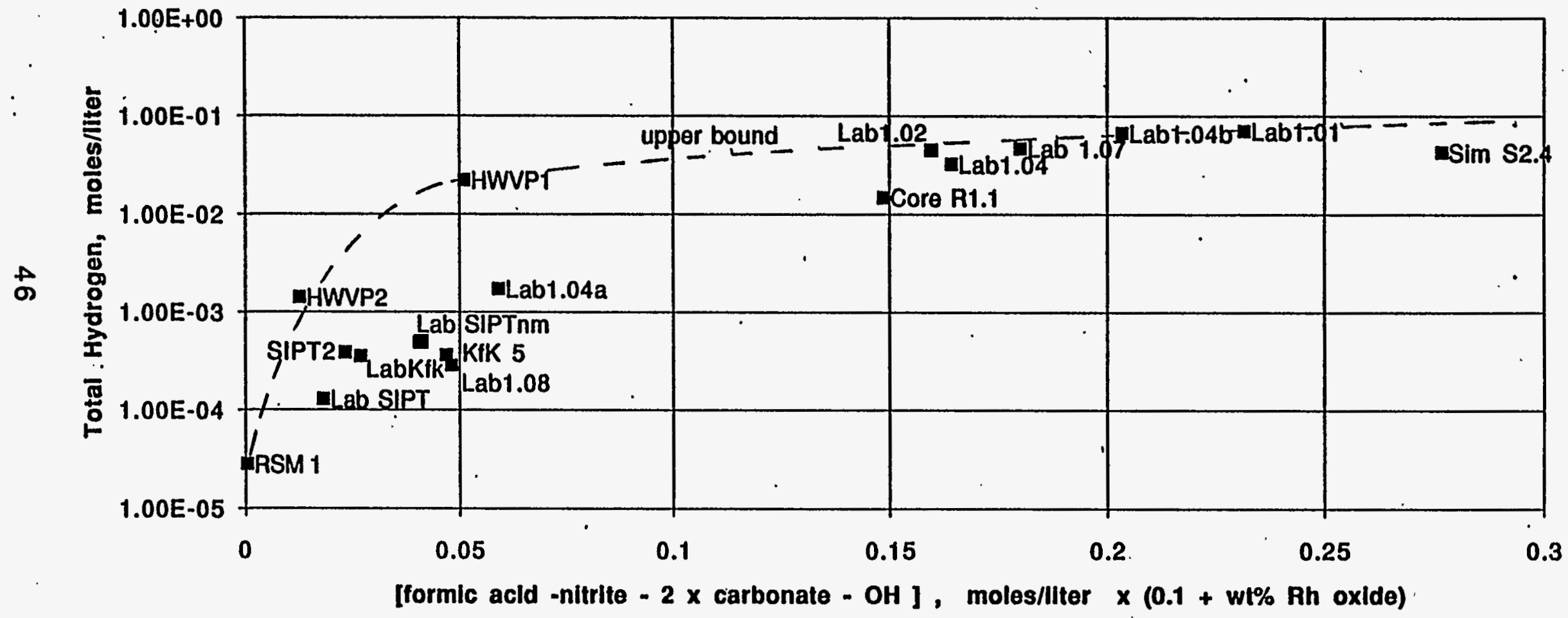


Flgure 18. Correlation of Peak Hydrogen Offgas Rate with Total Hydrogen Offgas

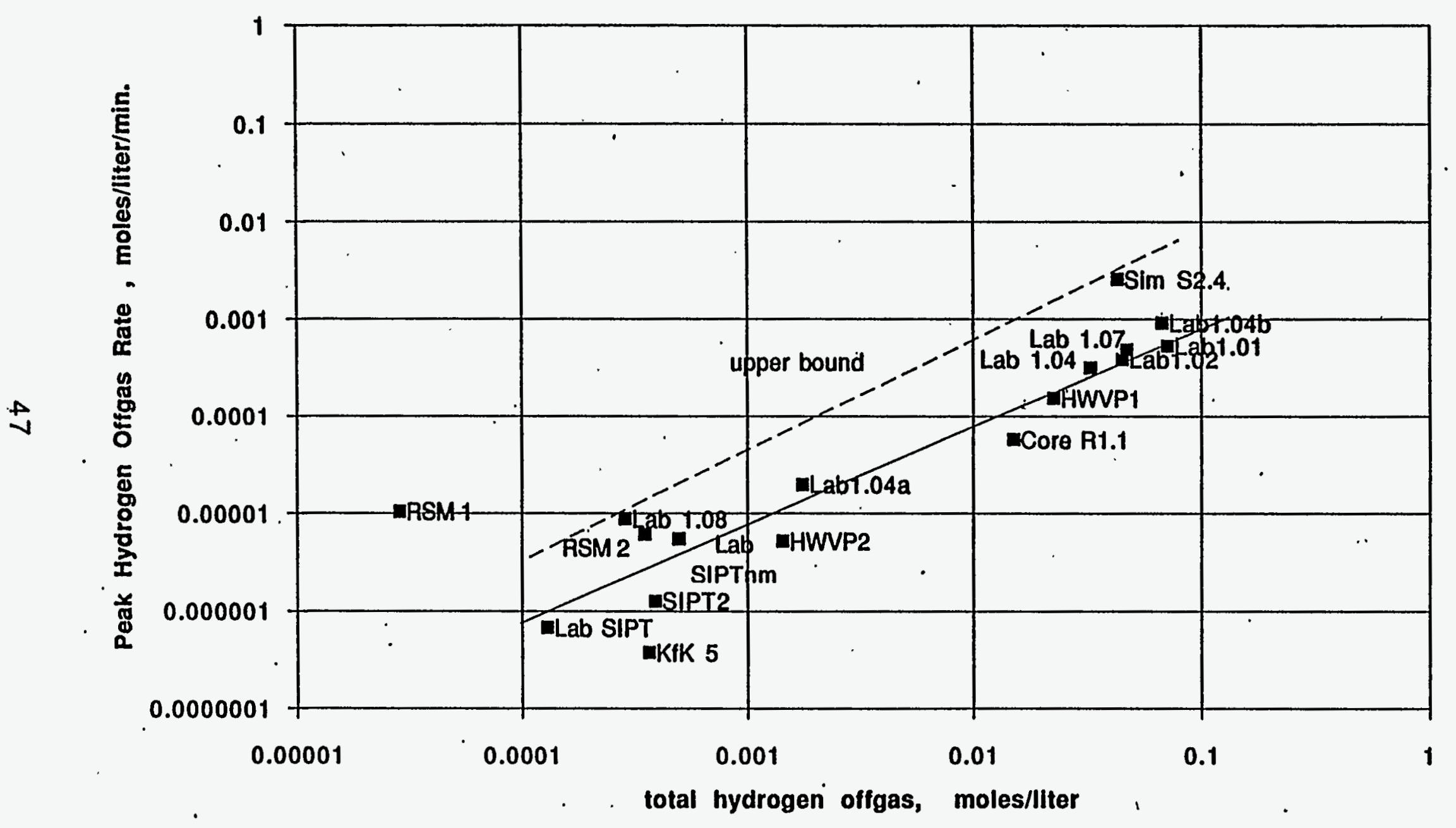


Flgure 19. Total Ammonia Produced during Feed Preparation versus Total Hydrogen Offgas

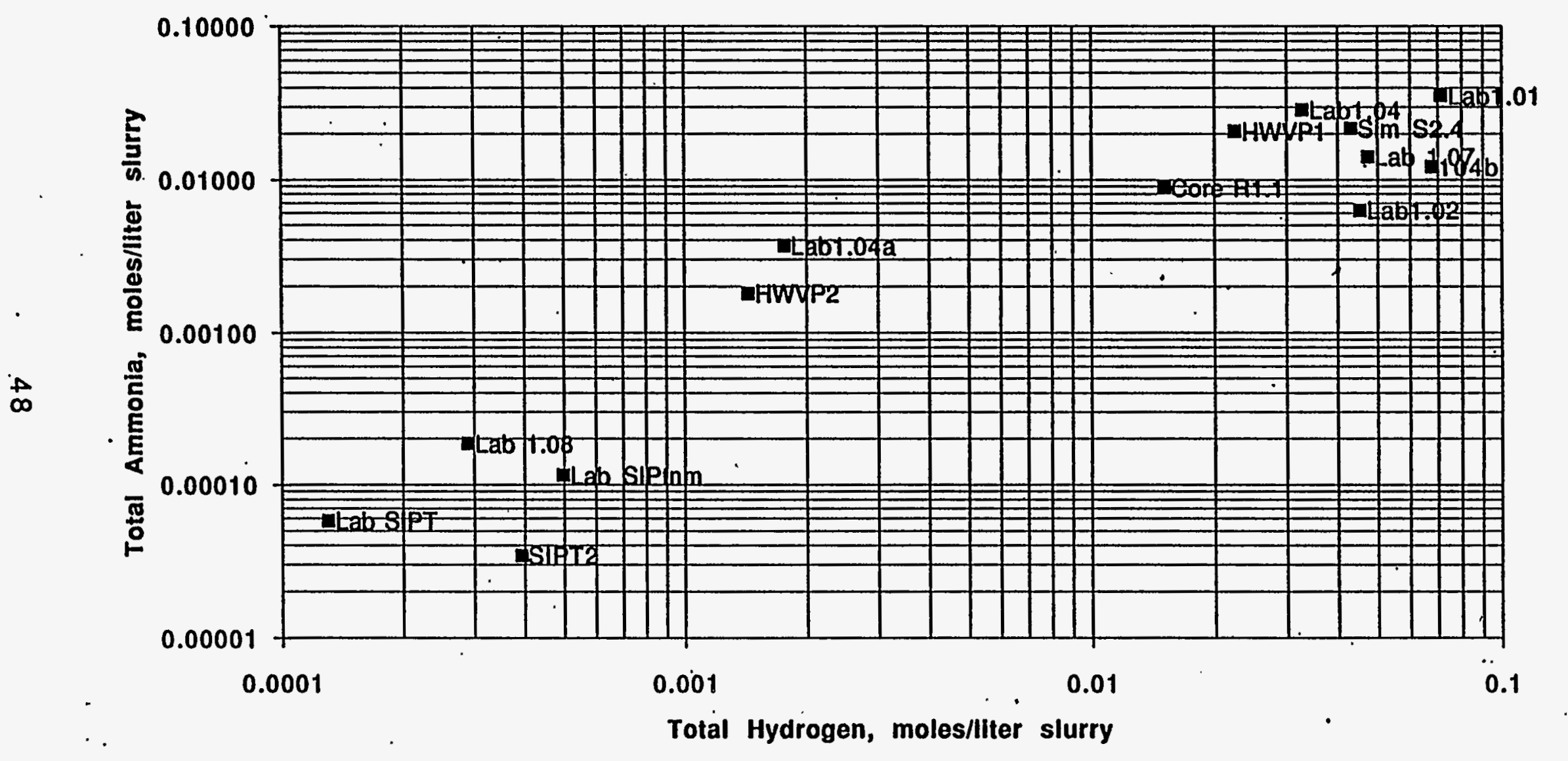


Figure 20. Total Ammonia Measured versus Amount of Formic Acid Added During Feed Preparation

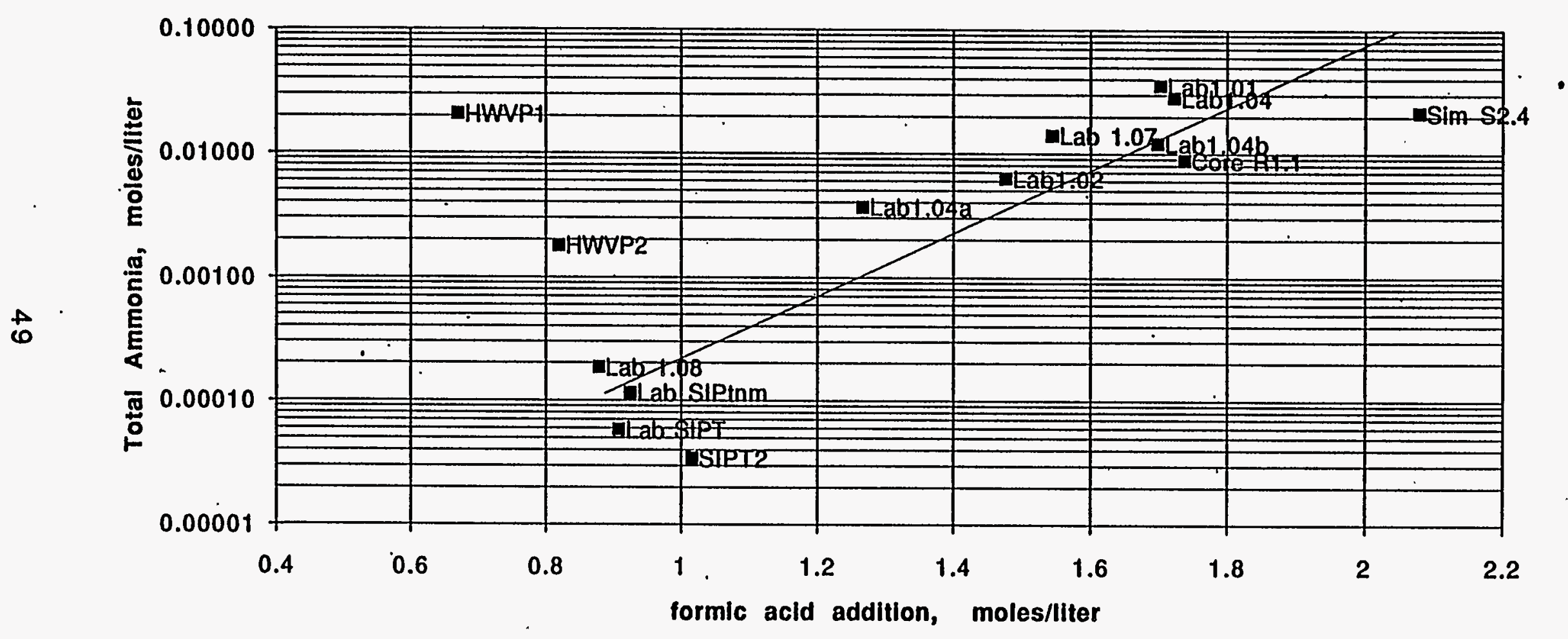


Figure 21. Offgas Profiles 'Showing Offgas Rates vs. Time for Laboratory-Scale Lab Kfk Test
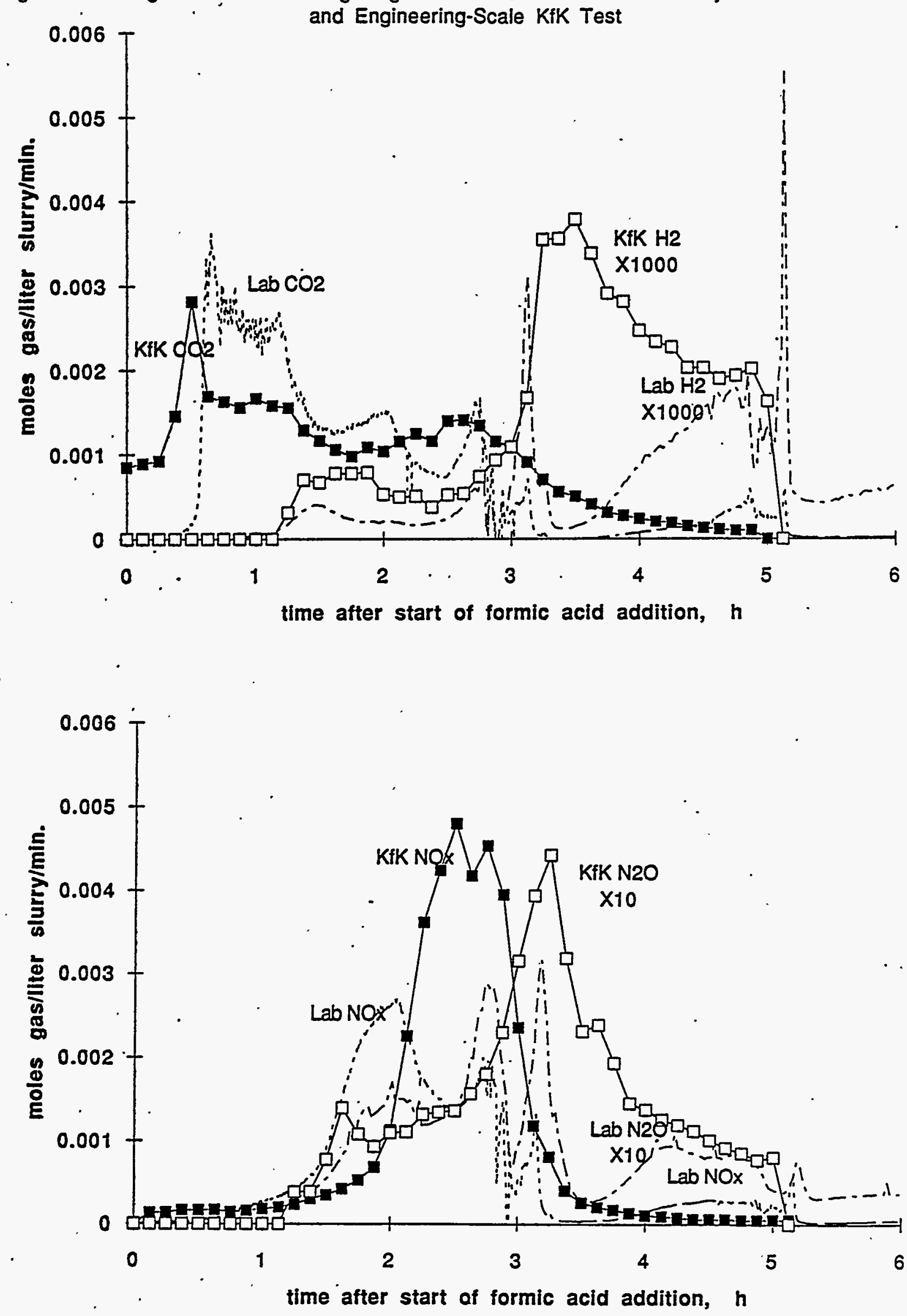


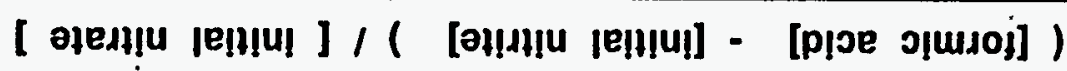

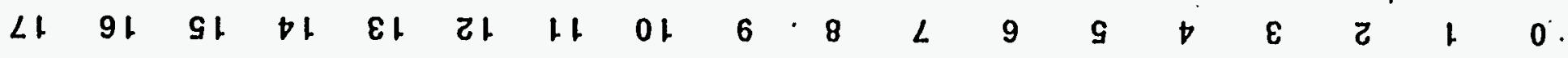

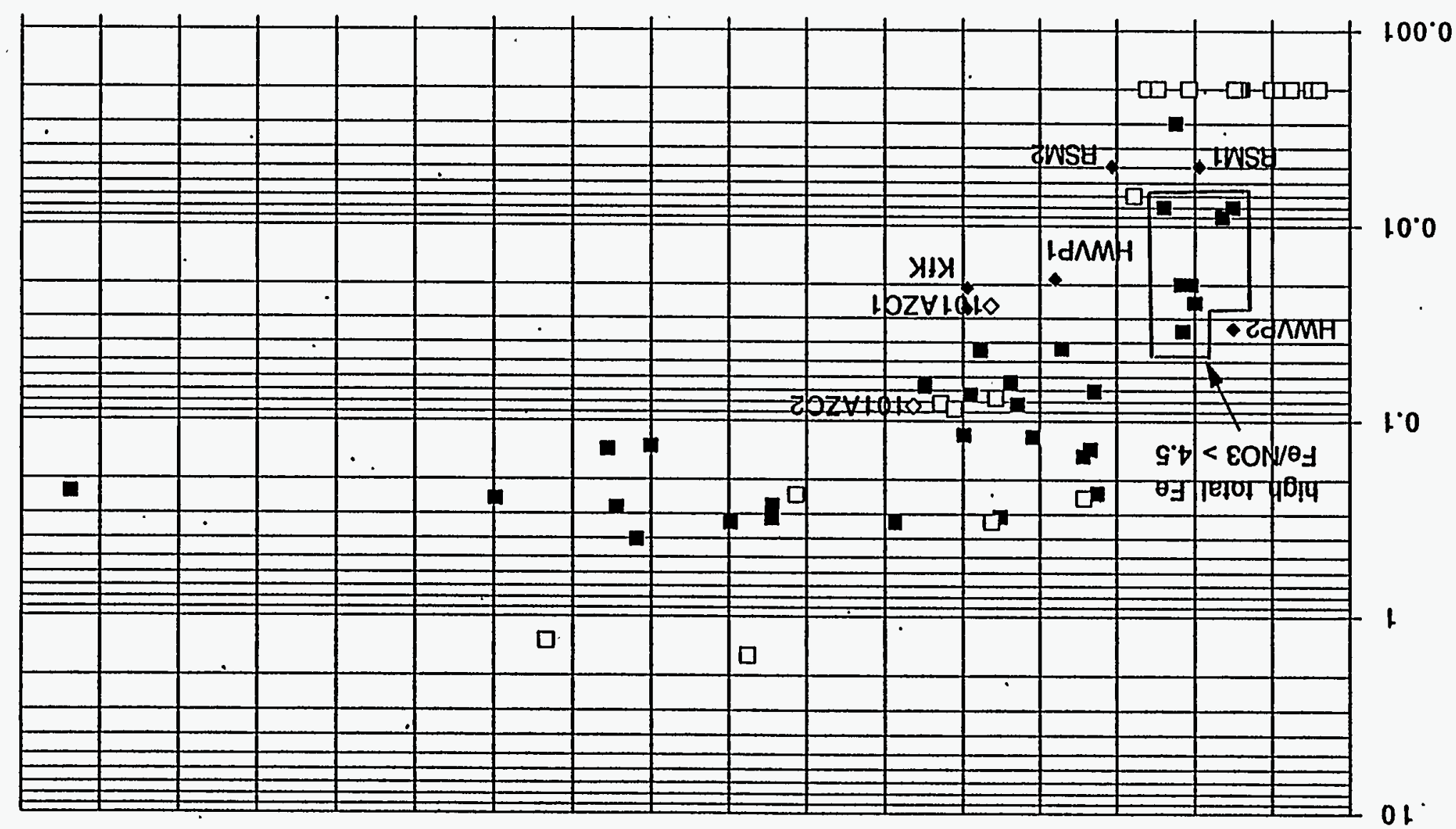

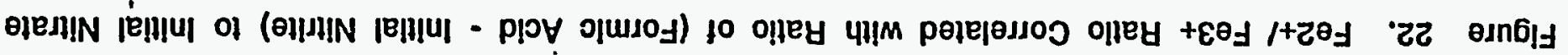


•

.
TABLES

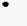

.

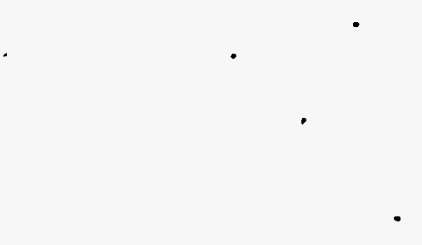


Table 1. System Characteristics for Various Feed Preparation Tests

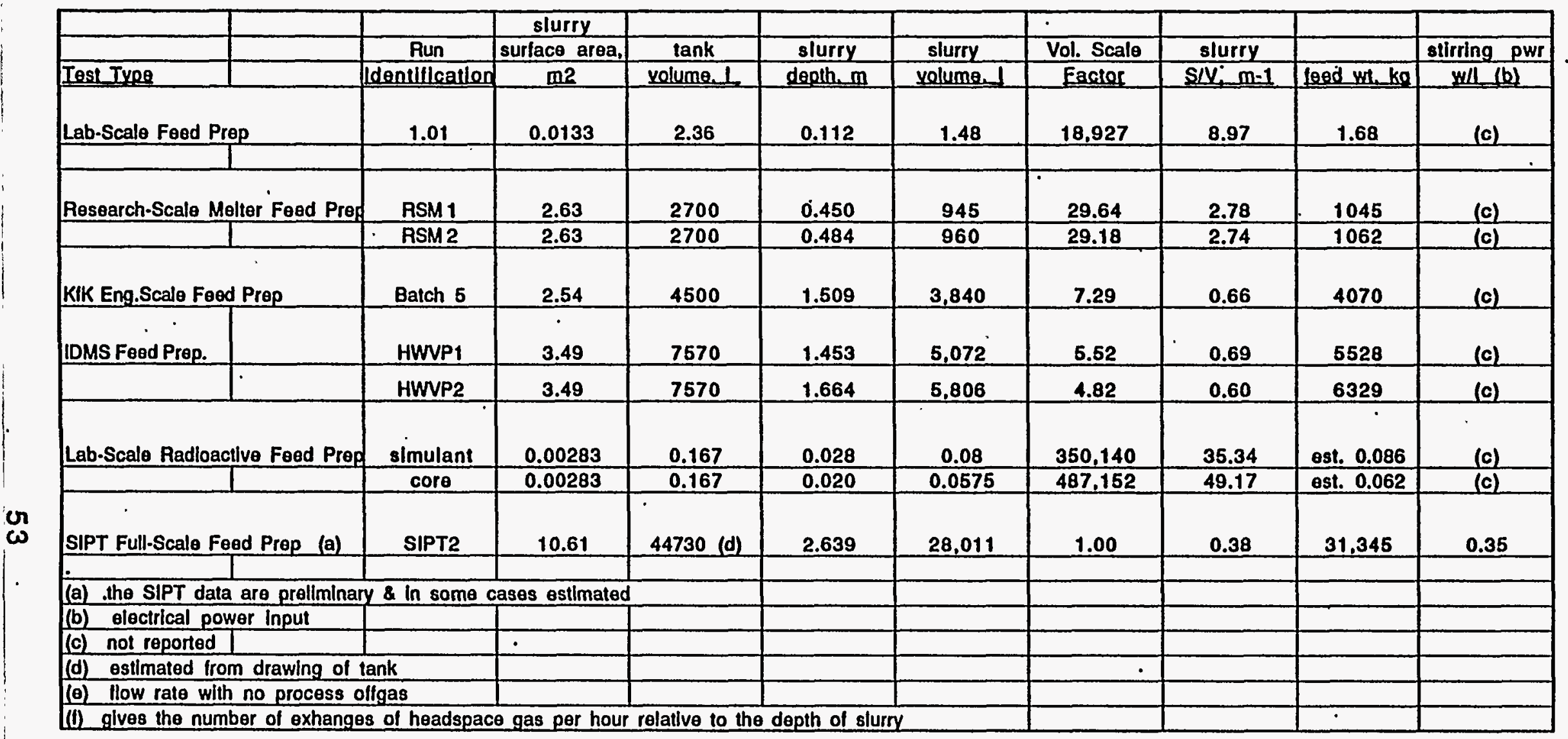


Table 1. System Characterlstics for Various Feed Preparatlon Tests

( cont.)

\begin{tabular}{|c|c|c|c|c|c|c|c|c|c|}
\hline & & purge gas & fllow rato/slurry vol. & How rate/headspace & & turnover per unit & nominal & high & Tow \\
\hline Fun & & flow rate, $(\theta)$ & turnover & Iurnover & volume ratlo & depth of slurry & headspace pressure & pressure & prossure \\
\hline Ientification & purgegoas & $\mathrm{m} 3 / \mathrm{hr}$ (STP) & rate, $1 / \mathrm{h}$ & rate, $1 / \mathrm{h}$ & sluru/hdspace & $1 / \mathrm{h}: m-1$ (i) & atm (in, water) & atm (ln water) & alm (in. water) \\
\hline 1.01 & Ar & 0.036 & 24.00 & 40.91 & 1.70 & 366.90 & $1.01(+5)$ & $1.02(+10)$ & $1.01(+5)$ \\
\hline & & & & & & & & & \\
\hline RSM 1 & alr & 23.8 & 25.19 & 13.56 & 0.54 & 37.70 & $<1$ & (c) & (c) \\
\hline RSM2 & alr & 23.8 & 24.79 & 13.68 & 0.55 & 37.43 & & $\dot{-}$ & - \\
\hline Batch 5 & alr & 20 & 5.21 & 30.30 & 5.82 & 20.08 & $0.99(-5.9) / 0.97(-12)$ & $0.99(-5.9)$ & $0.96(-17.3)$ \\
\hline HWVP1 & air & 69 & 13.56 & 27.53 & 2.03 & 18.94 & $0.99(-3)$ & $0.99(-3)$ & $0.95(-20)$ \\
\hline HWVP2 & alr & 71 & 12.17 & 40.06 & 3.29 & 24.08 & $0.98(-2)$ & $0.98(-2)$ & $0.95(-20)$ \\
\hline simulant & Ar/ $10.3 \% \mathrm{He}$ & 0.0072 & 90.00 & 82.76 & 0.92 & 2924 & $1.02(+9)$ & $1.04(+15)$ & $1.01(+5)$ \\
\hline core & Ar $10.3 \% \mathrm{HO}_{\mathrm{O}}$ & 0.0072 & 125.22 & 65.75 & 0.53 & 3233 & $1.01(+4)$ & $1.01(+4)$ & $1.01(+4)$ \\
\hline SIPT & alr & 161.31 & 6.76 & 9.65 & 1.68 & 3.66 & $0.98 \quad(-10)$ & $0.99(-5)$ & $0.98(-10)$ \\
\hline$\theta$ & & & & . & & & & & \\
\hline & & & & & & & & & \\
\hline & & & & & & & & & $\div$ \\
\hline & & & & & & & & & \\
\hline & & & & & & & & & \\
\hline & & & & & & & & & \\
\hline
\end{tabular}


Table 2. Summary of Formating/Digestlon/Recycle and Filt Addition Conditlons

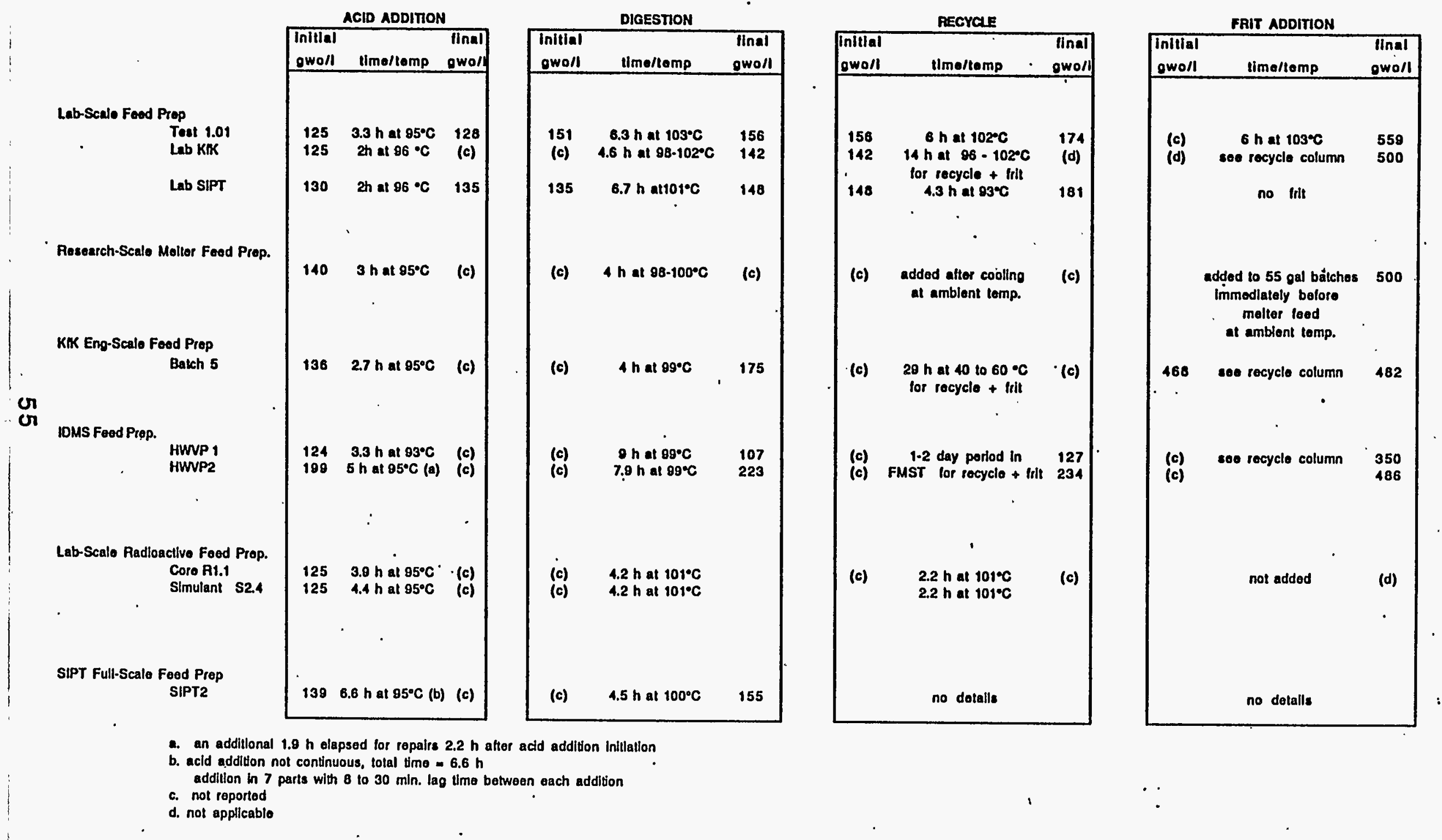




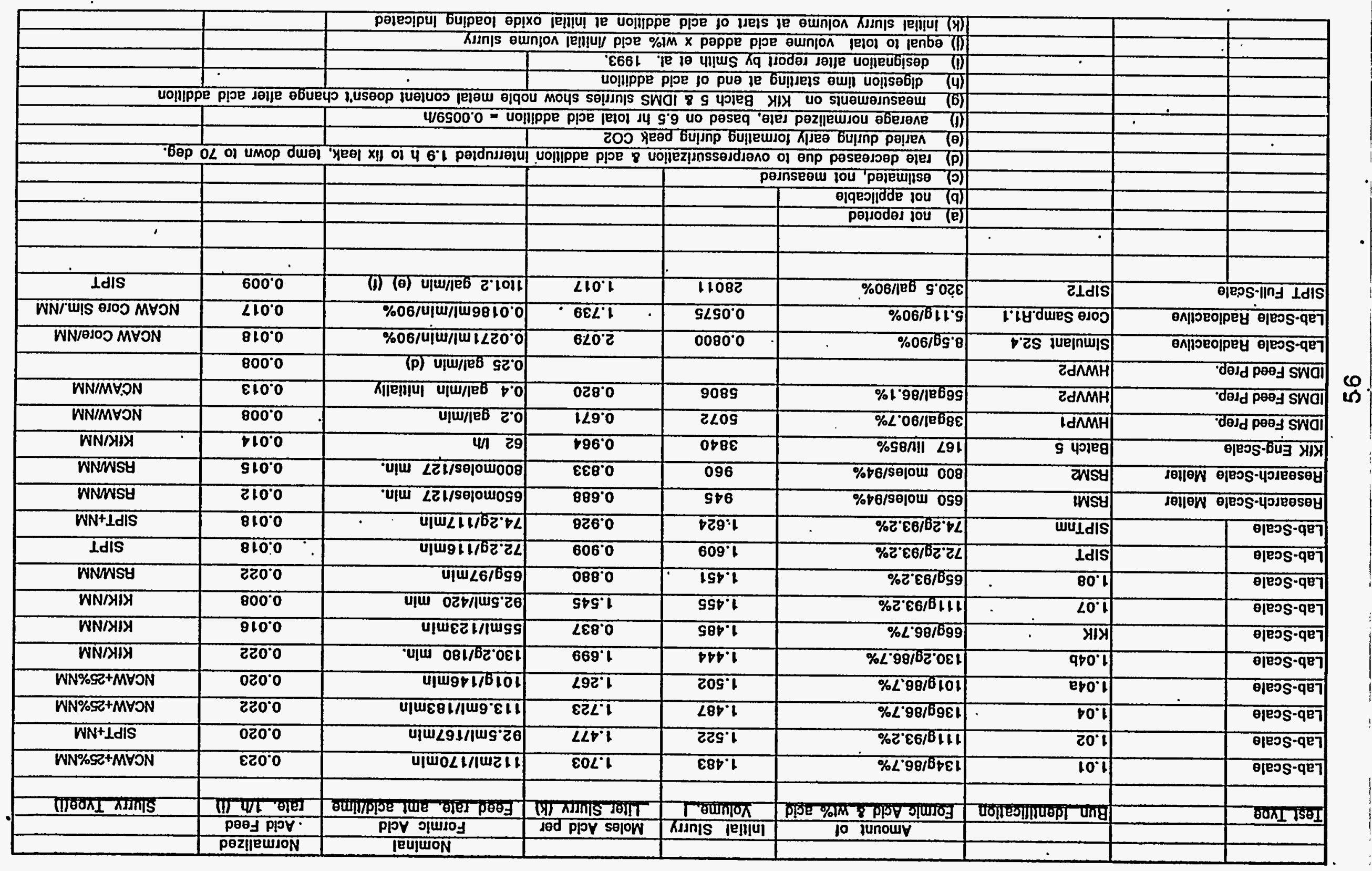

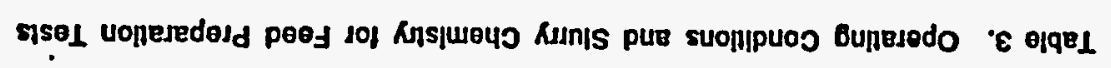


Table 3. Operating Conditlons and Slurry Chemistry for Feed Preparation Tests (cont.)

\begin{tabular}{|c|c|c|c|c|c|c|c|c|c|c|}
\hline & \multicolumn{3}{|c|}{ Foed composition (bolore formating) } & \multirow[b]{2}{*}{ Ph } & \multirow[b]{2}{*}{$\mathbf{R u}$} & \multirow[b]{2}{*}{ Pd } & \multirow[b]{2}{*}{ oxide loading } & \multirow[b]{2}{*}{ InItial } & \multirow[b]{2}{*}{ Moasure } & \multirow[b]{3}{*}{ BIOH } \\
\hline & $\mathrm{NO3}$ & $\mathrm{NO} 2$ & $\infty$ & & & & & & & \\
\hline Bun Identillication & molar & molar & molar & W1\% $\mathrm{Bh} 203$ & wt\% Bu?O3 & $w \% P d O$ & $\pi /$ & $\mathrm{OH}$ & Temp. ${ }^{\circ} \mathrm{C}$ & \\
\hline 1.01 & 0.152 & 0.454 & 0.125 & 0.132 & 0.481 & 0.141 & 125 & 8.9 & 95 & (a) \\
\hline 1.02 & 0.126 & 0.452 & $0.125(c)$ & 0.106 & 0.387 & 0.123 & 133 & 9.8 & 95 & 11.74 \\
\hline 1.04 & 0.146 & 0.435 & 0.125 (c) & 0.132 & 0.481 & 0.141 & 134 & 10 & 95 & (a) \\
\hline $1.04 a$ & 0.146 & 0.431 & 0.125 (c) & 0.132 & 0.481 & 0.141 & 133 & 9.2 & 95 & (a) \\
\hline $1.04 \mathrm{~b}$ & 0.149 & 0.131 & $0.125(c)$ & 0.106 & 0.387 & 0.123 & 124 & 10.8 & 95 & (a) \\
\hline KIK & 0.129 & 0.457 & 0.125 (c) & 0.106 & 0.387 & 0.123 & 125 & 9.4 & 95 & (a) \\
\hline 1.07 & 0.119 & 0.420 & $0.125(c)$ & 0.106 & 0.387 & 0.123 & 125 & 9.4 & 95 & (a) \\
\hline 1.08 & 0.132 & 0.396 & $0.125(c)$ & 0.106 & 0.387 & 0.123 & 127 & 9.7 & 85 & (a) \\
\hline SIPT & 0.103 & 0.475 & 0.125 (c) & 0.000 & 0.000 & 0.000 & 130 & 10 & 95 & 11.7 \\
\hline SIPTnm & 0.102 & 0.478 & 0.125 (c) & 0.106 & 0.387 & 0.123 & 130 & . 9.1 & 96 & 11.7 \\
\hline RSMI & 0.130 & 0.435 (c) & 0.125 (c) & 0.106 & 0.769 & 0.118 & 140 & (a) & (b) & (a) \\
\hline RSMR & (a) & (a) & 0.125 (c) & 0.106 & 0.385 & 0.118 & 140 & 10.8 & 86 & (a) \\
\hline Balch 5 & 0.094 & 0.499 & (a) & 0.118 & 0.355 & 0.135 & 136 & (a) & (b) & 11.4 \\
\hline HWVP1 & 0.160 & 0.100 & 0.125 & 0.060 & 0.410 & 0.060 & 94 & (a) & (b) & 11.7 \\
\hline HWUP2 & 0.280 & 0.400 & 0.17 & 0.060 & 0.420 & 0.070 & 189 & (a) & (b) & 10.5 \\
\hline \multicolumn{11}{|l|}{ HWVP2 } \\
\hline Simulant S2.4 & 0.115 & 0.261 & 0.253 & 0.111 & 0.404 & 0.128 & 125 & 9.5 & 95 & (a) \\
\hline Core Samp.Rt.1 & 0.116 & 0.261 & 0.075 & 0.012 & 0.105 & 0.006 & & 9 & 85 & (a) \\
\hline \multirow[t]{6}{*}{ SIPT2 } & 0.117 & 0.504 & 0.139 & 0.000 & 0.000 & 0.000 & 139 & 9.11 & 95.6 & (a) \\
\hline & & & & & & & & 9.85 & 65.5 & \\
\hline & . & & & & & & & & & \\
\hline & & & & & & & & & & \\
\hline & & & & & & & & & & \\
\hline & & & & & & & & & $\therefore$ & \\
\hline \multicolumn{11}{|l|}{ - } \\
\hline \multirow{2}{*}{\multicolumn{11}{|c|}{. }} \\
\hline & & & & & & & & & & \\
\hline & & & & & & & & $\div$ & & \\
\hline & & $\cdot$ & & & & & & & & \\
\hline & & & & & & & & & & \\
\hline$\dot{-}$ & & & & & & & & & & \\
\hline & & & & & & & & & & \\
\hline
\end{tabular}


Table 3. Operating Condilions and Slurry Chemistry for Feod Preparatlon Tests (cont.)

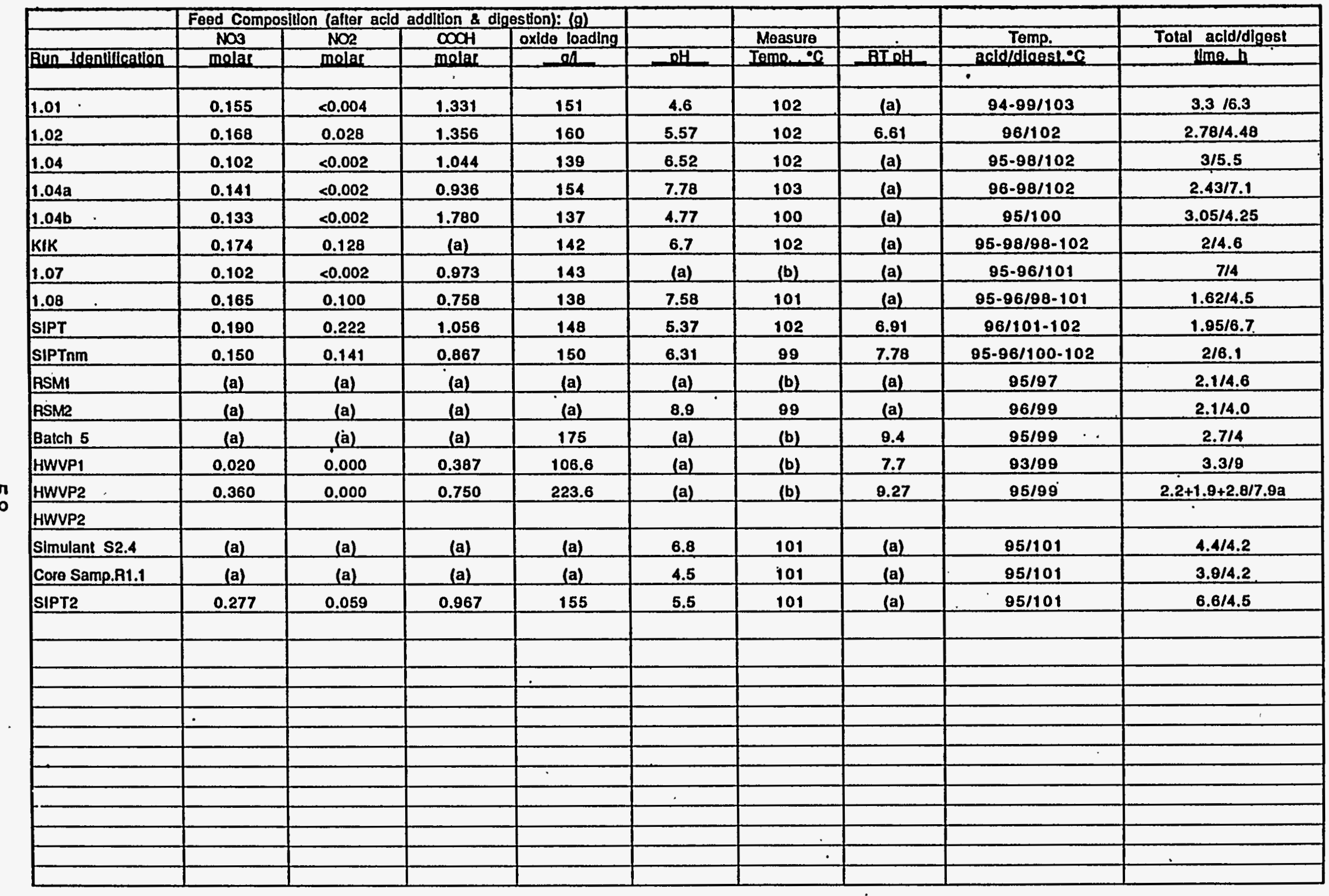


Table 3. Operating Conditions and Slurry Chemistry for Feed Preparation Tosts (cont.)

\begin{tabular}{|c|c|c|c|c|c|c|c|}
\hline & Food Com & n lafter & $\theta$ and $t$ & addition): & & & $\cdot$ \\
\hline & NOB & $\mathrm{NO2}$ & $\infty \mathrm{OH}$ & oxlde loading & & Measure & \\
\hline Bun Idenililcatlon & molar & molar & molar & o1 & $\mathrm{OH}$ & Iemp C & ATnH \\
\hline & & & & & & & \\
\hline 1.01 & 0.34 & 0.004 & 1.42 & 568 & 7.4 & 104. & n.m. \\
\hline 1.02 & (b) & (b) & (b) & (b) & (b) & (b) & (b) \\
\hline 1.04 & (b) & (b) & (b) & (b) & (b) & (b) & (b) \\
\hline $1.04 a$ & (b) & (b). & (b) & (b) & (b) & (b) & (b) \\
\hline $1.04 \mathrm{~b}$ & (b) & (b) & (b) & (b) & (b) & (b) & (b) \\
\hline KIK & (a) & (a) & (a) & 631.5 & 7.81 & 97 & (a) \\
\hline 1.07 & (b) & (b) & (b) & (b) & (b) & (b) & (b) \\
\hline 1.08 & (b) & (b) & (b). & (b) & (b) & (b) & (b) \\
\hline SIPT & 0.41 & 0.18 & 1.14 & 181(no irli) & 5.83 & 100 & 6.69 \\
\hline SIPTnm & 0.39 & 0.13 & 1.07 & 182 (no frit) & 6.31 & 98 & 7.92 \\
\hline RSMI & 0.24 & 0.20 & (a) & 400 & (a) & (a) & (a) \\
\hline RSM2 & 0.30 & 0.21 & (a) & 400 & (a) & (a) & (a) \\
\hline Balch 5 & (a) & (a). & (a) & 482 & (a) & (b) & 8.9 \\
\hline HWVP1 & 0.54 & 0.00 & 0.36 & 456 & (a) & (b) & 9.69 \\
\hline HWVP2 & 0.34 & 0.00 & 0.46 & 486 & (a) & (b) & 10.03 \\
\hline \multicolumn{8}{|l|}{ HWVP2. } \\
\hline Slmulant S2.4 & (b) & (b) & (b) & (b) & (b) & (b) & (b) \\
\hline Core Samp.R1.1 & (b) & (b) & (b) & (b) & (b) & (b) & (b) \\
\hline SIPT2 & (b) & (b) & (b) & (b) & (b) & (b) & (b) \\
\hline & & $\dot{-}$ & & & & & \\
\hline & & & & & & & \\
\hline & & - & & & & & \\
\hline & & & & & & & \\
\hline & & & & & & i & \\
\hline & & & & & & & \\
\hline & & & & & & & \\
\hline & & & & & & & \\
\hline & & & & & & & \\
\hline & & & & & & & \\
\hline & & & & & & & \\
\hline & & & & & & & \\
\hline & & & & & & & \\
\hline
\end{tabular}




\begin{tabular}{|c|c|c|c|c|c|c|c|c|c|c|c|}
\hline & & Olloa & sduring formic acto & addition: & & & Durdng digession & & & Tolal & H-oas: \\
\hline Tesl Type & & Total gas, (d) & Peak gas flow, (o) & $\operatorname{ITIm} \theta$, (i) & Duration acld & Total gas, & Peak gas low & & $\frac{.}{\text { Direatho }}$ & Tolal & \\
\hline & Bun Idenillicallon & melosuliner & molos/mindi & $\frac{10}{h}$ & addilion $h$ & 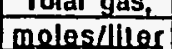 & moles $/ \mathrm{min} / \mathrm{s}$ & 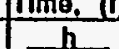 & \begin{tabular}{|l} 
uduation \\
diostion h
\end{tabular} & $\frac{\text { Tolal, }}{\text { moles }}$ & $\frac{\text { Tolal gas, }}{\text { moles/llier }}$ \\
\hline Lab-Scalo Foed Prep. & 1.01 & 0.498 & 0.0132 & 2.13 & 3.3 & 0.281 & 0.0084 & 2.20 & 6.3 & 1.154 & 0.778 \\
\hline & 1.02 & 0.527 & 0.0081 & 2.78 & 2.8 & 0.166 & 0.0081 & 2.78 & 4.5 & 1.056 & 0.694 \\
\hline & 1.04 & 0.754 & 0.0065 & 0.90 & 3.0 & 0.456 & 0.0011 & 4.33 & 5.5 & 1.343 & 0.903 \\
\hline & $1.04 a$ & 0.557 & 0.0059 & 0.90 & 2.4 & 0.099 & 0.0009 & 3.55 & 7.1 & 0.986 & 0.656 \\
\hline & $104 b$ & 0.371 & 0.0065 & 2.78 & 3.1 & 0.235 & 0.0026 & 3.30 & 4.3 & 0.874 & 0.605 . \\
\hline & KIK & 0.272 & 0.0043 & 2.00 & 2.0 & 0.229 & 0.0044 & 2.08 & 4.6 & 0.794 & 0.534 \\
\hline & 1.07 & 0.682 & 0.0038 & 2.18 & 7.0 & 0.177 & 0.0018 & 7.63 & 4.0 & 1.251 & 0.860 \\
\hline & 1.08 & 0.298 & 0.0064 & 0.53 & 1.6 & 0.234 & 0.0050 & 2.03 & 4.5 & 0.772 & 0.532 \\
\hline & ISIPT & 0.229 & 0.0040 & 0.57 & 2.0 & 0.158 & 0.0017 & 2.75 & 6.7 & 0.623 & 0.387 \\
\hline & SIPTnm & (a) & 0.0036 & 0.50 & 2.0 & (a) & 0.0028 & 2.55 & 6.1 & 0.708 & 0.436 \\
\hline Research-Scale Melter Feed Prep. & $\frac{\text { ASM } 1}{12}$ & $\frac{0.203}{0.030}$ & 0.0038 & 1.00 & 2.1 & 0.133 & 0.0042 & 3.05 & 4.6 & 318 & 0.337 \\
\hline & RSM2 & 0.232 & 0.0036 & 1.00 & 2.1 & 0.159 & 0.0024 & 2.12 & 4.0 & 375 & 0.391 \\
\hline KIK Eng-Scalo Foed Prep. & Batch 5 & 0.336 & 0.0061 & 2.88 & 2.8 & 0.276 & 0.0061 & 3.40 & 4.0 & 2354 & 0.613 \\
\hline IDMS Foed Prep. & HWWP1 & 0.211 & 0.0018 & 1.10 & 3.3 & 0.116 & 0.0000 & 5.70 & 8.0 & 1658 & 0.327 \\
\hline & HWVP2 & 0.446 & 0.0031 & 1.50 & $5(9)$ & 0.193 & 0.0016 & 5.80 & 7.8 & 3707 & 0.640 \\
\hline Lab-Scale Radioacilvo Food Prep. & Simulanis2.4 & $\frac{0.556}{0.097}$ & 0.0049 & 2.50 & 4.4 & 0.1769 & 0.0013 & 4.67 & 4.2 & 0.062 & 0.780 \\
\hline & Core SampleA1.1 & 0.287 & 0.0041 & 0.83 & 3.8 & 0.0765 & 0.0003 & 6.00 & 4.2 & 0.022 & 0.392 \\
\hline SIPT Full-Scale Food Prep. & SIPT2 & 0.440 & 0.0017 & 1.75 & 6.6 & 0.085 & 0.0008 & 6.67 & 4.5 & 15218 & 0.543 \\
\hline & (a) nol reponted & & & & & & & & & & \\
\hline & (b) not applicable & & & & & & & & & & \\
\hline & (c) eslimaled, not & measured & & & & & & & & & \\
\hline & (d) ollgas norma & llized with ress & c to slurry volur & me al sta & an of acld addi & Ion & & & & & \\
\hline & (e) peak gas flow & rale normaliz & ed with rospect to & slurry vo & lume & & & & & & \\
\hline & (i) lime at occurre & nce of peak, & hours past slan o & acld ad & dilion. & & & & & & \\
\hline & (9) an addilional & $1.9 \mathrm{~h}$ lapsod to & or repalis aller 2.2 & h Into ac & Id addiliton & & & & & & \\
\hline & (h) amouni found & In condensate, & per liter of slurn & & & & & & & & \\
\hline & (i) amouni lound & In condensale & \& slurry. per liter & of slurry & & & & & & & \\
\hline & (i) peak belore inl & erruplion of a & cid addifion & & & & & & & & \\
\hline & (k) peak alter res & stan of acid a & ddilion, lime atter & restan & & & & & & & \\
\hline & (1) at delection II & imil & E. & & 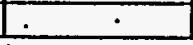 & & & & & & \\
\hline & & & & & & & & & & & \\
\hline
\end{tabular}


Table 4. Ollgas Dala for Various Foed Preparailon Tesis (cont.)

\begin{tabular}{|c|c|c|c|c|c|c|c|c|c|c|c|c|}
\hline & \multicolumn{3}{|c|}{ CO2: } & \multicolumn{3}{|c|}{ Nox: } & \multicolumn{3}{|c|}{ NQ2: } & \multicolumn{3}{|c|}{ NO: } \\
\hline & & & & & & & & & & & & \\
\hline & Total gas, & Peak llow. & Time, (1) & Tolal gas, & Poak llow, & Time. (1) & Tolal gas, & Peak flow & Time, 10 & Total gas, & Poak llow. & Time, (1) \\
\hline Bun Idenillication & molestliner & molos/min/1 & $h$ & moleslliter & moles/minll & $h$ & molesllier & molas/mind & h & molesiliter & molos/min & h \\
\hline 1.01 & 0.610 & 0.0084 & 2.20 & 0.0701 & 0.00519 & 2.10 & (a) & (a) $\quad \cdot$ & (a) & (a) & (a). & (a) \\
\hline 1.02 & 0.361 & 0.0039 & 0.42 & 0.2674 & 0.00414 & 2.68 & (a) & (a) & $\frac{10}{\text { (a) }}$ & (a) & (a) & (a) \\
\hline 1.04 & 0.666 & 0.0061 & 0.90 & 0.0380 & 0.00046 & 2.50 & (a) & (a) & (a) & (a) & (a) & (a) \\
\hline $1.04 a$ & 0.463 & 0.0058 & 0.90 & 0.0268 & 0.00038 & 2.45 & (a) & (a) & (a) & (a) & (a) & (a) \\
\hline $104 b$ & 0.437 & 0.0049 & 0.90 & 0.0845 & 0.00093 & 1.25 & (a) & (a) & (a) & (a) & (a) & (a) \\
\hline KIK & 0.263 & 0.0036 & 0.66 & 0.2357 & 0.00269 & 2.08 & $\frac{1}{(a)}$ & $\frac{d a}{\text { (a) }}$ & (a) & (a) & (a) & (a) \\
\hline 1.07 & 0.502 & 0.0020 & 2.18 & 0.2536 & 0.00179 & 5.67 & (a) & (a) & (a) & (a) & (a) & (a) \\
\hline 1.08 & 0.302 & 0.0062 & 0.53 & 0.1799 & 0.00314 & 1.58 & (a) & (a) & (a) & (a) & (a) & (a) \\
\hline SIPT & 0.174 & 0.0039 & 0.57 & 0.2070 & 0.00276 & 2.75 & (a) & (a) & (a) & (a) & (a) & $\cdot$ (a) \\
\hline SIPTnm & 0.217 & 0.0035 & 0.50 & 0.1841 & 0.00208 & 1.05 & (a) & (a) & (a) & (a) & (a) & (a) \\
\hline ASM 1 & 0.255 & 0.0038 & 1.00 & 0.0243 & 0.00033 & 3.05 & (a) & (a) & (a) & (a) & (a) & (a) \\
\hline ASM 2 & 0.279 & 0.0037 & 0.65 & 0.0323 & 0.00041 & 2.50 & (a) & (a) & (a) & (a) & $\frac{1}{a}$ & (a) \\
\hline Batch 5 & 0.285 & 0.0028 & 0.50 & 0.2910 & 0.00480 & 3.13 & 0.217000 & 0.004200 & 3.10 & 0.074000 & 0.000700 & 3.37 \\
\hline HWWP1 & 0.305 & 0.0016 & 1.10 & 0.0144 & 0.00024 & 2.50 & 0.005170 & 0.000130 & 2.50 & 0.009240 & 0.000118 & 2.10 \\
\hline HWVP2 & 0.473 & 0.0026 & 1.50 & 0.0685 & 0.00060 & 0.0 (i) & 0.046900 & 0.000382 & 3.60 & 0.021600 & 0.000152 & 1.40 \\
\hline & & & & & 0.00054 & $1.5(k)$ & & & & & & \\
\hline SImulants2.4 & 0.626 & 0.0049 & 2.50 & 0.0220 & 0.00041 & 3.75 & (a) & (a) & (a) & (a) & (a) & (a) \\
\hline Core SampleA1.1 & 0.254 & 0.0041 & 0.83 & 0.0880 & 0.00134 & 1.67 & (a) & (a) & (a) & (a) & (a) & (a) \\
\hline SIPT2 & 0.321 & 0.0016 & 1.75 & 0.2052 & 0.00132 & 5.17 & (a) & (a) & (a) & (a) & (a) & (a) \\
\hline & & & & & & & & & & & & \\
\hline & & & & & & & & & & & & \\
\hline & & & & & & & & & & & & \\
\hline & & & & & $\therefore$ & & & & & & & \\
\hline & & & & & & & & & & & & \\
\hline & & & & & & & & & & & & \\
\hline & & & & & & & & . & & & & \\
\hline & & & & & & & & & & & & \\
\hline & & & & & & & & & & & & \\
\hline & & & & & & & & & & & & \\
\hline & & & & & & & & & & & & \\
\hline & & & & & & & & $\cdot$ & & & & \\
\hline & & & & & & & & & & & & \\
\hline & & & & & & & & & & & & \\
\hline
\end{tabular}




\begin{tabular}{|c|c|c|c|c|c|c|c|c|c|}
\hline & \multicolumn{3}{|c|}{ N2O: } & \multicolumn{3}{|c|}{ H2: } & \multicolumn{3}{|c|}{$\mathrm{NH}_{4}$} \\
\hline & & & & & & & acid \& dlgest & acid \& digest & recycle \& frit \\
\hline & Total gas. & Poak flow, & $\operatorname{Tim} \theta, 0$ & Tolal gas, & Poak llow. & Time, (1) & condensale, (b) & lolal (i) & condensale. \\
\hline Bun Idenilicallon & molesfiliar & molos/minll & $h$ & molos/liter & moles/min $/ 1$ & $h$ & moles dilier & molesaiter & moles niter \\
\hline 1.01 & 0.025 & $1.01 E-03$ & 2.20 & $7.15 E-02$ & 5.39E-04 & 2.70 & $6.94 E-04$ & $3.58 E-02$ & 1.27E-02 \\
\hline 1.02 & 0.020 & $5.78 E-04$ & 2.73 & $4.54 E-02$ & $3.94 E-04$ & 3.28 & 9.52E-06 & $6.34 \mathrm{E}-03$ & (b) \\
\hline 1.04 & 0.167 & 1.73E-03 & 2.00 & $3.28 \mathrm{E}-02$ & $3.23 E-04$ & 3.00 & $1.55 \mathrm{E}-02$ & $2.89 E-02$ & (b) \\
\hline $1.04 \mathrm{a}$ & 0.164 & 1.69E-03 & 2.05 & $1.76 \mathrm{E}-03$ & 2.00E-05 & 1.13 & 2.82E:03 & $3.71 E-03$ & (b) \\
\hline $104 b$ & 0.016 & $4.22 E-04$ & 1.95 & 6.79E-02 & $9.28 E-04$ & 2.87 & $7.13 \mathrm{E}-04$ & $1.22 \mathrm{E}-02$ & (b) \\
\hline KIK & 0.036 & $3.03 E-04$ & 2.87 & 3.57E-04 & (a) & (b) & (a) & (a) & (a) \\
\hline 1.07 & 0.057 & $4.19 E-04$ & 5.02 & 4.74E-02 & $4.95 E-04$ & 7.18 & $2.67 \mathrm{E}-04$ & $1.42 \mathrm{E}-02$ & (b) \\
\hline 1.08 & 0.050 & 1.34E-03 & 3.13 & $2.89 \mathrm{E}-04$ & 8.96E-06 & - (a) & $4.46 E-05$ & $1.86 E-04$ & (b) \\
\hline SIPT & 0.006 & 1.12E-04 & 1.95 & $1.31 \mathrm{E}-04$ & 6.84E-07 & (a) & $5.85 \mathrm{E}-05$ & $5.85 E-05$ & $1.28 \mathrm{E}-05$ \\
\hline SIPTnm & 0.034 & 3.57E.04 & 3.17 & 4.99E-04 & 6.54E-06 & (a) & 5.43E-05 & $1.16 E-04$ & $1.34 E-05$ \\
\hline RSM 1 & 0.057 & $2.28 E-03$ & 3.17 & $2.86 \mathrm{E}-05$ & 1.06E-05 & 3.00 & (a) & (a) & (a) \\
\hline ASM2 & 0.078 & 1.17E-03 & 2.67 & 3.52E-04 & $6.25 E-06$ & 2.50 & (a) & (a): & (a) \\
\hline Balch 5 & 0.037 & $4.00 \mathrm{E}-04$ & 3.80 & $3.69 \mathrm{E}-04$ & 3.80E-07 & 4.30 & (a) & (a) & (a) \\
\hline HiWPI & 0.008 & 6.11E-05 & 2.50 & $2.25 \mathrm{E}-02$ & 1.56E-04 & 4.80 & $1.65 E_{0}: 03$ & $2.08 E-02$ & 1.52E-02 \\
\hline HWVP2 & 0.097 & 5.77E-04 & 1.40 & $1.44 \mathrm{E}-03$ & 5.31E-06 & 7.00 & $4.02 E-03$ (c) & 1.82E-03 & $6.06 \mathrm{E}-03(\mathrm{c})$ \\
\hline Simulanis2.4 & 0.088 & 1.15E-03 & 3.50 & 4.32E-02 & 2.59E-03 & 5.00 & $2.18 E-02$ & $2.18 \mathrm{E}-02$ & (m) \\
\hline Core SamploA1.1 & 0.034 & 4.41E-04 & 2.00 & 1.51E-02 & 5.80E-05 & 6.00 & 2.34E-04 & 8.94E-03 & (m) \\
\hline SIPT2 & 0.016 & $9.64 E-05$ & 4.33 & $3.93 E-04$ & $1.29 \mathrm{E}-06$ & 9.17 & (1) & $3.47 E-05$ & (b) \\
\hline & & & & & & & & & \\
\hline & & & & & & & & & \\
\hline & & & & & & & & & \\
\hline & & & & & & & & & \\
\hline & & & & & & & & & \\
\hline & & & & & & & & & \\
\hline & & & & & & & & & \\
\hline & & & & & & & & & \\
\hline & & & & & & & & & \\
\hline & & & & & & & & & \\
\hline & & & & & & & & & \\
\hline & & & & & & & & & \\
\hline
\end{tabular}


Table 5. Total Olfgas Data for All Tests Showing Comparlson of Laboratory-Scale KfK and Engineering-Scale KfK Tests.

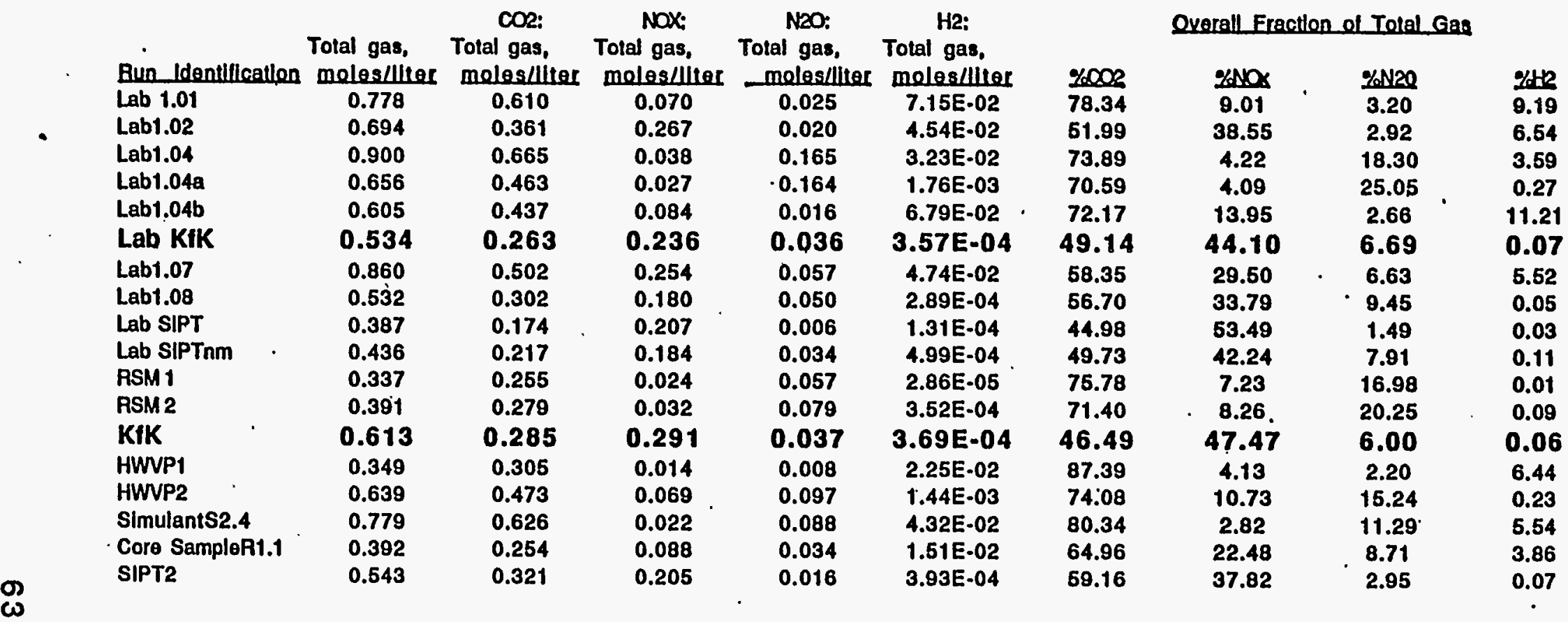


Table 6. Redox of Glasses and Related Slurry Feed Preparation Chemistry Data.

\begin{tabular}{|c|c|c|c|c|c|c|c|}
\hline Test & Identification & $\begin{array}{c}\mathrm{HOOOH} \\
\text { moleslliter }\end{array}$ & $\begin{array}{c}\mathrm{NOS} \\
\text { moles/liter }\end{array}$ & $\begin{array}{c}\mathrm{NO} 2 \\
\text { moles/liter }\end{array}$ & $\begin{array}{l}\text { HCOOHNO3 } \\
\text { Latio }\end{array}$ & $\begin{array}{c}\text { (HCOOH-NO2) } \\
\text { ratio }\end{array}$ & $\begin{array}{c}\mathrm{Fet+} / \mathrm{Fe}+++ \\
\text { ratio }\end{array}$ \\
\hline & KfK & .0 .964 & 0.094 & 0.499 & 10.26 & 4.95 & 0.027 \\
\hline & KfK & 0.964 & 0.094 & 0.499 & 10.26 & 4.95 & 0.021 \\
\hline & Lab KfK & 0.837 & 0.129 & 0.457 & 6.49 & 2.95 & (a) \\
\hline & SIPT2 & 0.995 & 0.113 & 0.498 & 8.81 & 4.40 & (a) \\
\hline & RSM1 & 0.688 & 0.13 & 0.435 & 5.29 & 1.95 & 0.005 \\
\hline & RSM2 & 0.833 & 0.13 & 0.435 & 6.41 & 3.06 & 0.005 \\
\hline & HWVP1 & 0.671 & 0.15 & 0.1 & 4.47 & 3.81 & 0.019 \\
\hline & HWVP2 & 0.820 & 0.28 & 0.4 & 2.93 & 1.50 & 0.034 \\
\hline 101 & $A Z$ Core1(b) & 0.745 & 0.125 & 0.165 & 5.96 & 4.64 & 0.026 \\
\hline 101 & AZ Core2(b) & 0.455 & 0.055 & 0.145 & 8.27 & 5.64 & 0.085 \\
\hline
\end{tabular}

(a)not reported

(b) M.L. Elliott, E.V. Morrey and J.M. Tingey, September 1991. Status Lettler Report on Radioactive Formating, Vitrification and Product Testing to. Westinghous Hanford Company, Doc. PHTD-C91-05.05F, Pacific Northwest Laboratory, Richland, Washington 


\section{APPENDIX A}

\section{A1.1 Rate of Conversion of $\mathrm{NO}$ to $\mathrm{NO}_{2}$}

The rate of $\mathrm{NO}$ conversion to $\mathrm{NO}_{2}$ can be estimated from published data by Yost and Russell (1944), given by

$$
\text { rate of formation of } \mathrm{NO}_{2}=\mathrm{k}_{f}(\mathrm{NO})^{2} \times\left(\mathrm{O}_{2}\right) \text { moles } / \mathrm{sec}
$$

$$
\text { where } \quad \begin{aligned}
(\mathrm{NO}) & =\text { concentration } \mathrm{NO}, \mathrm{moles} / \mathrm{cm}^{3} \\
\left(\mathrm{O}_{2}\right)= & \text { concentration } \mathrm{O}_{2}, \text { moles } / \mathrm{cm}^{3} \\
\mathrm{k}_{\mathrm{f}}= & \text { rate constant }=4.47 \times 10^{9} \mathrm{~cm}^{2} / \mathrm{mole}^{2} / \mathrm{sec} \\
& \text { at } 95^{\circ} \mathrm{C} .
\end{aligned}
$$

The rate increases on dropping to room temperature $\left(7.9 \times 10^{9}\right)$. A graph following the format of Burger ${ }^{5}$ was prepared based on the Yost and Russell (1944) data showing the concentration of NO remaining at the end of specified times for various starting concentrations, Figure A.1, in air. For an initial concentration of $1 \%$, or $10,000 \mathrm{ppm}$, about $60 \%$ of the starting NO remains after 1 minute in air. At higher starting concentrations, an even lower fraction remains, e.g. Only about $15 \%$ of the NO remains after 1 minute for an initial concentration of $10 \%$. Thus, it is reasonable to expect large fractions of the NO produced during feed preparation to be converted to $\mathrm{NO}_{2}$ during transport in a gas stream with appreciable oxygen.

5 Burger, L.L., 1993, unpublished calculation, private communication. 


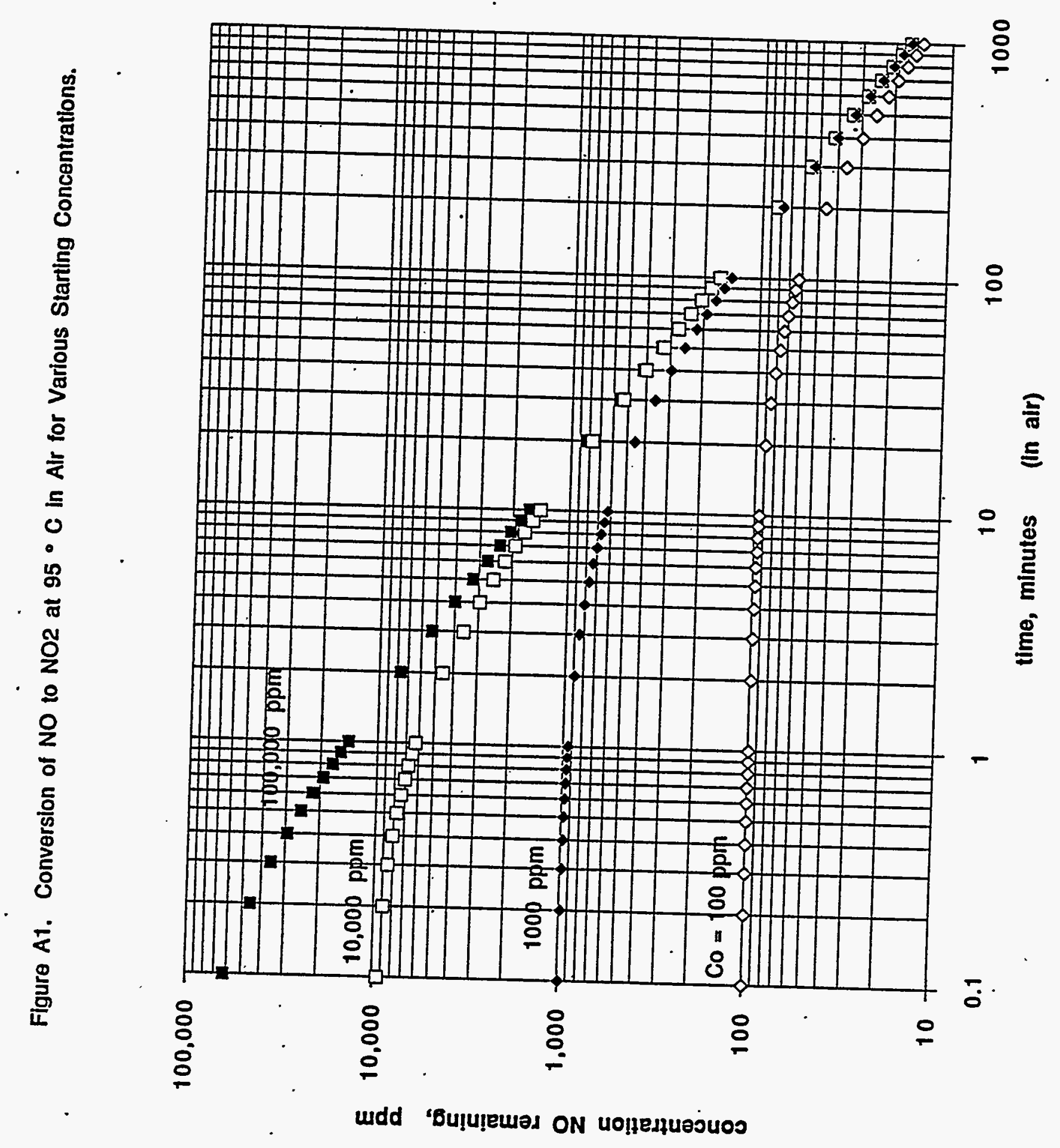




\section{APPENDIX B}

B1.1 Hanford Waste Vitrification Plant Neutralized Current Acid Waste Target Compositions 
Table B.1. HWVP Feed NCAW Simulant Target Compositions

Weight \%

\begin{tabular}{|c|c|c|}
\hline $\begin{array}{c}\text { NCAW '86 } \\
\text { (Farnsworth 1987) }\end{array}$ & $\begin{array}{c}\text { FY } 1990 \\
\text { (Wiemers 1990) }\end{array}$ & $\begin{array}{c}\text { FY 1991 } \\
\text { (Wiemers 1993) } \\
\end{array}$ \\
\hline . & & 0.12 \\
\hline \multirow[t]{2}{*}{10.34} & · $\quad 9.35$ & 9.25 \\
\hline & 0.10 & 0.006 \\
\hline 0.41 & 0.42 & 0.179 \\
\hline \multirow[t]{2}{*}{0.31} & 0.31 & 0.806 \\
\hline & 3.12 & 3.08 \\
\hline 0.62 & 0.62 & 0.656 \\
\hline 0.52 & 0.52 & 0.267 \\
\hline 0.62 & 0.62 & 0.612 \\
\hline 0.62 & 0.62 & 0.250 \\
\hline 1.24 & 1.25 & 0.099 \\
\hline \multirow[t]{2}{*}{29.10} & 29.09 & 28.80 \\
\hline & & $1.57 \mathrm{E}-04$ \\
\hline \multirow[t]{2}{*}{ - } & & $4.50 \mathrm{E}-06$ \\
\hline & & 0.200 \\
\hline \multirow[t]{2}{*}{2.08} & 3.01 & 0.667 \\
\hline & & 7.23E-05 \\
\hline 0.37 & 0.38 & 0.372 \\
\hline 0.62 & 0.62 & 2.19 \\
\hline 1.24 & 1.25 & 0.570 \\
\hline \multirow[t]{2}{*}{18.16} & 18.70 & 21.90 \\
\hline & & 0.010 \\
\hline 2.29 & $3.74^{\circ}$ & 3.56 \\
\hline 2.39 & 2.39 & 2.35 \\
\hline
\end{tabular}

68 
Table B.1. (cont.)

Weight $\%$

\begin{tabular}{|c|c|c|c|}
\hline $\begin{array}{l}\text { Waste } \\
\text { Oxide }\end{array}$ & $\begin{array}{c}\text { NCAW '86 } \\
\text { (Farnsworth 1987) }\end{array}$ & $\begin{array}{c}\text { FY } 1990 \\
\text { (Wiemers 1990) } \\
\end{array}$ & $\begin{array}{c}\text { FY 1991 } \\
\text { (Wiemers 1993) } \\
\end{array}$ \\
\hline $\mathrm{P}_{2} \mathrm{O}_{5}$ & & 0.91 & 0.887 \\
\hline $\mathrm{PbO}_{2}$ & & . & 0.715 \\
\hline PdO & 0.21 & 0.21 & 0.123 \\
\hline $\mathrm{Pr}_{2} \mathrm{O}_{3}$ & & & 0.156 \\
\hline $\mathrm{Pr}_{6} \mathrm{O}_{11}$ & 0.41 & 0.43 & \\
\hline $\mathrm{Rb}_{2} \mathrm{O}$ & & $-\quad 0.21$ & \\
\hline $\mathrm{Rb}_{2} \mathrm{O}_{3}$ & & - & 0.059 \\
\hline $\mathrm{Rh}_{2} \mathrm{O}_{3}$ & 0.21 & 0.21 & 0.106 \\
\hline $\mathrm{RuO}_{2}$ & 0.62 & 0.66 & \\
\hline $\mathrm{Ru}_{2} \mathrm{O}_{3}$ & & & 0.387 \\
\hline $\mathrm{SO}_{3}$ & 1.87 & 0.68 & 0.669 \\
\hline $\mathrm{Sb}_{2} \mathrm{O}_{3}$ & & & 0.006 \\
\hline $\mathrm{SeO}_{2}$ & & & 0.016 \\
\hline $\mathrm{SiO}_{2}$ & 9.34 & 4.16 & 4.11 \\
\hline $\mathrm{Sm}_{2} \mathrm{O}_{3}$ & 0.21 & 0.21 & 0.077 \\
\hline $\mathrm{SnO}$ & & & 0.011 \\
\hline SrO & 0.41 & 0.42 & 0.121 \\
\hline $\mathrm{Ta}_{2} \mathrm{O}_{5}$ & & & 0.003 \\
\hline $\mathrm{TeO}_{2}$ & & & 0.101 \\
\hline $\mathrm{TiO}_{2}$ & 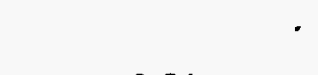 & & 0.666 \\
\hline $\mathrm{Y}_{2} \mathrm{O}_{3}$ & 0.21 & 0.21 & 0.082 \\
\hline $\mathrm{ZnO}$ & & & 0.341 \\
\hline $\mathrm{ZrO}_{2}$ & 15.55 & 15.59 & 15.40 \\
\hline Total & 99.97 & 100.01 & 100.00 \\
\hline
\end{tabular}

69 
Table B.1. (cont.)

$\mathrm{g} / 100 \mathrm{~g}$ waste oxide

\begin{tabular}{|c|c|c|c|}
\hline $\begin{array}{l}\text { Waste } \\
\text { Oxide } \\
\end{array}$ & $\begin{array}{c}\text { NCAW '86 } \\
\text { (Farnsworth 1987) } \\
\end{array}$ & $\begin{array}{c}\text { FY } 1990 \\
\text { (Wiemers 1990) } \\
\end{array}$ & $\begin{array}{c}\text { FY 1991 } \\
\text { (Wiemers 1993) } \\
\end{array}$ \\
\hline $\mathrm{CO}_{3}^{2-}$ & & 17 & 6.00 \\
\hline $\mathrm{NO}_{3}^{-}$ & 7.13 & 9 & 5.76 \\
\hline $\mathrm{NO}_{2}^{-}$ & & & 16.00 \\
\hline $\mathrm{PO}_{4}^{3-}$ & & & 0.08 \\
\hline $\mathrm{Cl}$ & . & & 0.30 \\
\hline $\operatorname{TOC}^{(\alpha)}$ & 2.08 & & 0.13 \\
\hline
\end{tabular}

(a) Added as sodium oxalate, $\mathrm{Na}_{2} \mathrm{C}_{2} \mathrm{O}_{4}$. 